UCRL-CR-116651

PO \#B239589

\title{
A Study of Small Explosions and Earthquakes During 1961-1989 Near the Semipalantinsk Test Site, Kazakhstan
}

Vitaly I. Khalturin

Tatyana G. Rautian

Paul G. Richards

March, 1994.

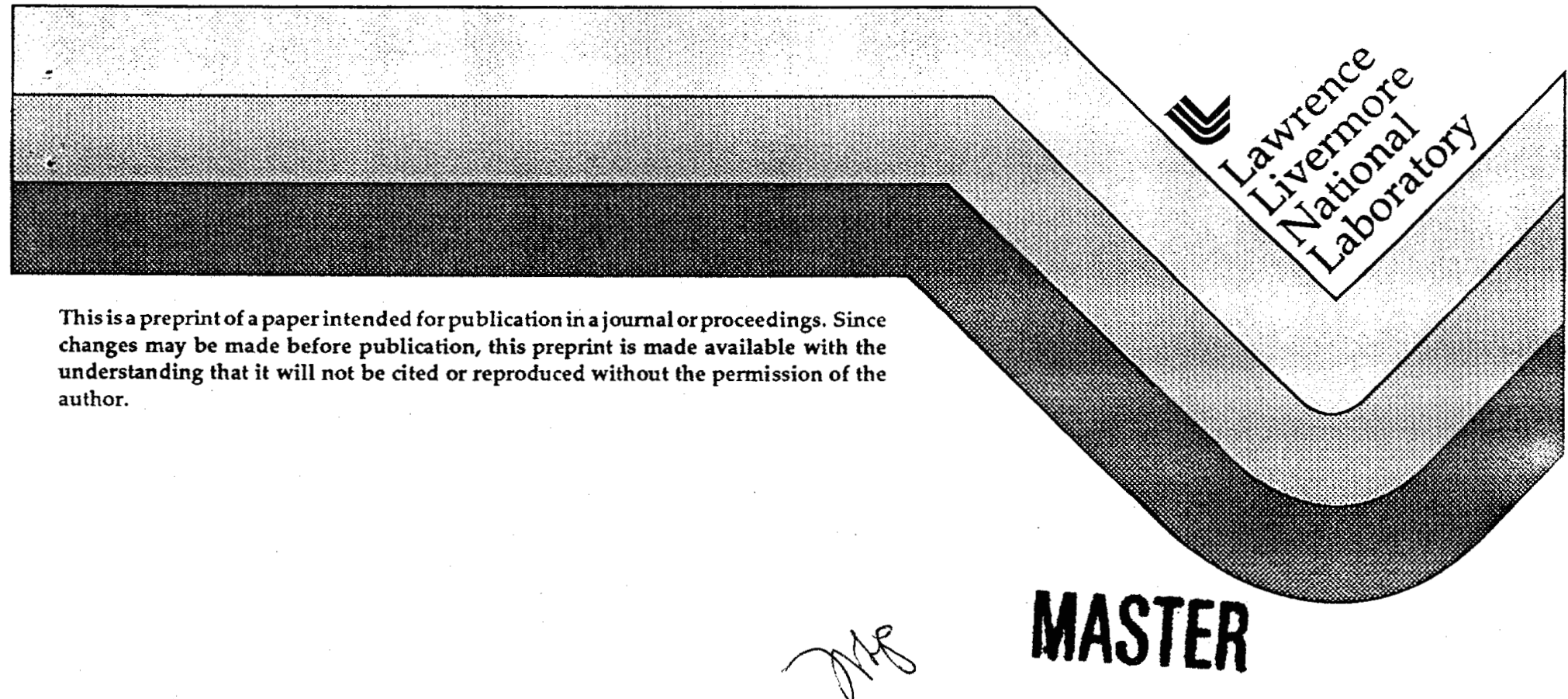




\section{DISCLAIMER}

This document was prepared as an account of work sponsored by an agency of the United States Government. Nejther the United States Government nor the University of California nor any of their employees, makes any warranty, express or implied, or assumes any legal liability or responsibility for the accuracy, completeness, or usefulness of any information, apparatus, product, or process disdesed, or represents that its use would not infring e privately owned rights. Reference herein to any specificcommercial products, process, or service by trade name, trademark, manufacturer, or otherwise, does not necessarily constitute or imply its endorsement, recommendation, or favoring by the United States Government or the University of Califormia. The views and opinions of authors expressed herein do not mecessanily state or reflect those of the United States Government or the University of California, and shall not be used for advertising or product endorsenent purposes. 


\section{DISCLAIMER}

Portions of this document may be illegible in electronic image products. Images are produced from the best available original document. 


\title{
A STUDY OF SMALL EXPLOSIONS AND EARTHQUAKES DURING 1961-1989 NEAR THE SEMIPALATINSK TEST SITE, KAZAKHSTAN
}

\author{
Vitaly I. Khalturin ${ }^{1}$, Tatyana G. Rautian ${ }^{1}$, and Paul G. Richards ${ }^{2}$ \\ ${ }^{1}$ Institute of Physics of the Earth, Russian Academy of Sciences, Moscow \\ ${ }^{2}$ Lamont-Doherty Earth Observatory, Palisades, NY 10964, \\ and Dept. of Geological Sciences, Columbia University
}

\section{ABSTRACT}

Several Russian sources have stated that 343 underground nuclear explosions were conducted during 1961-1989 at the Semipalatinsk Test Site. However, only 282 of them appear to have been described, in the openly available technical literature, with well-determined coordinates; and only 272 have both good locations and magnitudes.

We have used regional data from 52 stations to study 65 seismic sources initially thought to be in or near the Semipalatinsk region, additional to the 272 underground nuclear explosions with known locations and magnitudes. Of these 65 events, we believe 8 are not explosions on the test site, namely: two earthquakes close to the test site (one of them, on March 20, 1976, was previously well-known); three earthquakes or chemical explosions $100-300 \mathrm{~km}$ from the test site; and three events at greater distances from Semipalatinsk. Of the remaining 57 events: 10 were known to be underground nuclear explosions with known locations and we have supplied magnitudes where none were previously available; one was a chemical explosion at Degelen (June 5, 1961, a few months prior to the first Soviet underground nuclear explosion); we believe 21 were underground nuclear explosions (20 at Degelen, one at Murzhik); 13 were chemical explosions at Balapan; 8 were chemical explosions elsewhere on the test site; three were either nuclear or chemical explosions; and one was either a chemical explosion or a cavity collapse.

Our seismological data is principally of two types: (1) the bulletins of stations in Central Asia, Kazakhstan and the Altai; and (2) the multichannel narrowband analog records (ChISS) of the station at Talgar, operated throughout the time period 1961-89, together with other ChISS stations at Garm, Zerenda, and Novosibirsk, operated for part of this time. The largest magnitude of our 44 possible underground nuclear explosions is around 5 (February 4,1965, obscured at many teleseismic stations by a large Aleutian earthquake). Others lie in the magnitude range 3.5-4.5, and clearly most have subkiloton yields. 
Our data set of small events is important for purposes of evaluating the detection capability of teleseismic arrays, and the detection and identification capability of regional stations.

\section{INTRODUCTION}

This paper reports our practical experience in documenting the occurrence of small underground nuclear explosions and large chemical explosions at the main nuclear weapons test site of the U.S.S.R., near Semipalatinsk, Kazakhstan.

We have worked with five sources of information. First, are the various lists of explosions published by western scientists based upon teleseismic observations. Second, are lists of Soviet explosions and summary statements on total numbers of such explosions, published by Russian sources. We find that teleseismically observed events appear to be only about $90 \%$ of the total. Some of the teleseismically observed events are poorly located, or have not been assigned a magnitude, or appear on explosion lists that incorrectly include earthquakes. It appears that less than $80 \%$ of the underground nuclear explosions conducted at the Semipalatinsk Test Site have good locations and a magnitude, determined and published on the basis of teleseismic data. Third, we have used our experience in the analysis of data recorded at the Talgar station on a dayto-day basis, and at stations on the Kokchetav massif (Zerenda, Borovoye). Fourth, we used regional seismic data from 49 other stations in Kazakhstan, Kyrgystan, Russia, Tadjikistan and Uzbekistan, most of them operated at distances of less than $1000 \mathrm{~km}$ from the Semipalatinsk Test Site in East Kazakhstan. Fifth, we have used personal communications from western seismologists (Frode Ringdal, Peter Marshall, Jack Murphy, Bob North) giving us information based for the most part on teleseismic data from particular events.

Our goals were to reduce the discrepancies between explosion lists generated from teleseismic data and numbers of events reported by Russian sources, and thus to develop a more complete list of Soviet nuclear explosions; and to document some strengths and weaknesses of teleseismic and regional data for purposes of explosion detection and identification. More fundamentally, we wanted to build a database of small seismic events, so that efforts can be focussed on solving the hardest technical problems of monitoring a Comprehensive Test Ban Treaty, namely how to identify underground nuclear explosions that have very small seismic signals - and how to avoid false alarms over small events. This work is complicated in the case of seismic events near Semipalatinsk, by the fact 
that 75 chemical explosions have been carried out on the test site, according to Saybekov (1993), including 44 chemical explosions larger than ten tons that have been conducted during the period 1970-1988.

Our database so far, as reported in this paper, consists of numerous station reports and analog seismograms that we have analysed ourselves. We often relied upon methods of discrimination that cannot in general be used in CTBT monitoring (for example, the interpretation of the time of day at which the event occurred). However, we believe we have identified a suitable set of small events (both explosions and earthquakes), on and near the Semipalatinsk Test Site, that may be an important focus for future work. That is, we anticipate further efforts to acquire data for these events, preferably digital data, recorded at teleseismic and regional distances, in order to test objectively the capability of various detection and discrimination algorithms. In such future work we could digitize some of the analog data reported here, or we could hope to use digitally recorded data from Borovoye since 1965 (at a distance about $700 \mathrm{~km}$ ), some digital data acquired by the Natural Resources Defense Council in 1987-1988 (at distances about $200 \mathrm{~km}$ from the test site), and, since 1988, IRIS/IDA digital data (at distances more than $1000 \mathrm{~km}$ ).

\section{SOURCES OF INFORMATION ABOUT SMALL EVENTS}

In this section, we first summarize the information contained in a series of papers published in the West, concerning numbers of underground nuclear explosions (UNEs) that have occurred at the Semipalatinsk Test Site in Kazakhstan, and for which accurate locations and magnitudes are both available. We then briefly summarize additional information made available in recent years by various Russian and Kazakh sources, which indicates that a significant number of UNEs at Semipalatinsk have not been previously recognized in western publications. The section concludes with a list of 65 events which are the main focus of attention in this paper, being candidates for the additional UNEs, and/or UNEs with previously unknown locations or magnitudes, or perhaps earthquakes or chemical explosions in the region.

Table 1 gives the information available on 282 known UNEs at the Semipalatinsk Test Site. Our primary sources of information on locations comes (1) from Bocharov et al (1989), who published origin time, depth, latitude and longitude on 96 UNEs prior to 1973; and (2) from Lilwall and Farthing (1990) who used the Bocharov et al locations as master events for a joint epicentral determination of other UNEs at Semipalatinsk, using $P$ wave arrival times as reported by the ISC. The Lilwall and Farthing seismically determined locations were given to the nearest thousandth of a 
degree (five significant figures). The "area" entry in Table 1 is the area of the error ellipse given by Lilwall and Farthing (blank entries signify events given a location to the nearest tenth of a second of arc by Bocharov et al: such locations are listed in Table 1 with seven significant figures). An event of 1984 September 15, presumed to be a UNE located at $49.992^{\circ} \mathrm{N}, 78.881^{\circ} \mathrm{E}$ by Lilwall and Farthing, was apparently a chemical explosion at Balapan. The event of 1968 November 12 was a triple explosion (Bocharov et al) so we have counted it three times.

Table 1 also indicates the subsite $(B=$ Balapan, $D=$ Degelen, $M=$ Murzhik); the ISC $P$-wave magnitude, where available; the number of stations upon which the ISC magnitude is based; the number of stations reporting dilatations and the number reporting polarity; and the number of stations reporting arrival times to the ISC. Other magnitudes in Table 1 include the $P$-wave magnitude for many Balapan UNEs reported by Ringdal et al (1992), which is a maximum likelihood value derived by the British Atomic Weapons Establishment (AWE); a $P$-wave magnitude also obtained by AWE for many Degelen and Murzhik UNEs (personal communication to Richards - these magnitudes have four significant figures) but which is not maximum likelihood; and an $L g$-wave magnitude for many Balapan events reporied by Ringdal et al (1992). Finally, the $L g$-wave magnitude for two Balapan events (1980 April 25, and the large event of 1980 September 14) is given by Richards and Shi (1994), who digitized high quality $L g$ recordings from the station WMQ and calibrated RMS $L g$ measurements at WMQ in terms of the NORSAR $L g$ magnitude scale.

Note in Table 1 that there are ten events (reported by Bocharov et al, 1989) for which no magnitude information is listed. Thus, the Table gives locations for 282 UNEs (100 at Balapan, 157 at Degelen, 25 at Murzhik), and magnitude information for only 272 .

In recent years, several Russian and Kazakh sources have published information on the total number of UNEs conducted at Semipalatinsk from the first event on 1961 October 11, to the last on 1989 October 19 prior to the break up of the U.S.S.R. and the closing down of this test site. For example, Mikhailov et al (1992) state that 343 UNEs were conducted at the Semipalatinsk Test Site. And van der Vink et al (1992, their Figure 6) give the number of UNEs in each year at this test site, the total coming to 343 .

Figure 1 shows a histogram comparing the number of events per year from Table 1, with the number indicated by van der Vink et al. Such a comparison should be associated with several caveats, since it is not always clear what constitutes a "nuclear test" for counting purposes. For example, if three nuclear devices are shot at the same time in the same 
shaft, would that count as one or three tests? (It would be counted as one test according to the definition of a nuclear test under the verification protocol to the Threshold Test Ban Treaty, and there would be only one test apparent from seismic signals.) If a nuclear test explosion was initiated but did not result in significant nuclear yield, then there would typically be no seismic signal - yet for some purposes this would be counted as a nuclear test. (A successful one-point safety test would have these latter characteristics, as would a "fizzle" - a device that failed to attain even a small fraction of its design yield. Several of the UNEs conducted in the early years of testing at the Nevada Test Site have announced yields of either zero or less than a ton of TNT equivalent.) Note in Figure 1 for 1984 that there is one more UNE in the total of claimed explosions (based on Table 1), than in the total given by Russian sources: perhaps one of the claimed events is a chemical explosion. Finally, the number 343. for Semipalatinsk may refer to nuclear weapons tests only, when at least some of the explosions at this test site have been described in Soviet literature as part of the Peaceful Nuclear Explosion program. Nevertheless, the number reported from teleseismic observations (the 282 reported in Table 1) appears to be significantly lower that the 343 now reported as the total carried out at Semipalatinsk, and this difference was a stimulus for our project reported here.

The location of the test site itself appears not to have been shown accurately in any publication available in the western literature. But when the Threshold Test Ban Treaty entered into force in December 1990, the Soviet Union and the United States formally exchanged information on the boundaries of their respective test sites. The extent of the Semipalatinsk Test Site was then specified (a) by a list, given to the U.S., of the locations of 152 posts on the test site boundary, and (b) by a map, now held in the U.S. State Department Treaty Library. There are some slight discrepancies between (a) and (b), but the map (b) is presumably definitive and was used to prepare the illustration of test site boundaries shown in Figure 2.

In order to begin a systematic program of data acquisition for other seismic events that might or might not be UNEs at Semipalatinsk, or that were relevant to a program of research into regional discriminants for the area, we first made a list of all the seismic events for which we would seek additional information. The list appears here as Table 2, giving dates, sources of information, and approximate times, locations, and magnitudes (if available) for 65 events. It includes the 10 events in Table 1 that lack magnitude information. It includes 24 events pointed out by Sykes and Ruggi (1989) and claimed by these authors to be UNEs, that are located only approximately, since often the Large Aperture Seismic Array (LASA) in Montana was their only source of teleseismic data for small events. 
(Their list also includes most of the events in Table 1.) The sources of information for Table 2 are as follows:

Boch. = Bocharov et al (1989), 10 UNEs with no reported magnitude; H.R.R. = Hansen, Ringdal and Richards (1990), who incorrectly listed the event of 1988 September 26 as a UNE;

Ring. = personal communication from Frode Ringdal, who sent us event magnitudes and estimated origin times for several events as detected by NORSAR or NORESS;

Ring.(90) = Ringdal (1990), who describes teleseismic data for the small announced UNE of 1988 December 28;

Sult. $=$ Djamil Sultanov (personal communication), who informed us that the event of 1988 September 26 was not a UNE;

S\&R = Sykes and Ruggi (1989);

V.An = Vadim An (personal communication), whose information was usually based upon data recorded at the Borovoye Geophysical Observatory;

V.Kh. = The working notes of Vitaly Khalturin, based on observations made in Central Asia prior to working on this paper.

\section{STATIONS AND INSTRUMENTATION}

Our procedure was to study the 65 events of Table 2 using the seismological data from local networks receiving regional seismic waves from the Semipalatinsk Test Site. We wanted to determine event locations and magnitudes, and to get some evidence about their nature (whether UNE, earthquake, or chemical explosion).

We used readings of records from stations installed by the Complex Seismological Expedition of the Institute of Physics of the Earth, of the Russian Academy of Sciences. Part of this data was obtained from permanent stations GRM, NSB, TLG, and ZRN. Most of the Expedition's stations were temporary, each working for about 2 years. Also we have used the arrival times from bulletins of permanent stations in Central Asia, Kazakhstan and Altai, and in some cases from the digital station at Borovoye (station BRV: see Richards et al, 1992). Table 3 lists the 52 stations we used, and Figure 3 shows a station map.

The basic characteristics of the five different types of instruments that we used were as follows: 


\begin{tabular}{|l||l|l|}
\hline Type & $T_{1}-T_{2}$ seconds & Magnification \\
\hline \hline SKD & $0.2-18$ & $(1-1.5), \mathrm{K}$ \\
\hline SKM & $0.1-1.4$ & $(30-60), \mathrm{K}$ \\
\hline RVZT & $0.2-1.2$ & $(0.1-0.3), \mathrm{M}$ \\
\hline KSE & $0.7-1.1$ & $(0.5-1.0), \mathrm{M}$ \\
\hline ChISS & $\begin{array}{l}\text { multichannel } \\
0.022-40\end{array}$ & - \\
\hline
\end{tabular}

$T_{1}$ and $T_{2}$ here are the periods at which the response is down to half the power of the peak response. Most stations were equipped with the standard short-period instrument known as SKM, which records displacement in a quite wide band $(0.7-10 \mathrm{~Hz})$. Their records or the bulletins were used to calculate epicentral distances and origin time as discussed below. Some of the stations listed in Table 3 also have the broad band instrument SKD, and some had the RVZT instrument. A few stations had the very high gain narrow-band KSE instrument. All four of these seismometers consist of a coupled inertial sensor/galvanometer sensor/velocity pickup, and can be described by the standard equations for such systems (see for example Aki and Richards, 1980, equation 10.63; or, equation 10.64 since coupling is negligible). Their displacement responses are shown in Figure 4a. It may be a surprise to some western seismologists that it is possible to achieve such a flat response to displacement (e.g. for SKM and SKD) in an instrument with a coil that provides a voltage proportional to velocity. The way the desired result is achieved, for the SKD instrument, is to have a strongly overdamped galvanometer (e.g. $T_{\text {gal }}=1 \mathrm{~s}, \varepsilon_{\text {gal }}$ in the range 4 to 6) and an underdamped inertial sensor (e.g. $T_{\mathrm{s}}=20 \mathrm{~s}, \varepsilon_{\mathrm{s}}$ in the range 0.4 to 0.45 ), with only a small amount of coupling (less than 0.1).

The fifth instrument we used is known by its Russian acronym, ChISS, and such data were obtained from 4 stations: TLG, NSB, ZRN and GRM. ChISS was designed by Zapolskii $(1960,1971)$ and is described by Zapolskii and Khalturin (1960), Rautian and Khalturin (1978), and Rautian et al (1978). The vertical component was analyzed. In this instrument, the signal from the seismometer, proportional to the velocity of ground motion, is passed through a system of narrow bandpass filters and recorded on photographic paper or by ink-recorder. Thus the amplitudes on each record are proportional to the velocity of ground motion in a particular frequency band. ChISS system at GRM and TLG stations have as 
many as 16 channels. We used data mostly from 8 channels in the range from 0.3 to $40 \mathrm{~Hz}$. For a large event, (with magnitude 5 and more) the Rayleigh wave is strong enough to see, and in that case we widened the frequency range studied to $0.05 \mathrm{~Hz}$ to include long periods. The bandwidth of ChISS channels $\Delta f$ is proportional to their central frequencies, $f_{c}$ :

$$
\Delta f=k f_{c}
$$

The parameter $k$ is equal 0.7 in the long-period part of the frequency range, 0.48 in the central part from 0.3 to $10 \mathrm{~Hz}$, and 0.22 for high-frequency channels, where $f_{c}$ values are 18,27 and $40 \mathrm{~Hz}$. Figure $4 \mathrm{~b}$ (upper) shows the ChISS spectral amplitude response for an 8-channel system. The roll-off on either side of each peak is very steep. Figure $4 \mathrm{~b}$ (lower) shows the impulse response for four channels. Note that time runs from right to left, a common convention in Russian seismograms.

Each channel was calibrated daily by driving the pendulum at constant velocity amplitude and very slowly decreasing frequency. The response of this calibration signal recorded directly on the seismogram has an envelope identical to the amplitude-frequency response curve. The maximum amplitudes of response usually correspond to $1 \mu \mathrm{m} / \mathrm{s}$ (i.e. one micron/second) of velocity of ground oscillation. This system lets us get the frequency-dependent content as well as the time-dependent content of each seismic wave. In kinematic studies we can choose the channel where the wave arrival looks most sharp and clear, to measure the time arrival more accurately. Figure $5 \mathrm{a}$ is an example of a ChISS record showing six channels (each with its calibration signal - in this case with maximum amplitude corresponding to $0.5 \mu \mathrm{m} / \mathrm{s}$ ) with data for the UNE of 1976 December 30 at Degelen. Again, note that time runs from right to left in each channel. This example of ChISS data recorded at a distance of 730 $\mathrm{km}$ shows several different regional phases, as we discuss in the section below. Figure $5 \mathrm{~b}$ shows six channels of a Talgar ChISS record of the Degelen explosion of April 21, 1976. Five minutes after this explosion, there was a Balapan explosion of similar magnitude, for which the Talgar ChISS record is shown in Figure 5c. Detailed examination of Figs $5 b$ and $5 c$ shows that different regional phases recorded at Talgar are excited to a slightly different degree by Degelen and Balapan explosions.

\section{REGIONAL PHASES IN CENTRAL ASIA AND KAZAKHSTAN}

Several different regional phases are seen at distances from 0 to $1400 \mathrm{~km}$ from the Semipalatinsk Test Site. 
At distances up to about $240 \mathrm{~km}$ the main regional phases are $\bar{P}$ and $\bar{S}$. Their velocities are 6.2 and $3.54 \mathrm{~km} / \mathrm{s}$ respectively. Beyond $230-250$ $\mathrm{km}$ the $P n$ wave appears as a first arrival. This wave has stronger highfrequency spectral content than all other regional waves.

As shown by Nersesov and Rautian (1964), the $P n$ wave is not simple. It consists of 2 or 3 waves. Each successive wave appears as a later arrival, with amplitude larger than the previous one. As distance increases, the $P n_{2}$ time arrival moves closer to the first arrival and amplitudes of $P n_{2}$ decrease. We do have not a good range of distances with the data of this paper to see this picture clearly. We can say only that the interval of distances where we observe $P n_{2}$ is small - between 500 and $750 \mathrm{~km} . P n_{2}$ is observed at some stations, but not at each of them.

At TLG the $P n_{2}$-wave arrives about 8-10 s later then $P n_{1}$ and has a larger amplitudes (2-5 times). Examples can be seen in Figures 5 abc (the phases marked $P_{1}$ and $P_{2}$ ). At ZRN the amplitudes of $P n_{2}$ are small. At NSB (all three stations are near the same distance from the test site), $P n_{2}$ is absent. The $P n_{1}$ amplitudes attenuate up to $1600-1800 \mathrm{~km}$, and then increase with distance, presumably due to a deep mantle arrival (which, however, is a continuation of the straight-line $P n_{1}$ travel-time curve, with only a slight increase in phase velocity). The amplitude behavior is strongly different depending on the direction of wave propagation from the Semipalatinsk Test Site. At the East direction amplitudes decrease with distance steeper and then, after $1600-1800 \mathrm{~km}$, increase sharper, than in the West direction.

The $P g$ wave can be observed up to distances of about $700-800 \mathrm{~km}$. The $P g$ arrival is impulsive at distances $250-400 \mathrm{~km}$. Its amplitudes are more than $P n$ (5-10 times). But beyond $500 \mathrm{~km} P g$ looks like a group of low-frequency waves with an emergent arrival. Its amplitudes are of the same order as $P$-coda amplitudes, increasing gradually with lapse time.

The $S n$ wave diverges from $L g$ near $280 \mathrm{~km}$. It can be seen clearly only on $40-50 \%$ of the records. If the propagation path is through the shield, $S n$ is stronger and can be seen better then in an orogenic area. In the shield it has nearly the same high-frequency spectral content as $P n$.

Beyond $1200-1400 \mathrm{~km}$ the $S$ wave appears about $20-25 \mathrm{~s}$ later then the $S n$ wave (unlike the relation between $P n$ and $P$, for which there is no time offset). This is the $S$ wave, with phase velocity $5.7 \mathrm{~km} / \mathrm{s}$ pointed out in J-B tables. It arrives clearly after $1400-1500 \mathrm{~km}$. Its spectral content is much more low-frequency, than that of $S n$. At Garm $(1350 \mathrm{~km}$ from the test site) one can observe both $S$ and $S n$ on the records from Semipalatinsk. The regional variations in travel time of $S n$ and especially for $S$ at $1300-1500 \mathrm{~km}$ are very large: up to about $8 \mathrm{~s}$.

Before the $L g$ wave arrival we sometimes find the low-frequency 
wave called $L i$.

At all the distances under consideration the dominant wave is $L g$. It appears to consist of several groups, from which we can identify arrivals that we call $L g_{1}$ and $L g_{2}$. The $L g_{1}$ arrival is impulsive, whereas $L g_{2}$ is emergent, with increasing amplitudes within a long group of interfering Lg oscillations.

The final recognizable wave is a Rayleigh wave, $R g$, but if the magnitude of the explosion is less then 4 , the signal-to-noise ratio is too small for this wave to be seen. This point requires some discussion. Thus, the terminology here implies a dispersive wave, but in practice there is little surface wave dispersion over paths extending less than $500 \mathrm{~km}$ from Semipalatinsk: periods from about 5-6 s, up to 25-30 s, are superimposed. The maximum amplitude of $R g$ for an explosion recording appears to have a period of about 5 to $6 \mathrm{~s}$ : for an earthquake, the period is longer. Note that for a conventional measurement of surface-wave magnitude, $M_{s}$, made from a fundamental mode 20-s Rayleigh wave at a distance where the wave is well dispersed, the difference between body-wave magnitude $m_{b}$ and surface wave magnitude for a nuclear explosion is on average about 1.2. But for a measurement made around $500 \mathrm{~km}$, where $M_{s}$ is measured at 5 to $6 \mathrm{~s}$ period, the difference $m_{b}-M_{s}$ is about 0.6. However, it needs a fairly large explosion (say, $m_{b}>4.8$ ) for such $R g$ observations to be made.

Although we had access to some data from over 50 stations, in practice our data came mostly from about ten stations. At the other extreme, about $60 \%$ of the stations were used for only 1-3 events. The number of events for which each station was used was as follows:

\begin{tabular}{|l|l|l|l|l|l|l|l|l|l|l|l|l|l|}
\hline Sta. & $\#$ & Sta. & $\#$ & Sta. & $\#$ & Sta. & $\#$ & Sta. & $\#$ & Sta. & $\#$ & Sta. & $\#$ \\
\hline TLG & 60 & KRG & 9 & CHR & 4 & BOM & 2 & SVE & 2 & BAY & 1 & NGN & 1 \\
\hline KZA & 44 & FRZ & 7 & NRN & 4 & CHGU & 2 & TDK & 2 & DZK & 1 & PDG & 1 \\
\hline UKN & 31 & EEE & 6 & ORT & 4 & CHK & 2 & TGM & 2 & FBR & 1 & RYB & 1 \\
\hline BRV & 25 & MDO & 6 & ATA & 3 & KBZ & 2 & ZRN1 & 2 & III & 1 & TUR & 1 \\
\hline NSB & 23 & PRZ & 6 & KRD & 3 & KKB & 2 & ABL & 1 & KKR & 1 & VED & 1 \\
\hline KRM & 16 & SEM & 6 & UKG & 3 & MIX & 2 & ALB & 1 & KSU & 1 & & \\
\hline ZRN2 & 11 & MAK & 5 & ULG & 3 & MRT & 2 & AND & 1 & KUS & 1 & & \\
\hline CHL & 10 & BYK & 4 & VOS & 3 & SKL & 2 & ART & 1 & MKR & 1 & & \\
\hline
\end{tabular}


The availability of quiet sites in the region enables the deployment of high gain instrumentation. The RVZT and KSE records of a presumed UNE at Degelen on January 29, 1971, are shown in Figure 6ab, indicating excellent signal-to-noise, in this example with gains of 120,000 and $1,100,000$.

\section{THE TRAVEL-TIMES IN A REGION AROUND THE TEST SITE}

Most of the events we have studied are small and high-gain records were not often available. Thus, in some records the $P n_{1}$ wave cannot be found and the only arrival times that can be read are for shear waves, such as $S n, L i$ and/or $L g$. So we need to use such shear wave data when calculating the epicentral distances and origin time. Earthquakes in the nearby orogenic Tien Shan region were studied by Nersesov and Rautian (1964) and Shazilov (1989), but in our case the seismic waves propagated in the Kazakh platform and we needed to obtain the travel times versus distances for this zone. For this purpose we used the data from UNEs for which the epicenters are known very accurately.

The $P n_{1}$ velocity is practically constant up to $1200-1300 \mathrm{~km}$ and is $8.1 \mathrm{~km} / \mathrm{s}$, and then slightly increasing up to $8.5 \mathrm{~km} / \mathrm{s}$ over the range $1300-1700 \mathrm{~km}$.

The velocity of $P n_{2}$ is $8.3 \mathrm{~km} / \mathrm{s}$.

The velocity for $\bar{P}$ as well as for $P g$ is the same, $6.2 \mathrm{~km} / \mathrm{s}$. This value is a little higher than usually observed in the Tien Shan and Pamir regions, and stays constant throughout the distance range within which these waves are observed.

Figure 7 shows the travel times for 9 different regional phases in East Kazakhstan. The following relationships between distance and arrival time are available to determine epicentral distances $D$ in kilometers:

$$
\begin{aligned}
& D=6.2 * t(\bar{P}) \\
& D=3.54 * t(\bar{S}) \\
& D=8.1 * t\left(P n_{1}\right)-69 \\
& D=8.3 * t\left(P n_{2}\right)-166 \\
& D=6.2 * t(P g) \\
& D=4.62 * t(S n)-69 \\
& D=3.9 * t(L i) \\
& D=3.54 * t\left(L g_{1}\right) \\
& D=3.4 * t\left(L g_{2}\right)
\end{aligned}
$$$$
\begin{gathered}
0-240 \mathrm{~km} \\
0-240 \\
240-1200 \\
500-750 \\
240-900 \\
240-1400 \\
600-1000 \\
240-1400 \\
600-1400 .
\end{gathered}
$$ 
The reliability of measured arrival times for small events is poor due to the small signal-to-noise ratios, and results in a typical standard error of about $15 \mathrm{~km}$ when the above relations are used to estimate $D$. The error in estimated epicentral distances is smallest for $P n_{1}$ and $L g_{1}$, when $D$ calculated from the above equations is compared with the real distances from published accurate epicenters.

\section{DETERMINATION OF EPICENTERS}

By taking the difference in arrival time between pairs of phases at a single station, and using the above relationships between distance and arrival time, we can estimate the epicentral distance from each station that has adequate data. The actual epicenter can then be found graphically as the point of intersection of circles with the stations at their centers and radius being the epicentral distance from the station. Figure 8 shows several examples. Using the data from many stations, we get an intersection point from each pair of stations. The epicenter is calculated by averaging all points of intersection, with a weight for each point, equal to the sine of the intersection angle.

If the epicenter is close to the center of the Test Site, we can simplify the calculation of epicenters, using straight lines rather than arcs of circles. To do this we choose the central point of Degelen, $\left(49.85^{\circ} \mathrm{E}, 78.08^{\circ} \mathrm{N}\right)$, as a master epicenter and estimate the value of $\Delta D=D-D_{0}$ where $D_{0}$ is the distance from the station to the central point. In many cases $\Delta D$ is only a few percent of $D_{0}$. For example, for the event of 1988 December 28 we had several phases recorded at 7 different stations. The average value of $\Delta D$, and the value of $D_{0}$, were as follows (all in $\mathrm{km}$ ):

$\begin{array}{llrl} & & \Delta D & D_{0} \\ \text { E } & \text { KSU } & -4.0 & 219 \\ \text { E } & \text { SEM } & 4.8 & 171 \\ \text { E } & \text { UKN } & -6.4 & 488 \\ \text { S } & \text { MRT } & 9.1 & 525 \\ \text { S } & \text { PDG } & -9.6 & 727 \\ \text { S } & \text { TIIG } & 4.2 & 733 \\ \text { W } & \text { BAY } & 0.7 & 211 .\end{array}$

Letters $E, N, S$ or $W$ here indicate the direction from source to station (whether East, North, South or West). Because $\Delta D$ is so much smaller than $D_{0}$, the curvature of arcs is low and we can replace the arcs by straight lines, perpendicular to the direction from epicenter to stations. 
If data were available from only 2 stations, we can get a single intersection of straight lines. The longer axis of the error area was calculated as $10 \mathrm{~km}$ divided by $\sin (\mathrm{az} 1-\mathrm{az} 2)$, and the minimum was taken as $10 \mathrm{~km}$. The azimuth of $\max$ error was taken as the average azimuth of the pair of stations.

Several UNEs with accurate epicenters were used to check the accuracy of epicenter determination. Results are shown in Table 4. Calculations were done in 2 versions: using only $P n_{1}$ (indicated as $P n$ in the Table), and using the average error in location from all waves where more than just $P n$ was used. In most cases the error is about $1-12 \mathrm{~km}$, but for a few UNEs it is large, up to $100 \mathrm{~km}$. The low accuracy can be due to error of arrival times (for some cases only bulletin data were available), and/or because stations were available only in one general direction (e.g. South) from the source. The standard deviation for an estimate of the distance, using $P n_{1}$ for a single station, is $12 \mathrm{~km}$.

One can see from Table 4 that the accuracy of epicenter location is of the same order for $P n$ alone, as for averaged data from all available waves. So, if $P_{n}$ data of many stations are available, we need not use other waves. But for small events, when $P n$ is not readable on seismograms, we used all wave data available.

The list of 52 stations (see Table 3) includes 10 to the East, 1 to the North, 24 to the South, and 17 to the West. If the stations recording an event are all from only one side, (for example May 7 and Aug 19, 1966, where we had data only from the South side), then only one coordinate can be found accurately. The number of stations for which data are available varied for each event from $1(11 \%), 2-4(46 \%)$; 5-9 (27\%) ; to 10-11 (only $8 \%$ ). For 10 events the data were obtained from stations localized only to one side, usually South or East.

\section{DETERMINATION OF EPICENTERS}

Of the 65 events studied in this paper (Table 2), 10 already have known locations (Bocharov et al, 1989). In this section we describe our first location estimates for the remaining 55 events, presenting the results in Tables $5,6,7$, and 8 (and see also Figure 8 , for 12 events). Throughout the year in which we worked on this project together at Lamont, we continued to receive additional information on arrival times for specific events at specific stations. Table 12 , in a later section presenting our final results, reflects this additional information, and reports hypocentral estimates that are slightly different for some events from the results reported in this section. 
Table 5 gives our first location estimates, for events that appear to be on or very close to the Semipalatinsk Test Site, and for which we have data available from more than one general azimuthal direction. These are our best located events.

Table 6 describes four events for which data were available at only one azimuth, either to the South (three events) or the East (one event). In these cases we can estimate only one coordinate, but it is consistent with a location on the test site. The estimated origin time in three of these cases is consistent with being on the exact minute (00 seconds) - further evidence that these events are explosions.

Table 7 describes six events for which data were available at only one station. The calculated epicentral distances $D$ for two of the events are practically the same as the distance $D_{0}$ to the central point of Degelen. For four of the events, $\Delta D=D-D_{0}$ was as much as $10-30 \mathrm{~km}$. Although we cannot find these epicenters, the data do not contradict our assumption that these events lie on the test site.

Table 8 describes three events (1967 June 3, 1967 July 16, 1981 March 31) at distances $100-300 \mathrm{~km}$ from the test site; and three more events that are even farther away. Thus, the event of 1980 October 26 is $1545 \mathrm{~km}$ from Talgar, more than twice the distance from Talgar to Degelen $(733 \mathrm{~km})$. The event of 1983 February 13 is $765 \mathrm{~km}$ from station UKN, whereas the distances from UKN to Degelen and Balapan are 488 and 425 $\mathrm{km}$ respectively The event of 1984 August 26, for which we have readings from two stations, lies at one of the two intersection of two circles. Both choices of epicenter lie far from the test site.

Commenting in general on this work of event location, we can say that the network of regional stations in Central Asia uncovered many events additional to those located from teleseismic data. The most important stations are those at distances less that $500 \mathrm{~km}$ from the Semipalatinsk Test Site. Even at $700 \mathrm{~km}$, detection becomes significantly worse. The worst distances are around $1000 \mathrm{~km}$. At $2000 \mathrm{~km}$ and beyond, amplitudes are stronger than at $1000 \mathrm{~km}$, these signals coming from the deep mantle phases $P$ and $S$, and teleseismic methods apply. These results about amplitude dependence on distance have been known for more than 30 years, and were well understood during test ban negotiations in the period 1960-1963. The data of Sykes and Ruggi (1989) for small events, based principally upon LASA signals, indicated that teleseismic data can be useful for detection of events with magnitude around 4 and below, but that locations based upon data from a single teleseismic array are often poor (compare Sykes' and Ruggi's locations noted in Table 2, with our locations in Tables 5-8). 


\section{DETERMINATION OF MAGNITUDES}

We found there are significant differences, some of which are systematic, between the determinations of magnitude by ISC, NORSAR, and AWE (the British Atomic Weapons Establishment) for small events. The ISC and AWE magnitudes are both based upon teleseismic $P$-wave observations; - and the NORSAR magnitude is based upon RMS $L g$ measurements (which usually require Semipalatinsk events to be above magnitude 5.5 in order to have an adequate signal-to-noise ratio at NORSAR, more than $4000 \mathrm{~km}$ away). It seems to us that the AWE determinations are preferable, especially for events with magnitudes less then 5. The differences between AWE and ISC are due to the systematic error that can follow when working with signals that are close to the noise level, since, in the ISC procedure, signals that are below the noise level are not allowed for in forming the average, so the averaged magnitude is biased high. The AWE maximum likelihood magnitude allows for the statistics of non-observation in the presence of noise. Figure $9 \mathrm{a}$ shows a comparison of ISC and AWE magnitudes, and the ISC magnitudes are indeed to be too high for the smaller events. Figure $9 \mathrm{~b}$ shows that the AWE and NORSAR magnitudes are in good agreement, as noted and discussed by Ringdal et al (1992).

However, although we prefer AWE values, we recognize that ISC magnitudes are widely used as a standard. Therefore we have used ISC $m_{b}(P)$ and separately AWE and NORSAR magnitudes when comparing our regional measurements with teleseismic observations.

We used two ways to calculate magnitude from regional data. One way is based on the $\mathrm{K}$ scale (energy class) which is used in the former Soviet Union in all local networks. $\mathrm{K}$ is approximately equal to $\log E$ where $E$ is the radiated energy in joules (Rautian, 1960). To derive the relationship between $K$ and teleseismic magnitude and to calculate the magnitudes $M(\mathrm{~K})$ reported in Table 9, we took $\mathrm{K}$ values from Soviet bulletins or calculated $\mathrm{K}$ ourselves from amplitude readings. Using the data on $\mathrm{K}$ and the ISC values of $m_{b}(P)$ for large UNEs at the Semipalatinsk Test Site the relationship can be found as

$$
m_{b}(P)=0.42 \mathrm{~K} \text {. }
$$

The values of ISC $m_{b}(P)$ are not good for small events (as noted from Figure $9 a$ ), and if we compare $K$ with the magnitudes from AWE or NORSAR we find a different relationship:

$$
m(\text { AWE or NORSAR })=0.44 \mathrm{~K}-0.53 \text {. }
$$


The points to which this last equation is fit, are shown in Figure 9c across six orders of magnitude in energy. (In addition to the $m_{b}(P)$ values from AWE and the $m_{b}(L g)$ values from NORSAR, we sometimes used $m_{b}(P)$ values from NORSAR for small events.) Either of the above two formulae may be used to estimate a magnitude based on $\mathrm{K}$, denoted $M(\mathrm{~K})$. We preferred to use the second formula.

Our next method of determining $m_{b}(P)$ was to get the separate relationship between $\log A$ (from ChISS records at TLG, NSB and ZRN) and ISC $m_{b}(P)$ for each station using the large events. We then extrapolated the formula using the observed values of $\log A$ to estimate magnitudes for the smaller events.

The equations were obtained separately for each wave $\left(P n_{1}, P n_{2}\right.$, $P g, S n, L g_{1}, L g_{2}, L g_{3}, R g$ and amplitudes of coda at the lapse time 500 seconds). Also we used the averaged amplitudes of all $P$ waves; the sum of amplitudes of $L g_{1}, L g_{2}$, and $L g_{3}$; and the absolute max of $L g$, independent of its time of arrival. The coda is the best parameter for magnitude calculation, giving the more accurate results. But for the small events we cannot see coda on records late enough in lapse time.

The estimations were made for each frequency band separately. In general the frequency range of ChISS used in this problem was from $14 \mathrm{~s}$ to $2.5 \mathrm{~Hz}$. The correlation equations obtained are as follows:

$$
m_{b}(P)=k^{*} \log A+b .
$$

with the values of $k$ and $b$ being different for each station, each wave, and each frequency band. Figure 9d shows the comparison between $m_{b}$ (AWE) and $m_{b}$ determined from ChISS measurements.

Small events sometimes were recorded by only 2-3 channels, corresponding to the maximum of the spectrum, and coda cannot be seen and used. So to estimate a magnitude for a small event we can use only a limited number of the above correlations between $m_{b}(P)$ and ChISS amplitudes, corresponding to those for which we have ChISS data. We form an average over all the magnitudes derived from ChISS readings in this way. The system of coefficients in the last equation, above, to calculate $m_{b}(P)$ from ChISS amplitudes, was obtained using ISC magnitudes. To get a second version of $m_{b}$ (ChISS), corresponding to AWE and NORSAR estimations, we use the relationship (e.g. from Figure 9a)

$$
\begin{aligned}
m_{b}(\text { AWE and NORSAR }) & =1.25 m_{b}(\text { ISC) }-1.50 \text { (for Balapan) } \\
& =1.25 . m_{b} \text { (ISC) }-1.37 \text { (for Degelen) }
\end{aligned}
$$


Our magnitude results are given in Table 9, and we see that values for previously unknown events typically lie in the range $3.5-4.5$, so these explosions are mostly subkiloton. The magnitude of the first Semipalatinsk UNE, assigned here as 4.81 , is somewhat uncertain. This event (on October $11,1961)$ had an amplitude 6.7 times smaller than that of the second UNE (on February 2,1962) on the Talgar record - and the latter event had a relatively well-determined $\mathrm{K}$ value of 14.0 from four stations and hence a magnitude of 5.63. Thus the magnitude of the first UNE at the Semipalatinsk Test Site is assigned as $5.63-\log 6.7=4.81$.

In view of the often excellent teleseismic detection capability of arrays (Ringdal, 1990), it was a surprise to us that the events were in many cases not detected by NORSAR. One difficulty with assessing the performance of teleseismic arrays, with our event set, is that until about 1980 it was not common for array data to be archived on a continuous basis. Only the detections that were noticed, were saved. (In the case of LASA, not even detections were saved, except within a limited period of operation of this array.) We checked with Yellowknife and learned that the only events confirmed at that array after 1978 (when it is possible to check against an archive) were those of 1981 March 31 and 1982 June 11 (personal communication from Bob North). This failure to demonstrate teleseismic detections is important to explore further, since plans are under development to build a global network of so-called alpha stations, mostly arrays, intended to provide continuous and virtually complete coverage of Eurasia at the magnitude 3.5 level and better using teleseismic signals, for purposes of monitoring compliance with a Comprehensive Test Ban Treaty (CTBT). If array detection is not reliable at the magnitude 3.5 level using teleseismic signals, then increased attention must be paid to regional signals for purposes of detection as well as identification - a conclusion that has implications for the numbers of seismic stations needed in an effective network for CTBT monitoring.

\section{DISCUSSION AND CONCLUSIONS}

The problem of identification of seismic events at the Semipalatinsk Test Site is considerably complicated by the occurrence of chemical explosions. To begin the discussion of identification, Table 10 reports for this test site the numbers of UNEs each year claimed by van der Vink et al (1993), the number of UNEs each year that have been identified from teleseismic data (see Table 1), and the number of chemical explosions greater than 10 tons in each year from 1970-1988 reported by Saybekov (1993). The Natural Resources Defense Council and the USSR Academy of Sciences set off a 10 ton chemical explosion near the test site in 1987, that 
was recorded successfully at Talgar (a distance of more than $700 \mathrm{~km}$ ), so we should expect no problem with observability of chemical explosions at regional distances in Central Asia

One important indicator that an event was an explosion, is whether it was shot on the exact minute. Prior to September 1980, it appears that virtually all previously known UNEs at Semipalatinsk were carried out either on or very close to an exact minute. The only exceptions in Table 1 are a single UNE at Murzhik (1978 July 18), and five UNEs that in each case were the second event of a pair carried out a few seconds apart, with the first shot being on the minute (1972 December 10, 1974 January 30, 1977 October 29, 1978 August 29, and 1978 November 29). For many years, a practical rule for identifying a UNE at Semipalatinsk was to note any event whose first arrival was about $29 \mathrm{~s}$ after the minute at Borovoye, and $38 \mathrm{~s}$ after the same minute at Talgar! We find that many of the previously unknown events studied in this paper did occur, if prior to September 1980 , on or very close to an exact minute. However, this method does not work after that date, nor does it help us directly to distinguish between chemical and nuclear explosions.

We have not carried out a systematic study of spectral ratios (using ChISS data), to attempt to discriminate between earthquakes and explosions, although a preliminary study of such ratios has indicated that $P$ to $S$ amplitude ratios are somewhat sensitive to event type, when signal-to-noise ratios are high. We did generate a preliminary summary of our results for 48 events - locations, magnitudes, and a brief and somewhat subjective comment on event type - which is given here as Table 11. Almost all of these events are listed as explosions. The only exceptions are the events of 1966 December 26 (listed as an earthquake because of the time of day and location just off the test site), 1980 November 6 (listed as an earthquake in this preliminary summary because of the time of day), 1988 September 26 (which a Russian colleague had told us was an earthquake and not a UNE - but which we have listed as either an earthquake or a chemical explosions), and 1989 October 20 (which a Russian colleague had told us was a UNE collapse).

Note in Table 11 that prior to 1978 the explosion candidates are listed as UNEs (except for one known ChE in 1961), but for 1978 and later they are listed as UNE or ChE (except for two UNEs at Degelen). The reason for this change in listing is that we noticed several differences between events occurring before and after about 1979, as follows:

- the error in latitude determination became worse with time (for 1964-1979, out of 23 events only 4 have latitude error $>10 \mathrm{~km}$; for 1980-1988, out of 18 events, only 4 have latitude error $<10 \mathrm{~km}$ ). 
- We developed our travel time table and identification of wave types using the well-recorded data from known UNEs from the test site. Events from other locations can have slightly different wave properties. For all events up till 1977 for which we have the records, the wave form is approximately similar. But after 1978 at least half of the events have a slightly different wave form: the arrival of the $L g$ group is not so sharp; and there is a very impulsive arrival of $P n_{2}$ on the ChISS $5 \mathrm{~Hz}$ channel. We called such events the Balapan series.

- Before 1973 all our small events occurred at Degelen. In 1973-1978 only half occurred at Degelen. In 1979-1984, among 19 events only one could have occurred at Degelen. And the last six events were again mostly at Degelen.

- For the period 1981-1984 the number of UNEs claimed per year by Russian sources (see Figure 1 or Table 10) was about equal to the number of events already identified as UNEs (Figure 1 or Table 1), so our small events for this period appear to be in excess of the number of UNEs. We therefore suspected at the time of preparing Table 11 that some of the Balapan series were special chemical explosions - quite large ones, in view of their seismic magnitudes.

When we circulated this preliminary summary table to a small number of individuals for comment, we received the following additional information from Jack Murphy:

"Of the 21 events since 1970 which you locate as being at or near Balapan [Table 11 identifies] 4 as probable UNE (probability > 0.9), 9 as likely UNE $(0.5<$ probability < $0.9), 1$ as definite $\mathrm{EQ}$ (probability $=1.00$ ), 6 as likely $C E$ (probability > 0.7) and 1 as about equally likely to be either $C E$ of $E Q$. In fact, more reliable data indicate that none of these events are UNE or EQ."

Obviously, this comment reinforced our opinion that a significant fraction of the events we have studied are chemical explosions at Balapan. The above statement can be used to infer that 21 events in Table 11 , on or near Balapan, are chemical explosions. We continue to believe that the explosions we have found at Degelen are UNEs.

Before giving our final results, Figure 10 shows the location of 282 UNEs at Semipalatinsk, one earthquake, and one chemical explosion, all previously known (further information for these UNEs, given in Table 1).

Our final results are given in Table 12 and Figures 11 and 12. Figure 11 shows our locations for 43 events not previously known on the 
Semipalatinsk Test Site. Most of those at Degelen, we believe to be UNEs. Most of those at Balapan, we now believe to be chemical explosions. (Two of the ChE events are co-located in Figure 11, as are two pairs of UNEs on Degelen.) Figure 12 shows events in our study that are located off the test site, but are still within about $300 \mathrm{~km}$.

It should be emphasized that we have no seismological basis for discriminating between UNEs and chemical explosions. We have chosen to make the final distinction, in Table 12, by inference from Murphy's comment on our preliminary Table 11 (which named many events at or near Balapan as either UNE or $\mathrm{ChE}$ ). Note that we used seismic methods to detect them - and indeed to label them, in almost all cases - as some type of explosion. But under a CTBT, it would appear to be necessary to use non-seismic methods (for example, on-site inspection) to confirm that explosions as large as these did indeed have a chemical nature.

One particularly interesting event is that of December 26, 1966, which we believe to be a small earthquake just off the test site to the southeast (see Figure 12). Figure 13a shows the three-component SKM record of this event at a station only $260 \mathrm{~km}$ away. The $P$ and $S$ waves both have very high frequency content, and $L g$ has a sharp onset and an amplitude several times bigger than that of $P g$ (which in turn is more than 20 times bigger than $P n$ ). Figure 13b shows a similar record of a presumed small UNE at Degelen, at a distance of $306 \mathrm{~km}$. The regional phases are different in several respects from those of Figure 13a - for example, in the $P n$ to $L g$ ratio.

Our list of UNEs in Table 12 includes 13 occurring in the period prior to 1973 that was the subject of the paper by Bocharov et al (1989). We therefore believe that the 96 UNEs Bocharov et al describe were not a complete set of UNEs for 1961-1972 at Semipalatinsk.

The problem remains, of a significant difference between the 303 UNEs we would now claim at Semipalatinsk (282 from Table 1, plus 21 additional UNEs from Table 12), and the 343 claimed as the total by several Russian sources (see earlier discussion: no doubt some very small UNEs at Semipalatinsk, as at the Nevada Test Site, did not generate observable seismic signals, even at regional distances).

In conclusion, we believe we have successfully located and identified about 50 small events on or near the Semipalatinsk Test Site, not previously listed or well-located from openly available teleseismic data. These events presumably include a few earthquakes, and a few tens of explosions (chemical or nuclear). We have no capability with the data we have used, to distinguish between chemical and nuclear explosions. A useful guide to identification is the number of each type of event reported 
by various sources (see Table 10), but, though of some interest, it would not be prudent to rely too greatly on these numbers; nor can such a guide be used in future CTBT monitoring. Our event list can be made the basis for numerous projects to evaluate teleseismic detection capability, and also to evaluate regional discriminants. We have accumulated and used several hundred analog seismograms for these events. Many of these seismograms, particularly those obtained on ChISS instruments, can be used for spectral analysis; and we believe digital data can also be found, now that we have a list of events as the basis for data requests.

\section{ACKNOWLEDGEMENTS}

We thank many station operators in Central Asia for their response to our numerous requests for information; and Jack Murphy for technical advice. This work was supported initially by contract B239589 with Lawrence Livermore National Laboratory, and later by grant F49620-92-J0497 from the Air Force Office of Scientific Research.

*This work was performed under the auspices of the U.S. Department of Energy by Lawrence Livermore National Laboratory under contract No. W-7405-Eng-48. REFERENCES

Aki, K., and P.G. Richards, Methods of Quantitative Seismology, W.H. Freeman and Co., San Francisco, 1980.

Bocharov, V.S., S.A. Zelentsov, and V.I. Mikhailov, Characteristics of 96 underground nuclear explosions at the Semipalatinsk test site (in Russian), Atomnaya Energiya, 67, 210-214, 1989.

Hansen, R., F. Ringdal, and P.G. Richards, The stability of RMS Lg measurements and their potential for accurate estimation of the yields of Soviet underground explosions, Bulletin of the Seismological Society of America, 80, 2106-2126, special issue, December 1990.

Lilwall, R.C., and J. Farthing, Joint epicentre determination of Soviet underground nuclear explosions 1973-89 in Eastern Kazakhstan, AWE Report No. O 12/90, H.M. Stationery Office, 1990.

Nersesov, I.L, and T.G. Rautian, Kinematics and dynamics of seismic waves at epicentral distances less than $3500 \mathrm{~km}$, Proceedings (Trudy) of the Institute of Physics of the Earth, Academy of Sciences of the U.S.S.R. (in Russian), 32, 1964. 
Mikhailov, V.N., A.M. Matuschenko, V.P. Dumik, V.G. Safronov, and G.A. Tsyrkov; "Chronicle and Phenomenology of Nuclear Tests on the Novaya Zemlya Range", in Proceedings of a Conference on The Radiological and Radiation Protection Problems in Nordic Regions, Troms $\varnothing$ 21-22 Nov 1991, ed. Johan Baarli, published by the Nordic Society for Radiation Protection, Oslo 1992.

Rautian, T.G., Attenuation of seismic waves and energy of earthquakes, Proceedings of the Institute of Seismology, Tadjikian Academy of Sciences (in Russian), \#7, 1960

Rautian, T.G., and V.I. Khalturin, The use of the coda for determination of the earthquake source spectrum, Bulletin of the Seismological Society of America, 68, 923-948, August 1978.

Rautian, T.G., V.I. Khalturin, V.G. Martynov, and P. Molnar, Preliminary analysis of spectral content of $P$ and $S$ waves from local earthquakes in the Garm, Tadjikistan Region, Bulletin of the Seismological Society of America, 68, 949-971, August 1978.

Richards, Paul G., Won-Young Kim, and Göran Ekström, The Borovoye Geophysical Observatory, Kazakhstan, EOS, Transactions of the American Geophysical Union, 73, 201 and 205-6, May 51992.

Richards, Paul G., and Jinghua Shi, in Final Report on RMS $L g$ studies of underground nuclear explosions in the U.S.S.R. and the U.S., Air Force Phillips Laboratory Technical Report, PL-TR-93-2227, 1994.

Ringdal, F., Teleseismic event detection using the NORESS array, with special reference to low-yield Semipalatinsk explosions, Bulletin of the Seismological Society of America, 80, 2127-2142, special issue, December 1990.

Ringdal, F., P.D. Marshall, and R. Alewine, Seismic yield determination of Soviet underground nuclear explosions at the Shagan River test site, Geophysical Journal International, 109, 65-77, 1992.

Saybekov, Toqtasyn, Impact of nuclear explosions in Semipalatinsk, Ata Meken, August 14, 1993 (in Kazakh); also in JPRS-TAC-93-019 (in English), September 29, 1993. 
Shazilov, V.I., Methods of evaluation of seismic risk, Publishing House Nauka, Alma Ata (in Russian), 1989.

Sykes, L.R., and S. Ruggi, Soviet Nuclear Testing, chapter 10 in the book Soviet Nuclear Weapons, vol IV of the Nuclear Weapons Databook series, ed. T.B. Cochran, W.M. Arkin, R.S. Norris, and J.I. Sands, Harper \& Row, Ballinger Division, New York, 1989.

van der Vink, Gregory E., Vitaly V. Adushkin, and Vitaly A. Laushkin, "Experience of the Verification of the Nonproliferation of Nuclear Weapons Tests at the Network of Open Seismic Stations", unpublished ms. of a paper given at a Princeton conference, Fall 1992, on NonProliferation; also a similar paper at AGU, Baltimore, Spring 1993.

Zapolskii, K.K., Measurement of the level and spectral content of shortperiod microseisms, Proceedings (Trudy) of the Institute of Physics of the Earth, Academy of Sciences of the U.S.S.R. (in Russian), \#10, 1960.

Zapolskii, K.K., The ChISS frequency-selective seismic station, in Experimental Seismology, Publishing House Nauka, Moscow (in Russian), 1971.

Zapolskii, K.K., and V.I. Khalturin, Frequency of seismic vibration, in Method of detailed study of seismicity, Proceedings (Trudy) of the Institute of Physics of the Earth, Academy of Sciences of the U.S.S.R. (in Russian), \#10, 1960.

\section{LIST OF TABLES}

Table 1. Parameters of previously known UNEs at the Semipalatinsk Test Site.

Table 2. Parameters of 65 seismic events in the Semipalatinsk region, that we initially regarded as potential UNEs, or UNEs of unknown magnitude, or earthquakes/chemical explosions. These are the events studied in this paper.

Table 3. Location of 52 stations at regional distances from the Semipalatinsk Test Site, operated during 1961-1989.

Table 4. A test of our method of epicenter determination.

Table 5. Location estimates for events on or close to the Semipalatinsk Test Site, and for which we have seismic data from more than one general azimuthal direction. 
Table 6. Location estimates for events apparently on or close to the Semipalatinsk Test Site, and for which we have seismic data from only one general azimuthal direction.

Table 7. Location estimates for events apparently on or close to the

Semipalatinsk Test Site, and for which we have seismic data from only one station.

Table 8. Location information for events $100-300 \mathrm{~km}$ distant from the Semipalatinsk Test Site, or at even greater distances.

Table 9. The determination of two magnitudes, $M(K)$ and $M(C h I S S)$, from regional data; and three magnitudes reported from teleseismic data. Table 10. Numbers of UNEs, and chemical explosions, each year at the Semipalatinsk Test Site, reported by various sources.

Table 11. Locations, magnitudes, and initial comments on identification, for 48 events. We later received information that most of the events in this Table on or near Balapan were chemical explosions.

Table 12. Our final locations, magnitudes, and summary comments on identification, for the 65 events studied in this paper.

\section{LIST OF FIGURES}

Figure 1. Numbers of underground explosions (UNEs) each year from 1961-1989 at the Semipalatinsk Test Site, as reported by van der Vink et al (1993) and as determined from lists of teleseismically observed events (Table 1).

Figure 2. The boundaries of the Semipalatinsk Test Site. The town of Kurchatov, on the Irtysh River, lies just inside the test site, to the northeast.

Figure 3. The location of 52 seismic stations at regional distances from the Semipalatinsk Test Site.

Figure 4. Instrument responses.

(a) Displacement spectral responses for the SKM, SKD, RVZT, and KSE seismometers.

(b) Velocity spectral response, and impulse response, for different channels of the ChISS system.

Figure 5. Examples of ChISS seismograms recorded at Talgar:

(a) the calibration signals, and several regional phases from a known Degelen explosion on December 30, 1976 (distance of $730 \mathrm{~km}$ );

(b) a Degelen explosion on April 21, 1976;

(c) a Balapan explosion also on April 21, 1976. Note first that the various $P, S$, and $L g$ phases are seen with different amplitudes on different channels, for each of these three examples. Detailed analysis shows that the regional phases are excited slightly differently by 
Degelen and Balapan events, as recorded at Talgar.

Figure 6. Examples of high gain records:

(a) the RVZT records (three component); and

(b) the KSE records, both at station Krasny Kordon, for the presumed UNE of January 29, 1971, at Degelen.

Figure 7. Regional travel time curves for East Kazakhstan.

Figure 8. Twelve examples of worksheets for event location.

Figure 9. Relations between magnitude scales and energy class:

(a) comparison between maximum likelihood $m_{b}(P)$ values due to the British Atomic Weapons Establishment, and the ISC $m_{b}(P)$, showing the latter is biassed high for small events;

(b) comparison between the AWE $m_{b}(P)$ and the NORSAR $m_{b}(L g)$, showing lack of bias and hence a rough equivalence for these two magnitude scales;

(c) comparison of magnitudes and the energy class, $\mathrm{K}$. Circles denote $m_{b}$ (NORSAR) vs. K(Talgar), triangles denote $m_{b}$ (AWE) vs. K(bulletins), and crosses denote $m_{b}$ (AWE) vs. K(bulletins); and

(d) comparison of $m$ (ChISS) against $m_{b}(\mathrm{AWE})$.

Figure 10. The location of 282 previously known UNEs, one chemical explosion, and one earthquake, all on or near the Semipalatinsk Test Site. (Epicenters of these UNEs are given in Table 1.)

Figure 11. The location of 43 previously unknown events on or very near the Semipalatinsk Test Site. Most of the UNEs are at Degelen, most of the chemical explosions (ChEs) are at Balapan. Part of the test site boundary is also shown.

Figure 12. Similar to Figure 11, but with a different scale to show seismic events off the test site but within $300 \mathrm{~km}$. Two earthquakes are also indicated, one previously known (1976 March 20), one unknown (1966 December 26).

Figure 13. SKM records of two events recorded at Ust-Kamenogorsk:

(a) an event we believe to be a small earthquake - note the efficient excitation of $L g$;

(b) a presumed UNE at Degelen. 


\begin{tabular}{|c|c|c|c|c|c|c|c|c|c|c|c|c|c|}
\hline Date & $h$ & mi & $s$ & at & long. & area & subsite & $\frac{\mathrm{MAG}}{\mathrm{ISG}}$ & AMP & $\mathrm{REV} / \mathrm{POL}$ & TOT & $\frac{m b}{A W E}$ & $\begin{array}{l}m b(\mathrm{Lg}) \\
\mathrm{NOR} G \mathrm{GRF}\end{array}$ \\
\hline & & & & & & & & & & & & & \\
\hline $61-0 \mathrm{ct}-11$ & 7 & 39 & 59.9 & 49.77272 & 77.99500 & & $\mathrm{D}$ & & & & & & \\
\hline $62-\mathrm{Feb}-02$ & 8 & 0 & 0.2 & 49.77747 & 78.00164 & & $\mathrm{D}$ & & & & & & \\
\hline $64-\operatorname{Mar}-15$ & 8 & 0 & 0.4 & 49.81597 & 78.07517 & & $\mathrm{D}$ & 5.6 & 14 & 5132 & 68 & 5.563 & \\
\hline 64-May-16 & 6 & 0 & 59.8 & 49.80772 & 78.10197 & & $\mathrm{D}$ & 5.6 & 15 & $9 / 35$ & 80 & 5.549 & \\
\hline 64-Jul-19 & 6 & 0 & 0.6 & 49.80908 & 78.09292 & & $\mathrm{D}$ & 5.2 & 14 & $4 / 33$ & 68 & 5.433 & \\
\hline $64-\mathrm{Nov}-16$ & 6 & 0 & 0.2 & 49.80872 & 78.13344 & & $\mathrm{D}$ & 5.6 & 15 & $3 / 35$ & 83 & 5.642 & \\
\hline $65-J a n-15$ & 6 & 0 & 0.8 & 49.93500 & 79.00936 & & $B$ & 5.8 & 11 & $6 / 50$ & 79 & 5.87 & \\
\hline $65-\mathrm{Mar}-03$ & 6 & 14 & 59.4 & 49.82472 & 78.05267 & & D & 5.5 & 14 & $51 \quad 36$ & 53 & 5.443 & \\
\hline $65-\mathrm{May}-11$ & 6 & 40 & 0.2 & 49.77022 & 77.99428 & & $D$ & 4.9 & 4 & $2 / 13$ & 19 & 4.742 & \\
\hline $65-$ Jun-17 & 3 & 45 & 0.0 & 49.82836 & 78.06686 & & $\mathrm{D}$ & 5.2 & 10 & $5 / 23$ & 36 & 5.244 & \\
\hline $65-J u l-29$ & 3 & 5 & 0.2 & 49.77972 & 77.99808 & & $D$ & & & & & & \\
\hline $65-\mathrm{Sep}-17$ & 4 & 0 & 0.1 & 49.81158 & 78.14669 & & $\mathrm{D}$ & 5.2 & 9 & $3 / 16$ & 34 & 5.219 & \\
\hline $65-0 \mathrm{ct}-08$ & 6 & 0 & 0.4 & 49.82592 & 78.11144 & & $\mathrm{D}$ & 5.4 & 14 & $51 \quad 32$ & 54 & 5.471 & \\
\hline $65-0 \mathrm{ct}-14$ & 4 & 0 & 0.2 & 49.99064 & 77.63572 & & $\mathrm{M}$ & & & & & & \\
\hline $65-\mathrm{Nov}-21$ & 4 & 58 & 0.0 & 49.81919 & 78.06358 & & $\mathrm{D}$ & 5.6 & 33 & $6 / 48$ & 114 & 5.605 & \\
\hline $65-\mathrm{Dec}-24$ & 5 & 0 & 0.2 & 49.80450 & 78.10667 & & $\mathrm{D}$ & 5.0 & 13 & $3 / 7$ & 47 & 4.944 & \\
\hline $66-F e b-13$ & 4 & 58 & 0.1 & 49.80894 & 78.12100 & & $\mathrm{D}$ & 6.1 & 51 & $15 / 113$ & 179 & 6.256 & \\
\hline $66-\mathrm{Mar}-20$ & 5 & 50 & 0.3 & 49.76164 & 78.02389 & & D & 6.0 & 53 & 7190 & 154 & 6.040 & \\
\hline $66-\mathrm{Apr}-21$ & 3 & 58 & 0.1 & 49.80967 & 78.10003 & & $\mathrm{D}$ & 5.3 & 33 & $11 / 54$ & 99 & 5.370 & \\
\hline $66-\mathrm{May}-07$ & 3 & 58 & 0.2 & 49.74286 & 78.10497 & & $\mathrm{D}$ & 4.8 & 16 & $3 / 7$ & 32 & 4.734 & \\
\hline $66-J u n-29$ & 6 & 58 & 0.5 & 49.83442 & 78.07336 & & $\mathrm{D}$ & 5.6 & 34 & $8 / 50$ & 96 & 5.508 & \\
\hline $66-J u \mid-21$ & 3 & 58 & 0.0 & 49.73667 & 78.09703 & & $\mathrm{D}$ & 5.3 & 31 & $12 / 51$ & 99 & 5.360 & \\
\hline 66-Aug-05 & 3 & 57 & 59.6 & 49.76431 & 78.04242 & & $\mathrm{D}$ & 5.4 & 30 & 8147 & 98 & 5.390 & \\
\hline $66-A u g-19$ & 3 & 52 & 59.9 & 49.82708 & 78.10875 & & $\mathrm{D}$ & 5.1 & 8 & $2 / 4$ & 28 & 4.633 & \\
\hline $66-\mathrm{sep}-07$ & 3 & 51 & 59.7 & 49.82883 & 78.06375 & & $\mathrm{D}$ & 4.8 & 8 & 21 & 27 & 4.661 & \\
\hline $66-0 \mathrm{ct}-19$ & 3 & 57 & 59.9 & 49.74711 & 78.02053 & & $\mathrm{D}$ & 5.6 & 39 & $10 / 67$ & 132 & 5.669 & \\
\hline $66-\mathrm{Dec}-03$ & 5 & 2 & 0.2 & 49.74689 & 78.03336 & & $\mathrm{D}$ & 4.8 & 9 & $3 !$ & 17 & 4.600 & \\
\hline $66-\mathrm{Dec}-18$ & 4 & 58 & 0.0 & 49.92458 & 77.74722 & & $\mathrm{M}$ & 5.8 & 42 & 5194 & 166 & 5.922 & \\
\hline $67-\operatorname{Jan}-30$ & 4 & 1 & 59.5 & 49.76744 & 77.99139 & & $\mathrm{D}$ & 4.8 & 12 & $1 / 6$ & 43 & 4.627 & \\
\hline $67-F \mathrm{eb}-26$ & 3 & 57 & 59.8 & 49.74569 & 78.08231 & & $D$ & 6.0 & 53 & $12 / 99$ & 196 & 6.034 & \\
\hline $67-\mathrm{Mar}-25$ & 5 & 58 & 1.1 & 49.75361 & 78.06300 & & $\mathrm{D}$ & 5.3 & 34 & $6 / 47$ & 101 & 5.320 & \\
\hline $67-\mathrm{Apr}-20$ & 4 & 8 & 1.0 & 49.74161 & 78.10542 & & $\mathrm{D}$ & 5.5 & 37 & $12 / 68$ & 105 & 5.556 & \\
\hline $67-$ May-28 & 4 & 7 & 59.6 & 49.75642 & 78.01689 & & $\mathrm{D}$ & 5.4 & $38:$ & $8 / 57$ & 127 & 5.464 & \\
\hline $67-$ Jun-29 & 2 & 56 & 59.9 & 49.81669 & 78.04903 & & $\mathrm{D}$ & 5.3 & 32 & $9 / 38$ & 95 & 5.336 & \\
\hline $67-J u l-15$ & 3 & 26 & 59.9 & 49.83592 & 78.11817 & & $D$ & 5.4 & 35 & $5 / 48$ & 109 & 5.387 & \\
\hline $67-A u g=04$ & 6 & 58 & 0.3 & 49.76 & 78.0 & & $\mathrm{D}$ & 5.3 & 32 & $10 / 53$ & 95 & 5.316 & \\
\hline $67-\mathrm{Sep}-16$ & 4 & 4 & 0.3 & 49.93719 & 77.72811 & & $M$ & 5.3 & 28 & $14 / 61$ & 106 & 5.245 & \\
\hline $67-5 \mathrm{ep}-22$ & 5 & 4 & 0.0 & 49.95964 & 77.69106 & & $M$ & 5.2 & 26 & $8 / 39$ & 84 & 5.160 & \\
\hline $67-0 \mathrm{ct}-17$ & 5 & $4 !$ & 0.2 & 49.78089 & 78.00383 & & $D$ & 5.6 & 45 & 9/ 80 & 134 & 5.629 & \\
\hline $67-0 \mathrm{ct}-30$ & 6 & 4 & 0.0 & 49.79436 & 78.00786 & & $\mathrm{D}$ & 5.3 & 42 & $9 / 45$ & 112 & 5.413 & \\
\hline $67-\mathrm{Nov}-22$ & 4 & 3 & 59.9 & 49. & 77.68683 & & $M$ & 4.8 & 5 & 213 & 14 & 4.410 & \\
\hline $67-\mathrm{Dec}-08$ & 6 & $3 !$ & 59.8 & 49.81 & 78.16378 & & $\mathrm{D}$ & 5.4 & 26 & 2137 & 88 & 5.314 & \\
\hline $68-\mathrm{Jan}-07$ & 3 & 46 & 59.9 & 49.75442 & 78.03094 & & $\mathrm{D}$ & 5.1 & 23 & $14 / 31$ & 77 & 4.977 & \\
\hline $68-\mathrm{Apr}-24$ & 10 & 35 & 59.7 & 49.84519 & 78.10322 & & $\mathrm{D}$ & 5.0 & 18 & $5 / 18$ & 58 & 4.911 & \\
\hline $68-J u n-11$ & 3 & 5 & 59.7 & 49.79300 & 78.14508 & & $\mathrm{D}$ & 5.2 & 30 & $5 / 32$ & 92 & 5.240 & \\
\hline 68 -Jun-19 & 5 & 5 & 59.8 & 49.98025 & 78.98550 & & $\mathrm{~B}$ & 5.4 & 38 & $9 / 63$ & 119 & 5.28 & \\
\hline $68-J u l-12$ & 12 & 8 & 0.0 & 49.75469 & 78.08994 & & D & 5.3 & 25 & 8137 & 85 & 5.169 & \\
\hline 68 -Aug-20 & 4 & 5 & 59.6 & 49.82264 & 78.07447 & & $\mathrm{D}$ & 4.8 & 14 & 214 & 43 & 4.761 & \\
\hline 68 -Sep-05 & 4 & 5 & 59.6 & 49.74161 & 78.07558 & & $\mathrm{D}$ & 5.4 & 41 & 3155 & 114 & 5.439 & \\
\hline $68-$ ep -29 & 3 & 43 & 0.0 & 49.81197 & 78.12194 & & D & 5.8 & 54 & $9 / 86$ & 160 & 5.861 & \\
\hline $68-0 c t-21$ & 3 & 52 & 0.0 & 49.72786 & 78.48628 & & $\mathrm{M}$ & & & & & & \\
\hline $68-\mathrm{Nov}-09$ & 2 & 54 & 0.1 & 49.80053 & 78.13911 & & $\mathrm{D}$ & 4.9 & 11 & 219 & 41 & 4.751 & \\
\hline $68-\mathrm{Nov}-12$ & 7 & 30 & 0.0 & 49.71244 & 78.46133 & & $\mathrm{M}$ & & & & & & \\
\hline $68-\mathrm{Nov}-12$ & $7:$ & 30 & 0.0 & 49.71244 & 78.46133 & & $M$ & & & & & & \\
\hline
\end{tabular}




\begin{tabular}{|c|c|c|c|c|c|c|c|c|c|c|c|c|c|}
\hline $68-\mathrm{Nov}-12$ & 7 & 30 & 0.0 & 49.71244 & 78.46133 & & $M$ & & & & & & \\
\hline 68-Dec-18 & 5 & 1 & 59.7 & 49.74594 & 78.09203 & & $\mathrm{D}$ & 5.0 & 22 & $4 ! 23$ & 78 & 5.044 & \\
\hline $69-M a r-07$ & 8 & 26 & 59.8 & 49.82147 & 78.06267 & & $\mathrm{D}$ & 5.6 & 54 & $13 / 90$ & 156 & 5.664 & \\
\hline $69-\mathrm{May}-16$ & 4 & 2 & 59.7 & 49.75942 & 78.07578 & & $\mathrm{D}$ & 5.2 & 41 & $6 / 39$ & 105 & 5.264 & \\
\hline $69-\mathrm{May}-31$ & 5 & 1 & 59.4 & 49.95031 & 77.69422 & & $M$ & 5.3 & 39 & 8146 & 98 & 5.290 & \\
\hline $69-\mathrm{Jul}-04$ & 2 & 46 & 59.6 & 49.74603 & 78.11133 & & $\mathrm{D}$ & 5.2 & 42 & & 111 & 5.241 & \\
\hline $69-$ Jul-23 & 2 & 47 & 0.2 & 49.81564 & 78.12961 & & $\mathrm{D}$ & 5.4 & 46 & 5167 & 130 & 5.504 & \\
\hline $69-$ Sep-11 & 4 & 2 & 0.0 & 49.77631 & 77.99669 & & D & 5.0 & 19 & $5 / 19$ & 63 & 4.910 & \\
\hline $69-0 \mathrm{ct}-01$ & 4 & 2 & 59.9 & 49.78250 & 78.09831 & & D & 5.2 & 36 & $5 / 28$ & 97 & 5.256 & \\
\hline $69-\mathrm{Nov}-30$ & 3 & 32 & 59.7 & 49.92428 & 78.95575 & & $\mathrm{~B}$ & 6.0 & 65 & $12 / 115$ & 202 & 6.02 & 6.043 \\
\hline $69-\mathrm{Dec}-28$ & 3 & 47 & 0.2 & 49.93733 & 77.71422 & & $M$ & 5.7 & 54 & $14 / 90$ & 171 & 5.791 & \\
\hline 69-Dec-29 & 4 & 2 & 0.0 & 49.73367 & 78.10225 & & $\mathrm{D}$ & 5.1 & 3 & 212 & 12 & 4.217 & \\
\hline $70-J a n-29$ & 7 & 3 & 0.0 & 49.79558 & 78.12389 & & $\mathrm{D}$ & 5.5 & 50 & $8 / 68$ & 138 & 5.599 & \\
\hline $70-\mathrm{Mar}-27$ & 5 & 2 & 59.6 & 49.74781 & 77.99897 & & $\mathrm{D}$ & 5.0 & 20 & $0 / 18$ & 58 & 4.929 & \\
\hline $70-$ May-27 & 4 & 3 & 0.0 & 49.73131 & 78.09861 & & $\mathrm{D}$ & & & & & & \\
\hline $70-J u n-28$ & 1 & 58 & 0.0 & 49.80150 & 78.10681 & & $\mathrm{D}$ & 5.7 & 54 & 15192 & 168 & 5.870 & \\
\hline $70-$ Jul-21 & 3 & 2 & 59.7 & 49.95242 & 77.67289 & & $M$ & 5.4 & 43 & $8 / 50$ & 120 & 5.376 & \\
\hline $70-J u l-24$ & 3 & 57 & 0.0 & 49.80972 & 78.12839 & & $\mathrm{D}$ & 5.3 & 36 & $1 / 38$ & 103 & 5.337 & \\
\hline $70-\operatorname{sep}-06$ & 4 & 2 & 59.9 & 49.75975 & 78.00539 & & $\mathrm{D}$ & 5.4 & 49 & $6 / 69$ & 134 & 5.533 & \\
\hline $70-\mathrm{Nov}=04$ & 6 & 2 & 59.8 & 49.98922 & 77.76244 & & $M$ & 5.4 & 45 & $5 / 62$ & 143 & 5.439 & \\
\hline $70-\mathrm{Dec}-17$ & 7 & 1 & 0.0 & 49.74564 & 78.09917 & & D & 5.4 & 42 & $3 / 61$ & 132 & 5.433 & \\
\hline $71-\mathrm{Mar}-22$ & 4 & 33 & 0.3 & 49.79847 & 78.10897 & & $\mathrm{D}$ & 5.7 & 54 & $10 / 83$ & 198 & 5.767 & \\
\hline $71-\mathrm{Apr}-25$ & 3 & 32 & 59.9 & 49.76853 & 78.03392 & & $\mathrm{D}$ & 5.9 & 62 & 181112 & 219 & 6.076 & \\
\hline $71-\mathrm{May}-25$ & 4 & 3 & 0.4 & 49.80164 & 78.13883 & & $\mathrm{D}$ & 5.1 & 21 & 2120 & 74 & 5.048 & \\
\hline $71-$ Jun -06 & 4 & 2 & 59.7 & 49.97542 & 77.66028 & & $M$ & 5.5 & 43 & $10 / 50$ & 146 & 5.526 & \\
\hline $71-J u n-19$ & 4 & 4 & 0.1 & 49.96903 & 77.64081 & & $\mathrm{M}$ & 5.4 & 52 & $13 / 57$ & 126 & 5.538 & \\
\hline $71-$ Jun-30 & 3 & 56 & 59.8 & 49.94600 & 78.98047 & & B & 5.2 & 30 & $6 / 31$ & 113 & 4.94 & \\
\hline $71-0 c t-09$ & 6 & 2 & 59.7 & 49.97789 & 77.64144 & & $\mathrm{M}$ & 5.3 & 46 & $13 / 53$ & 142 & 5.371 & \\
\hline $71-0 \mathrm{ct}-21$ & 6 & 2 & 59.7 & 49.97381 & 77.59733 & & $\mathrm{M}$ & 5.5 & 49 & $11 / 54$ & 133 & 5.580 & \\
\hline $71-$ Nov-29 & 6 & 2 & 59.9 & 49.74342 & 78.07850 & & $\mathrm{D}$ & 5.4 & 41 & $6 / 49$ & 113 & 5.462 & \\
\hline $71-D e c-15$ & 7 & 52 & 59.8 & 49.82639 & 77.99731 & & $\mathrm{D}$ & 4.9 & 7 & 214 & 31 & 4.677 & \\
\hline $71-\mathrm{Dec}-30$ & 6 & 21 & 0.2 & 49.76003 & 78.03714 & & $\mathrm{D}$ & 5.7 & 56 & 4173 & 162 & 5.838 & \\
\hline $72-F e b-10$ & 5 & 3 & 0.0 & 50.02428 & 78.87808 & & $\mathrm{~B}$ & 5.4 & 41 & $17 / 59$ & 143 & 5.27 & 5.372 \\
\hline $72-\operatorname{Mar}-10$ & 4 & 56 & 59.8 & 49.74531 & 78.11969 & & $\mathrm{D}$ & 5.4 & 54 & $5 / 62$ & 157 & 5.453 & \\
\hline 72-Mar-28 & 4 & 22 & 0.1 & 49.73306 & 78.07569 & & $\mathrm{D}$ & 5.1 & 35 & 7135 & 109 & 5.177 & \\
\hline $72-$ Jun- 07 & 1 & 28 & 0.0 & 49.82675 & 78.11547 & & D. & 5.4 & 42 & $13 / 46$ & 145 & 5.422 & \\
\hline 72-Jul-06 & 1 & 3 & 0.0 & 49.73750 & 78.11006 & C & D & 4.4 & 6 & $1 / 1$ & 21 & 4.275 & \\
\hline $2-A u g-16$ & 3 & 16 & 59.8 & 49.76547 & 78.05883 & ] & $\mathrm{D}$ & 5.0 & 30 & $6 / 29$ & 95 & 5.105 & \\
\hline $2-A u g-26$ & 3 & 46 & 59.7 & 49.98197 & 77.71661 & & $\mathrm{M}$ & 5.3 & 37 & 4136 & 131 & 5.363 & \\
\hline $72-$ sep-02 & 8 & 56 & 59.9 & 49.95942 & 77.64089 & & $M$ & 5.1 & 6 & & 21 & 4.788 & \\
\hline $72-\mathrm{Nov}-02$ & 1 & 27 & 0.2 & 49.92697 & 78.81725 & $E$ & 8 & 6.1 & 75 & $16 / 124$ & 259 & 6.16 & 6.118 \\
\hline $72-$ Dec-10 & 4 & 27 & 0.0 & 49.81939 & 78.05822 & 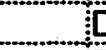 & D. & 5.6 & 62 & 14180 & 230 & 5.715 & \\
\hline $72-$ Dec-10 & 4 & 27 & 10.0 & 50.02700 & 78.99556 & $\mathrm{E}$ & & 6.0 & 26 & $6 / 49$ & 133 & 5.96 & 6.092 \\
\hline 2-Dec-28 & 4 & 27 & 0.0 & 49.73919 & 78.10625 & C & b & & & & & & \\
\hline $3-F e b-16$ & 5 & 3 & 0.0 & 49.816 & 78.116 & $3.9 \mathrm{C}$ & & 5.5 & 49 & $5 / 52$ & 153 & 5.477 & \\
\hline 3-Apr-19 & 4 & 32 & 59.9 & 49.984 & 77.614 & $5.3 \mathrm{M}$ & & 5.4 & 40 & $10 / 46$ & 133 & 5.356 & \\
\hline $3-J u l-10$ & 1 & 27 & 0.2 & 49.792 & 78.042 & $4.4 \mathrm{~L}$ & & 5.2 & 39 & $4 / 43$ & 130 & 5.335 & \\
\hline $73-J u l-23$ & 1 & 23 & 0.11 & 49.966 & 78.810 & $2.1 \mathrm{~B}$ & & 6.1 & 81 & $19 / 161$ & 261 & 6.17 & 6.199 \\
\hline $73-$ Oct-26 & 4 & 27 & 0.1 & 49.753 & 78.122 & $4.7 \mathrm{D}$ & & 5.2 & 39 & 4134 & 116 & 5.228 & \\
\hline 73-Dec-14 & 7 & 46 & 59.7 & 50.054 & 78.987 & $2.3 \mathrm{~B}$ & & 5.8 & 67 & $16 / 101$ & 210 & 5.79 & 5.868 \\
\hline $74-J a n-30$ & 4 & 57 & 0.2 & 49.829 & 78.012 & $12.2 \mathrm{C}$ & & 4.9 & 13 & 23 & 55 & 4.429 & \\
\hline $74-J a n-30$ & 4 & 57 & 4.6 & 49.845 & 78.051 & $6.4 \mathrm{D}$ & & 5.4 & 36 & $2 / 41$ & 134 & 5.477 & \\
\hline $74-\mathrm{Apr}-16$ & 5 & 52 & 59.8 & 50.039 & 78.946 & $15.3 \mathrm{~B}$ & & 4.9 & 11 & $0 / 1$ & 23 & 4.35 & \\
\hline 4-May-16 & 3 & 3 & 0.10 & 49.745 & 78.053 & 4.50 & & 5.2 & 47 & $6 / 50$ & 133 & 5.242 & \\
\hline 74-May-31 & 3 & 26 & 60.0 & 49.953 & 78.846 & $2.2 \mathrm{~B}$ & & 5.9 & 83 & $9 / 102$ & 236 & 5.81 & \\
\hline 74-Jun-25 & 3 & 57 & 0.2 & 49.844 & 78.111 & $66.9: 0$ & & 4.7 & 8 & 014 & 28 & 4.419 & \\
\hline 74-Jul-10 & 2 & 56 & 60.0 & 49.772 & 78.088 & $6.6: \mathrm{D}$ & & 5.2 & 47 & $31 \quad 40$ & 118 & 5.168 & \\
\hline
\end{tabular}

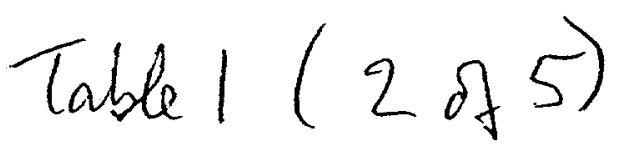




\begin{tabular}{|c|c|c|c|c|c|c|c|c|c|c|c|c|c|}
\hline $74-S e p-13$ & 3 & 3 & 0.0 & 49.775 & 78.036 & $6.8 \mathrm{D}$ & 5.2 & 40 & $5 /$ & 31 & 96 & 5.144 & \\
\hline $74-0 \mathrm{ct}-16$ & 6 & 33 & 0.10 & 49.985 & 78.896 & $3.0 \mathrm{~B}$ & 5.5 & 63 & 22 & 68 & 167 & 5.41 & 5.411 \\
\hline $74-\mathrm{Dec}-07$ & 6 & 0 & 0.0 & 49.916 & 77.605 & $31.6 \mathrm{M}$ & 4.7 & 4 & 0 I & 2 & 23 & 4.369 & \\
\hline $74-\mathrm{Dec}-16$ & 3 & 23 & 0.1 & 49.787 & 78.092 & $8.7 \mathrm{D}$ & 4.8 & 24 & 3 & 11 & 71 & 4.938 & \\
\hline $74-\mathrm{Dec}-16$ & 6 & 41 & 0.3 & 49.858 & 78.053 & $8.7 \mathrm{D}$ & 5.0 & 26 & 11 & 14 & 70 & 4.887 & \\
\hline 74-Dec-27 & 5 & 46 & 59.4 & 49.949 & 79.011 & $2.9 \mathrm{~B}$ & 5.6 & 60 & 81 & 73 & 175 & 5.50 & 5.708 \\
\hline $75-F e b-20$ & 5 & 33 & 0.0 & 49.781 & 78.019 & $3.6 \mathrm{D}$ & 5.7 & 70 & 91 & 83 & 188 & 5.765 & \\
\hline $75-$ Mar-11 & 5 & 43 & 0.10 & 49.740 & 78.102 & $4.0 \mathrm{D}$ & 5.4 & 56 & $10 /$ & 55 & 145 & 5.424 & \\
\hline $75-\mathrm{Apr}-27$ & 5 & 36 & 59.7 & 49.955 & 78.926 & $2.6 \mathrm{~B}$ & 5.6 & 71 & 221 & 97 & 201 & 5.51 & 5.547 \\
\hline $75-$ Jun-08 & 3 & 26 & 60.0 & 49.757 & 78.008 & $4.1 \mathrm{D}$ & 5.5 & 61 & 111 & 60 & 164 & 5.551 & \\
\hline $75-J u n-30$ & 3 & 26 & 59.9 & 50.001 & 78.996 & $17.0 \mathrm{~B}$ & 5.0 & 15 & 11 & 4 & 38 & 4.52 & \\
\hline $75-A u g-07$ & 3 & 57 & 0.10 & 49.808 & 78.120 & $4.9 \mathrm{D}$ & 5.2 & 41 & $10 /$ & 37 & 116 & 5.187 & \\
\hline $75-$ Oct -29 & 4 & 46 & 59.8 & 49.955 & 78.877 & $2.8 \mathrm{~B}$ & 5.8 & 64 & 71 & 67 & 207 & 5.61 & 5.629 \\
\hline $75-\mathrm{Dec}-13$ & 4 & 56 & 60.0 & 49.806 & 78.121 & $6.6 \mathrm{D}$ & 5.1 & 43 & 31 & 22 & $84 !$ & 5.001 & \\
\hline 75-Dec-25 & 5 & 16 & 59.7 & 50.051 & 78.813 & $2.2 \mathrm{~B}$ & 5.7 & 70 & $16 !$ & 97 & 232 & 5.69 & 5.801 \\
\hline $76-\operatorname{Jan}-15$ & 4 & 46 & 60.0 & 49.817 & 78.161 & $5.4 \mathrm{D}$ & 5.2 & 48 & $3 /$ & 34 & 107 & 5.182 & \\
\hline $76-A p r-21$ & 4 & 58 & 0.2 & 49.773 & 78.109 & $8.3 \mathrm{D}$ & 5.1 & 42 & 11 & 17 & 77 & 4.940 & \\
\hline $76-\mathrm{Apr}-21$ & 5 & 2 & 59.7 & 49.906 & 78.827 & $4.1 \mathrm{~B}$ & 5.3 & 70 & 81 & 45 & 125 & 5.12 & \\
\hline $76-$ May -19 & 2 & 57 & 0.2 & 49.789 & 78.019 & $17.4 \mathrm{D}$ & 5.0 & 28 & 21 & 14 & 47 & 4.722 & \\
\hline $76-J u n-09$ & 3 & 2 & 59.8 & 50.002 & 79.025 & $3.2 \mathrm{~B}$ & 5.3 & 47 & $4 !$ & 40 & 143 & 5.07 & 5.199 \\
\hline $76-J u l-04$ & 2 & 56 & 59.9 & 49.912 & 78.908 & $2.3 \mathrm{~B}$ & 5.8 & 83 & $10 \%$ & 117 & 231 & 5.85 & 5.870 \\
\hline $76-J u l-23$ & 2 & 33 & 0.2 & 49.774 & 78.046 & $6.3 \mathrm{D}$ & 5.1 & 49 & 91 & 22 & 100 & 4.961 & \\
\hline $76-A u g-28$ & 2 & 56 & 60.0 & 49.979 & 78.928 & $2.3 \mathrm{~B}$ & 5.8 & 82 & 101 & 100 & 223 & 5.74 & 5.733 \\
\hline $76-$ oct-30 & 4 & 57 & 0.2 & 49.825 & 78.022 & $25.1 \mathrm{D}$ & 4.9 & 15 & 11 & 4 & 33 & 4.618 & \\
\hline $76-\mathrm{Nov}-23$ & 5 & 2 & 59.8 & 50.013 & 78.962 & $2.2 \mathrm{~B}$ & 5.8 & 93 & $14 !$ & 140 & 264 & 5.79 & 5.819 \\
\hline $76-\mathrm{Dec}-07$ & 4 & 56 & 59.9 & 49.927 & 78.847 & $2.1 \mathrm{~B}$ & 5.9 & 76 & 10 I & 107 & 236 & 5.80 & 5.741 \\
\hline $76-\mathrm{Dec}-30$ & 3 & 57 & 0.3 & 49.795 & 78.030 & $7.8 \mathrm{D}$ & 5.2 & 40 & 11 & 26 & 78 & 5.086 & \\
\hline $77-\operatorname{Mar}-29$ & 3 & 56 & 60.0 & 49.781 & 78.042 & $4.6 \mathrm{D}$ & 5.4 & 60 & 11 & 51 & 162 & 5.405 & \\
\hline $77-\mathrm{Apr}-25$ & 4 & 7 & 0.2 & 49.811 & 78.107 & $7.9 \mathrm{D}$ & 5.1 & 46 & 31 & 29 & 91 & 5.066 & \\
\hline $77-\mathrm{May}-29$ & 2 & 57 & 0.0 & 49.932 & 78.774 & $2.0 \mathrm{~B}$ & 5.8 & 97 & 71 & 147 & 289 & 5.75 & 5.655 \\
\hline $77-$ Jun-29 & 3 & 7 & 0.4 & 50.033 & 78.861 & $3.6 \mathrm{~B}$ & 5.3 & 69 & 61 & 80 & 171 & 5.20 & 5.077 \\
\hline $77-\mathrm{Jul}-30$ & 1 & 57 & 0.1 & 49.754 & 78.057 & $6.4 \mathrm{D}$ & 5.1 & 58 & 51 & 46 & 116 & 5.127 & \\
\hline 77-Aug-17 & 4 & 26 & 60.0 & 49.817 & 78.128 & $7.9 \mathrm{D}$ & 5.1 & 35 & 2 & 23 & 81 & 5.010 & \\
\hline $77-$ Sep-05 & 3 & 2 & 59.9 & 50.048 & 78.923 & $2.1 \mathrm{~B}$ & 5.8 & 97 & 201 & 145 & 293 & 5.73 & 5.879 \\
\hline $77-$ oct-29 & 3 & 6 & 60.0 & 49.827 & 78.091 & $3.3 \mathrm{p}$ & 5.6 & 68 & 91 & 100 & 245 & 5.515 & \\
\hline $77-$ Oct-29 & 3 & 7 & 4.9 & 50.068 & 78.977 & $5.0 \mathrm{~B}$ & 5.6 & 53 & $3 /$ & 56 & 148 & 5.56 & 5.757 \\
\hline $77-$ Nov-30 & 4 & 6 & 59.9 & 49.966 & 78.890 & $2.1 \mathrm{~B}$ & 6.0 & 90 & 111 & 162 & 285 & 5.89 & 5.753 \\
\hline 77-Dec-26 & 4 & 3 & 0.2 & 49.843 & 78.070 & $15.3 \mathrm{D}$ & 4.9 & 38 & $4 !$ & 33 & 69 & 4.908 & \\
\hline $78-\mathrm{Mar}-19$ & 3 & 46 & 59.8 & 49.945 & 77.704 & $5.0 \mathrm{M}$ & 5.2 & 53 & $6 !$ & 67 & 128 & 5.190 & \\
\hline $78-\mathrm{Mar}-26$ & 3 & 56 & 60.0 & 49.766 & 78.008 & $3.0 \mathrm{D}$ & 5.6 & 98 & $11 /$ & 121 & 254 & 5.689 & \\
\hline 78-Apr-22 & 3 & 7 & 0.0 & 49.756 & 78.140 & $4.1 \mathrm{D}$ & 5.3 & 83 & 111 & 90 & 184 & 5.347 & \\
\hline $78-$ May-29 & 4 & 56 & 59.9 & 49.762 & 78.092 & $23.2 \mathrm{D}$ & 4.7 & 35 & $4 !$ & 15 & 55 & 4.678 & \\
\hline $78-$ Jun-11 & 2 & 57 & 0.10 & 49.903 & 78.791 & $2.0 \mathrm{~B}$ & 5.9 & 92 & 231 & 157 & 281 & 5.83 & 5.755 \\
\hline $78-\mathrm{Jul}-05$ & 2 & 46 & 60.0 & 49.896 & 78.868 & $1.8 \mathrm{~B}$ & 5.8 & 96 & 181 & 162 & 279 & 5.77 & 5.794 \\
\hline 78-Jul-28 & 2 & 46 & 59.9 & 49.752 & 78.100 & $3.2 \mathrm{D}$ & 5.7 & 90 & $15 !$ & 134 & 230 & 5.747 & \\
\hline 78-Aug-29 & 2 & 36 & 60.0 & 49.807 & 78.107 & $5.9 \mathrm{D}$ & 5.2 & 61 & 111 & 56 & 147 & 5.041 & \\
\hline $78-A u g-29$ & 2 & 37 & 8.8 & 50.011 & 78.976 & $2.2 \mathrm{~B}$ & 5.9 & 80 & 81 & 130 & 247 & 5.90 & 6.010 \\
\hline $78-$ Sep-15 & 2 & 36 & 59.9 & 49.922 & 78.876 & $1.9 \mathrm{~B}$ & 6.0 & 100 & 141 & 162 & 276 & 5.89 & 5.908 \\
\hline $78-$ Sep-20 & 5 & 3 & 0.0 & 49.848 & 78.212 & $22.2 \mathrm{D}$ & 4.3 & 15 & $0 l$ & 0 & 20 & 4.205 & \\
\hline $78-$ oct-15 & $=$ & 37 & 0.1 & 49.746 & 78.121 & $5.3 \mathrm{D}$ & 5.2 & 71 & 71 & 64 & 137 & 5.150 & \\
\hline $78-$ oct-31 & 4 & 17 & 0.2 & 49.803 & 78.099 & $4.0 \mathrm{D}$ & 5.2 & 82 & 91 & 79 & 150 & 5.251 & \\
\hline $78-\mathrm{Nov}-04$ & 5 & 5 & 59.8 & 50.040 & 78.941 & $2.0 \mathrm{~B}$ & 5.6 & 106 & 121 & 139 & 261 & 5.56 & 5.690 \\
\hline $78-$ Nov-29 & 4 & 33 & 0.2 & 49.808 & 77.999 & $4.2 \mathrm{D}$ & 5.3 & 75 & 171 & 81 & 176 & 5.205 & \\
\hline $78-$ Nov-29 & 4 & 33 & 5.0 & 49.959 & 78.801 & $2.7 \mathrm{~B}$ & 6.0 & 82 & 131 & 116 & 214 & 5.96 & 5.971 \\
\hline $78-D e c-14$ & 4 & 43 & 0.0 & 49.805 & 78.103 & $27.1 \mathrm{D}$ & 4.8 & 18 & 11 & 3 & 33 & 4.736 & \\
\hline $78-\mathrm{Dec}-20$ & 4 & 33 & 0.0 & 49.850 & 78.047 & $13.9 \mathrm{D}$ & 4.7 & 28 & 21 & 15 & 49 & 4.713 & \\
\hline 79-Feb-01 & 4 & 13 & 0.2 & 50.101 & 78.863 & $2.5 \mathrm{~B}$ & 5.4 & 93 & $19 /$ & 98 & 177 & 5.29 & \\
\hline
\end{tabular}

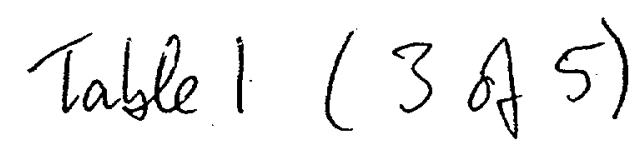




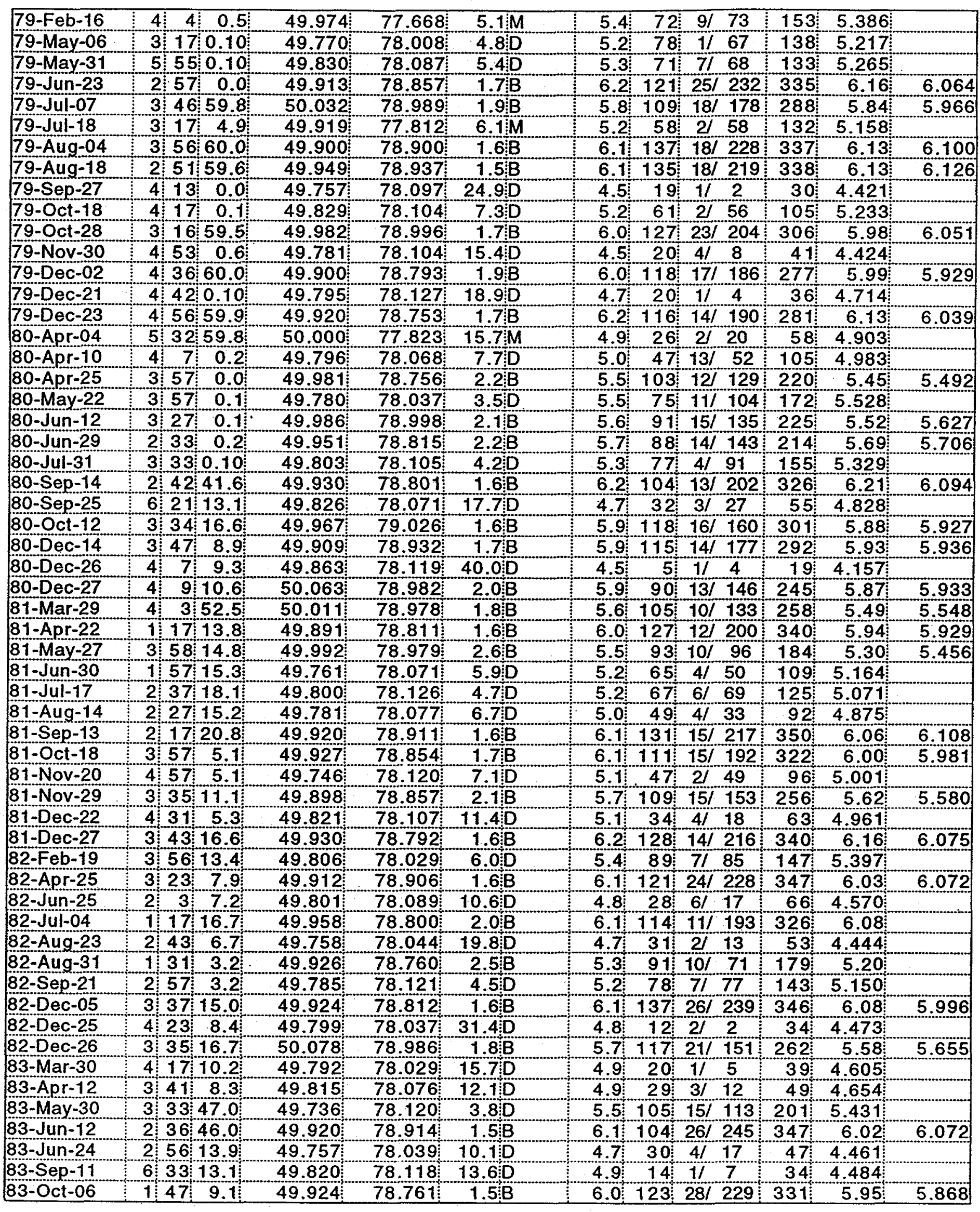

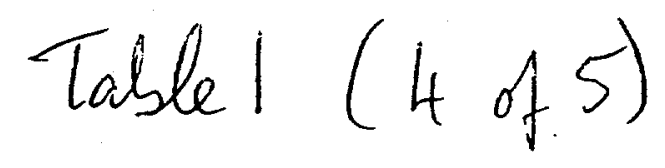




\begin{tabular}{|c|c|c|c|c|c|c|c|c|c|c|c|c|}
\hline $83-$ Oct-26 & 1 & $55 \quad 7.3$ & 49.912 & 78.828 & $1.6 \mathrm{~B}$ & 6.1 & 133 & 32 & 256 & 359 & 6.04 & 6.016 \\
\hline $83-\mathrm{NoV}-20$ & 3 & $27 \quad 6.9$ & 50.055 & 78.997 & $1.9 \mathrm{~B}$ & 5.5 & 103 & 121 & 121 & 221 & 5.33 & 5.409 \\
\hline $83-\mathrm{NoV}-29$ & 2 & 8.8 & 49.739 & 78.105 & $3.7 \mathrm{D}$ & 5.4 & 93 & $7 !$ & 81 & 174 & 5.313 & \\
\hline 83-Dec-26 & 4 & $29 \quad 9.3$ & 49.804 & 78.098 & $4.2 \mathrm{D}$ & 5.6 & 87 & 121 & 99 & 189 & 5.480 & \\
\hline $84-\mathrm{Feb}-19$ & 3 & $57 \quad 5.9$ & 49.894 & 78.745 & $1.6 \bar{B}$ & 5.9 & 107 & 201 & 204 & 311 & 5.77 & 5.725 \\
\hline 84-Mar-07 & 2 & 398.8 & 50.049 & 78.950 & $1.6 \mathrm{~B}$ & 5.7 & 106 & 191 & 161 & 292 & 5.56 & 5.680 \\
\hline $84-$ Mar- 29 & 5 & 1910.7 & 49.922 & 78.949 & $1.5 \mathrm{~B}$ & 5.9 & 131 & 221 & 215 & 348 & 5.86 & 5.902 \\
\hline $84-A p r-15$ & 3 & 1711.5 & 49.749 & 78.101 & $3.5 \mathrm{D}$ & 5.7 & 112 & 121 & 171 & 307 & 5.718 & \\
\hline 84-Apr-25 & 1 & 96.0 & 49.935 & 78.867 & $1.4 \mathrm{~B}$ & 6.0 & 135 & $24 !$ & 247 & 376 & 5.90 & 5.867 \\
\hline 84-May-26 & 3 & 1314.9 & 49.973 & 79.000 & $1.3 \mathrm{~B}$ & 6.1 & 126 & 291 & 269 & 413 & 6.01 & 6.079 \\
\hline $84-J u I-14$ & 1 & $9,13.0$ & 49.901 & 78.879 & $1.4 \mathrm{~B}$ & 6.2 & 140 & 311 & 289 & 406 & 6.10 & 6.054 \\
\hline 84-Sep-09 & 2 & 598.9 & 49.809 & 78.072 & $7.4 \mathrm{D}$ & 5.1 & 51 & $6 !$ & 43 & 108 & 4.889 & \\
\hline $84-0 c t-18$ & 4 & $57 \quad 8.3$ & 49.775 & 78.133 & $18.0 \mathrm{D}$ & 4.5 & 17 & 51 & 5 & 26 & 4.246 & \\
\hline $84-$ Oct-27 & 1 & 5012.9 & 49.925 & 78.776 & $1.2 \mathrm{~B}$ & 6.2 & 158 & 251 & 310 & 477 & 6.19 & 6.098 \\
\hline 84-Nov-23 & 3 & $55 \quad 7.5$ & 49.830 & 78.073 & $16.5 \mathrm{D}$ & 4.7 & 21 & 21 & 3 & 34 & 4.379 & \\
\hline $84-D e c-02$ & 3 & 1989 & 49.990 & 79.009 & $1.5 \mathrm{~B}$ & 5.9 & 151 & 251 & 202 & 388 & 5.77 & 5.880 \\
\hline 84-Dec-16 & 3 & $55 \quad 5.1$ & 49.930 & 78.816 & $1.3 \mathrm{~B}$ & 6.1 & 150 & $24 !$ & 242 & 424 & 6.12 & .043 \\
\hline 84-Dec- 28 & 3 & 5013.1 & 49.875 & 78.700 & $1.3 \mathrm{~B}$ & 6.0 & 147 & 321 & 238 & 408 & 6.00 & 5.980 \\
\hline $85-\mathrm{Feb}-10$ & 3 & 2710.0 & 49.893 & 78.783 & $1.5 \mathrm{~B}$ & 5.9 & 138 & 321 & 224 & 356 & 5.83 & 5.806 \\
\hline $85-\mathrm{Apr}-25$ & 0 & $57: 9.0$ & 49.921 & 78.899 & $1.4 \mathrm{~B}$ & 5.9 & 133 & 22 & 225 & 412 & 5.84 & 5.859 \\
\hline $85-$ Jun-15 & 0 & $57 \quad 3.1$ & 49.903 & 78.839 & $1.2 \mathrm{~B}$ & 6.1 & 147 & $17 !$ & 261 & 477 & 6.05 & 5.987 \\
\hline $85-$ Jun-30 & 2 & $39 \quad 5.1$ & 49.857 & 78.659 & $1.3 \mathrm{~B}$ & 6.0 & 137 & $25 /$ & 241 & 403 & 5.92 & 5.928 \\
\hline $85-J u l-20$ & 0 & 5316.9 & 49.943 & 78.783 & $1.3 \mathrm{~B}$ & 6.0 & 139 & 191 & 258 & 405 & 5.89 & 5.865 \\
\hline $85-\mathrm{Jul}-25$ & 3 & 119.2 & 49.836 & 77.998 & $7.7 \mathrm{D}$ & 5.0 & 60 & $5 !$ & 51 & 103 & 4.815 & \\
\hline $87-\mathrm{Feb}-26$ & 4 & 5824.3 & 49.844 & 78.088 & $3.50 \mathrm{D}$ & 5.4 & 83 & 131 & 98 & 215 & & \\
\hline $87-\operatorname{Mar}-12$ & 1 & 5719.6 & 49.929 & 78.824 & $1.8 \mathrm{~B}$ & 5.6 & 106 & 121 & 128 & 267 & 5.31 & 5.218 \\
\hline $87-\mathrm{Apr}-03$ & 1 & 1710.3 & 49.910 & 78.786 & $1.1 \mathrm{~B}$ & 6.2 & 134 & $36 !$ & 313 & 519 & 6.12 & 5.063 \\
\hline $87-\mathrm{Apr}-17$ & 1 & 3171 & 49.874 & 78.663 & $1.2 \mathrm{~B}$ & 6.0 & 127 & 281 & 279 & 470 & 5.92 & 5.910 \\
\hline 87-May-06 & 4 & 28.1 & 49.777 & 77.984 & $4.60 \mathrm{D}$ & 5.6 & 97 & 91 & 129 & 259 & & \\
\hline $87-J$ & 2 & $37 \quad 9.3$ & 49.837 & 78.065 & $3.90 \mathrm{D}$ & 5.4 & 89 & 161 & 107 & 232 & & \\
\hline $87-J$ & 0 & $53 \quad 7.1$ & 49.927 & 78.740 & $1.2 \mathrm{~B}$ & 6.1 & 145 & 331 & 332 & 540 & 6.03 & 5.971 \\
\hline $87-\mathrm{Jul}-17$ & 1 & $17 \quad 9.2$ & 49.769 & 78.035 & $3.20 \mathrm{D}$ & 5.8 & 96 & 231 & 200 & 391 & & \\
\hline 87 -Aug-02 & 0 & $58,9.2$ & 49.877 & 78.873 & $1.2 \mathrm{~B}$ & 5.9 & 127 & $34 !$ & 311 & 493 & 5.83 & .871 \\
\hline $87-\operatorname{sep}-18$ & 2 & 3210.0 & 49.976 & 78.024 & $115.6 \mathrm{O}$ & 4.3 & 7 & 01 & 0 & 10 & & \\
\hline $87-0 \mathrm{ct}-16$ & 6 & \begin{tabular}{l|l}
6 & 7.0
\end{tabular} & 49.802 & 78.140 & $35.0 \mathrm{D}$ & 4.6 & 9 & 21 & 2 & 19 & & \\
\hline $87-$ Nov- 15 & 3 & $31 \quad 9.1$ & 49.881 & 78.753 & $1.3 \mathrm{~B}$ & 6.1 & 155 & 381 & 272 & 483 & 5.98 & 5.975 \\
\hline $87-\mathrm{C}$ & 3 & 217.2 & 49.957 & 78.792 & $1.3 \mathrm{~B}$ & 6.1 & 146 & 291 & 290 & 487 & 6.06 & 6.082 \\
\hline 87-Dec-20 & 2 & 9.1 & 49.774 & 77.975 & $10.0 \mathrm{D}$ & 4.8 & 36 & $6 !$ & 18 & 65 & & \\
\hline $87-$ Dec- 27 & 3 & $5 \quad 7.2$ & 49.867 & 78.718 & $1.2 \mathrm{~B}$ & 6.1 & 145 & $26 !$ & 298 & 485 & 6.00 & 6.042 \\
\hline $88-F e b-06$ & 4 & 9.1 & 49.787 & 77.975 & $14.0 \mathrm{D}$ & 4.7 & 23 & 21 & 4 & 40 & & \\
\hline $88-F e b-13$ & 3 & 8.2 & 49.932 & 78.878 & $1.3 \mathrm{~B}$ & 6.1 & 143 & $37 !$ & 300 & 527 & 5.97 & 6.042 \\
\hline $88-A p r-03$ & 1 & $33 \quad 8.1$ & 49.909 & 78.918 & $1.4 \mathrm{~B}$ & 6.0 & 117 & 281 & 314 & 518 & 5.99 & 6.063 \\
\hline 88-Apr-22 & 9 & $30 \quad 9.4$ & 49.824 & 78.102 & $7.3 \mathrm{D}$ & 4.9 & 35 & $4 !$ & 21 & 81 & & \\
\hline 88-May-04 & 0 & $57 \quad 9.1$ & 49.931 & 78.741 & $1.4 \mathrm{~B}$ & 6.1 & 150 & 31 & 307 & 571 & 6.09 & 6.046 \\
\hline $88-J u n-14$ & 2 & $27 \quad 9.0$ & 50.034 & 78.964 & $2.9 \mathrm{~B}$ & 5.1 & 67 & 121 & 52 & 182 & 4.80 & \\
\hline $88-\mathrm{Sep}-14$ & 3 & 5959.7 & 49.869 & 78.825 & $1.4 \mathrm{~B}$ & 6.1 & 160 & $30 \%$ & 335 & 654 & 6.03 & 5.969 \\
\hline $88-0 c t-18$ & 3 & $40 \quad 9.2$ & 49.802 & 78.002 & $9.2 \mathrm{D}$ & 4.9 & 27 & 61 & 12 & 67 & & \\
\hline $88-\mathrm{NoV}-12$ & 3 & $30 \quad 6.3$ & 50.048 & 78.960 & $2.2 \mathrm{~B}$ & 5.4 & 85 & $19 /$ & 130 & 296 & 5.24 & \\
\hline $88-\mathrm{NoV}-23$ & 3 & $57 \quad 9.0$ & 49.765 & 78.029 & $5.2 \mathrm{D}$ & 5.4 & 85 & 131 & 92 & 228 & & \\
\hline $88-\mathrm{Dec}-17$ & 4 & $18 \quad 9.2$ & 49.879 & 78.924 & $1.5 \mathrm{~B}$ & 5.9 & 131 & 421 & 313 & 543 & 5.83 & 5.801 \\
\hline $89-\mathrm{Jan}-22$ & 3 & $57 \quad 9.0$ & 49.934 & 78.815 & $1.4 \mathrm{~B}$ & 6.0 & 150 & 281 & 314 & 491 & 6.10 & 5.960 \\
\hline $89-F e b-12$ & 4 & 9.2 & 49.911 & 78.704 & $1.5 \mathrm{~B}$ & 5.8 & 153 & 321 & 256 & 452 & 5.86 & 5.791 \\
\hline $89-\mathrm{Feb}-17$ & 4 & 19.2 & 49.849 & 78.064 & $5.5 \mathrm{D}$ & 5.0 & 55 & 71 & 49 & 124 & & \\
\hline $89-J u l-08$ & 3 & $47 \quad 0.0$ & 49.869 & 78.775 & $1.7 \mathrm{~B}$ & 5.6 & 102 & 251 & 196 & 375 & 5.55 & 5.418 \\
\hline $89-S e p-02$ & 4 & 1659.9 & 50.019 & 78.988 & $3.0 \mathrm{~B}$ & 5.0 & 60 & 111 & 46 & 135 & 4.94 & \\
\hline 89-Oct-04 & 11 & $30 \quad 0.2$ & 49.751 & 78.005 & 14.3:D & 4.6 & 24 & 31 & 14 & 39 & & \\
\hline $89-0 \mathrm{ct}-19$ & 9 & 4959.8 & 49.927 & 78.927 & 1.6:B & 6.0 & 108 & 251 & 190 & 428 & 5.86 & 5.789 \\
\hline
\end{tabular}

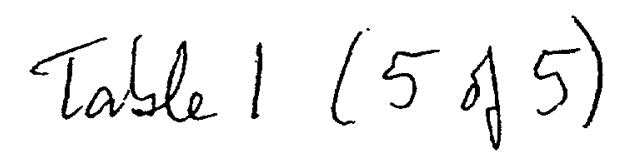




\begin{tabular}{|c|c|c|c|c|c|c|c|c|}
\hline Date & approx time & $\begin{array}{l}\text { sources of } \\
\text { information }\end{array}$ & Tzero,s & Tzero, $s$ & lat/long & $\mathrm{mag}$ & $\mathrm{mag}$ & $\mathrm{mag}$ \\
\hline & & information & & & S\&R & NORSAR & HFS & \\
\hline $61-$ Jun -05 & $03: 50$ & V.Kh. & & & & & & \\
\hline $61-0 c t-11$ & $07: 40$ & Boch. & & & & & & \\
\hline $62-F e b-02$ & $08: 00$ & Boch. & & & & & & \\
\hline $64-J u n-06$ & $00: 00$ & $\mathrm{~V} . \mathrm{Kh}$. & & & & & & \\
\hline $64-A u g-18$ & $06: 00$ & V.Kh. & & & & & & \\
\hline $65-\mathrm{Feb}-04$ & $06: 00$ & V.Kh. & & & & & & \\
\hline $65-\mathrm{Mar}-27$ & $06: 30$ & $\mathrm{~V} . \mathrm{Kh}$ & & & & & & \\
\hline $65-\mathrm{Jul}-29$ & $03: 05$ & V.Kh BOCh & & & & & & \\
\hline $65-0 c t-14$ & $04: 00$ & V.Kh:Boch & & & & & & \\
\hline $66-$ Oct -29 & $03: 58$ & $\mathrm{~V} A \mathrm{~N}$ & & & & & & \\
\hline $66-$ Nov -19 & $03: 58$ & $\mathrm{VKh}$. & & & & & & \\
\hline $66-\mathrm{Dec}-26$ & $17: 40$ & $\mathrm{~V} . \mathrm{Kh}$ & & & & & & \\
\hline $67-$ Jun -03 & $09: 21$ & $S \& R$ & & -1 & $(50,77)$ & & & 4.5 \\
\hline $67-\mathrm{Jul}-16$ & $04: 07$ & $\mathrm{~V} . \mathrm{Kh}$ & & & & & & \\
\hline $67-\mathrm{Sep}-02$ & $04: 04$ & $\mathrm{VKh}$ & & & & & & \\
\hline $68-0 c t-21$ & $03: 52$ & Boch & & & & & & \\
\hline $68-0 \mathrm{ct}-29$ & $03: 54$ & V.Kh & & & & & & \\
\hline $68-\mathrm{Nov}-12$ & $07: 30$ & Boch & & & & & & \\
\hline $68-\mathrm{Nov}-12$ & $07: 30$ & Boch. & & & & & & \\
\hline $68-\mathrm{NoV}-12$ & $07: 30$ & Boch & & & & & & \\
\hline $69-\mathrm{Apr}-04$ & $04: 57$ & $\mathrm{~V} K \mathrm{~K}$ & & & & & & \\
\hline $69-\mathrm{Apr}-13$ & $04: 04$ & V.Kh. & & & & & & \\
\hline $69-\mathrm{Nov}-27$ & $05: 02$ & $\mathrm{VKh}$ & & & & & & \\
\hline $70-M a y-27$ & $04: 03$ & V.Kh. S\&R; Boch. & & -3 & $(48.3,78.2)$ & & & 3.8 \\
\hline $71-J a n-29$ & $05: 03$ & V.Kh & & & & & & \\
\hline $71-\mathrm{Apr}-09$ & $02: 33$ & $\mathrm{~V} . \mathrm{Kh}$ & & & & & & \\
\hline 72-Dec-28 & $04: 27$ & $\mathrm{~V}$ Kh; S\&R; Boch & & 0 & $(51.7,77.2)$ & & & 4.9 \\
\hline $73-\mathrm{Mar}-23$ & $06: 30$ & $\mathrm{~V} A \mathrm{An}$ & 0 & & & 3.7 & & \\
\hline $73-\mathrm{Dec}-31$ & $04: 03$ & $\mathrm{~V} . \mathrm{Kh}$. & & & & 4.0 & & \\
\hline $74-\operatorname{sep}-27$ & $07: 34$ & Ping. & & & & & & \\
\hline $75-0 \mathrm{ct}-05$ & $04: 27$ & V.Kh:S\&R & -15 & 43.9 & $(55.8,75.1)$ & 4.0 & & 4.6 \\
\hline $76-\mathrm{Mar}-20$ & $04: 04$ & numerous & & & & & & \\
\hline $76-A u g-04$ & $02: 57$ & $\mathrm{VKh}, \mathrm{S} \& \mathrm{~B}$ & -15 & -2 & $(49.9,77.7)$ & 3.8 & & 4.1 \\
\hline $77-$ Nov -27 & $03: 57$ & Ring. & & & & & & \\
\hline $78-J u l-31$ & $08: 00$ & Ring. & & & & & & \\
\hline $79-M a y-24$ & $04: 07$ & V.Kh:S\&B & -03 & 0 & $(50,78)$ & 3.9 & & 4.9 \\
\hline $79-\operatorname{sep}-14$ & $07: 33$ & $\mathrm{~V} K \mathrm{Kh} ; \mathrm{S} \& \mathrm{R}$ & -04 & 0 & $(50,78)$ & 4.4 & & 5.2 \\
\hline $79-$ Sep-15 & $04: 07$ & $\mathrm{~V} K \mathrm{Kh}: \mathrm{S} \& \mathrm{R}$ & 01 & 0 & $(50,78)$ & 3.8 & & 4.6 \\
\hline $80-J u L-13$ & $08: 10$ & $\mathrm{~V} K \mathrm{Kh}: \mathrm{S} \& \mathrm{R}$ & & 0 & $(50,78)$ & & 5.0 & 5.0 \\
\hline $80-$ Sep-20 & $10: 40$ & $V K h: S \& R$ & -03 & 0 & $(50,78)$ & 3.8 & & 4.9 \\
\hline $80-\operatorname{sep}-30$ & $05: 57$ & $\mathrm{VKh} ; \mathrm{S \& R}$ & 12 & 0 & $(50,78)$ & 3.8 & & 4.6 \\
\hline $80-$ Sep-30 & $05: 57$ & V.Kh,$S \& R$ & 17 & 0 & $(50,78)$ & 4.4 & & 5.2 \\
\hline $80-0 c t-26$ & $11: 50$ & Ping... & & & & & & \\
\hline $80-\mathrm{Nov}-06$ & $17: 43$ & Ping. & & & & & & \\
\hline $81-\operatorname{Mar}-31$ & $07: 51$ & $\mathrm{VKh}$ & & 56 & $(50,79)$ & & & 3.6 \\
\hline $81-M a y-28$ & $04: 08$ & $\mathrm{VAn}$ & & & & & & \\
\hline $81-J$ un -05 & $03: 22$ & $V K h ; S \& R$ & 16 & 0 & $(50,78)$ & 4.0 & & 4.7 \\
\hline $81-$ Jul-05 & $03: 59$ & VKh, S\&R & & & $(50,78)$ & & 4.6 & 4.6 \\
\hline $81-\operatorname{Sep}-30$ & $12: 55$ & V.Kh:; S\&R & 01 & 0 & $(50,78)$ & 4.3 & & 4.6 \\
\hline $81-$ Nov-19 & $05: 57$ & Ring.: & & & & & & \\
\hline $82-J u n-11$ & $10: 59$ & $\mathrm{~V} K \mathrm{Kh}=\mathrm{S} \& \mathrm{R}$ & 01 & 0 & $(50,78)$ & 4.1 & & 4.7 \\
\hline $82-\mathrm{Jul}-12$ & $10: 29$ & $\mathrm{~V} K \mathrm{Kh}: \mathrm{S \& R}$ & & 0 & $(50,78)$ & & & 4.6 \\
\hline $82-\mathrm{Sep}-04$ & $05: 47$ & $\mathrm{~V} K \mathrm{Kh} ; \mathrm{S \& R}$ & & 0 & $(50,78)$ & & & 4.1 \\
\hline $82-$ Sep-15 & $04: 33$ & V.Kh:S\&R & & 0 & $(50,78)$ & & & 5.1 \\
\hline $83-F e b-13$ & $03: 02$ & V.An & & & & & & \\
\hline $83-J u I-28$ & $03: 41$ & $\mathrm{VKh}: S \& R$ & & 0 & $(49,78)$ & & & 5.0 \\
\hline $84-J u n-23$ & $02: 57$ & $V K h ; S \& A$ & & 0 & $(50,79)$ & & & 4.4 \\
\hline $84-A u g-26$ & $03: 33$ & $\mathrm{~V} A \mathrm{An}$ & & & & & & \\
\hline $85-J u n-27$ & $11: 57$ & V.An & & & & & & \\
\hline $85-J u 1-11$ & $02: 57$ & $V . K h ; S \& R$ & & 0 & $(50,78)$ & & & 4.0 \\
\hline $87-J$ un -29 & $04: 55$ & V.An & & & & & & \\
\hline $87-5 e p-16$ & $07: 30$ & V.Kh, S\&R & & 1 & $(49,78)$ & & & 5.0 \\
\hline $88-S e p-26$ & $07: 45$ & YKh: SUIt HRR & & & & & & \\
\hline $88-\mathrm{Dec}-28$ & $05: 28$ & $\mathrm{VKh}$, Ring $(90)$ & & & & & & \\
\hline $89-0 \mathrm{ct}-20$ & $13: 23$ & V.An & & & & & & \\
\hline
\end{tabular}




\begin{tabular}{|c|c|c|c|c|c|c|c|}
\hline Station code & Name & Lat & Long & Distance & Azimuth & Permanent & \\
\hline & & ${ }^{\circ} \mathrm{N}$ & ${ }^{\circ} \mathrm{E}$ & $\mathrm{km}$ & ${ }^{\circ}$ from $N$ & or & \\
\hline & & & & & & Temporary & \\
\hline & STATIONS TO TH & EAST & & & & & \\
\hline OKGU & Chagan-Uzun & 50.10 & 88.35 & 739 & 83 & $P$ & \\
\hline ELT & Eltsovka & 53.25 & 86.27 & 687 & 53 & $P$ & \\
\hline $\mathrm{KBZ}$ & Kebezen & 51.92 & 87.19 & 685 & 66 & $\mathrm{~T}$ & \\
\hline $\mathrm{KSU}$ & Karasu & 49.95 & 81.08 & 219 & 84 & $\mathrm{~T}$ & \\
\hline $\mathrm{MIX}$ & Mikhailovka & 48.49 & 81.22 & 273 & 121 & $T$ & \\
\hline $\mathrm{SEM}$ & Semipalatinsk & 50.40 & 80.25 & 171 & 66 & $\mathbf{P}$ & \\
\hline SKL & Skalistaya & 49.57 & 82.60 & 329 & 93 & $T$ & \\
\hline UKG & Ust-Kamenogorsk & 49.83 & 82.28 & 304 & $88:$ & $T$ & \\
\hline UKN & Ust-Kan & 50.60 & 84.77 & 488 & 77 & $P$ & \\
\hline \multirow[t]{2}{*}{ ULG } & Ust-Elegest & 51.34 & 94.05 & 1144 & 75 & $P$ & \\
\hline & STATION TO THE & NORTH & & & & & \\
\hline \multirow[t]{3}{*}{ NSB } & Novosibirsk & 54.85 & 83.23 & 667 & 30 & $\mathrm{P}$ & Chiss \\
\hline & & & & & & & \\
\hline & STATIONS TO TH & SOUTH & & & & & \\
\hline AND & Andizan & 40.80 & 72.40 & 1094 & 206 & $P$ & \\
\hline ATA & Alma-Ata & 43.27 & 76.95 & 731 & 187 & $P$ & \\
\hline $\mathrm{BOM}$ & Boomskoye & 42.55 & 76.00 & 821 & 192 & $T$ & \\
\hline BYK & Bayan-Kol & 42.63 & 79.98 & 810 & 169 & $T$ & \\
\hline $\mathrm{CHL}$ & Chilik & 43.57 & 78.42 & 693 & 178 & $T$ & \\
\hline $\mathrm{CHR}$ & Charyn & 43.48 & 79.22 & 708 & 172 & $\mathrm{~T}$ & \\
\hline$E E$ & $E$ & 43.03 & 80.46 & 775 & 165 & $T$ & \\
\hline FRZ & Frunze & 42.80 & 74.60 & 823 & 200 & $\mathrm{P}$ & \\
\hline GRM & Garm & 39.01 & 70.32 & 1345 & 210 & $P$ & Chiss \\
\hline III & ili & 43.95 & 77.08 & 655 & 187 & $\mathrm{~T}$ & \\
\hline KRG & Krasnogorka & 43.13 & 76.43 & 747 & 190 & $\mathrm{~T}$ & \\
\hline $\mathrm{KRM}$ & Kurmenty & 43.00 & 78.28 & 756 & 179 & $P$ & \\
\hline KZA & Kzyl-Agach & 45.37 & 78.73 & 496 & 174 & $T$ & \\
\hline MRT & Markatau & 45.28 & 80.10 & 525 & 162 & $T$ & \\
\hline MDO & Medeo & 43.17 & 77.05 & 741 & 186 & $T$ & \\
\hline MKR & Mukry & 44.78 & 78.20 & 558 & 179 & $T$ & \\
\hline NGN & Namangan & 41.00 & 71.67 & 1098 & 209 & $P$ & \\
\hline NRN & Naryn & 41.42 & 75.80 & 948 & 191 & $P$ & \\
\hline ORT & Ortomerke & 42.95 & 78.77 & 763 & 176 & $T$ & \\
\hline $\mathrm{PDG}$ & Podgornaya & 43.33 & 79.48 & 727 & 171 & $T$ & \\
\hline PRZ & Przhevalsk & 42.29 & 78.43 & 835 & 178 & $P$ & \\
\hline RYB & Bybachye & 42.43 & 76.12 & 833 & 191 & $T$ & \\
\hline TGM & Tegermen & 43.38 & 79.68 & 724 & 169 & $T$ & \\
\hline \multirow[t]{3}{*}{$T L G$} & Talgar & 43.23 & 77.23 & 733 & 185 & $\mathbf{P}$ & Chiss \\
\hline & & & & & & & \\
\hline & STATIONS TO TH & WEST & & & & & \\
\hline $\mathrm{ABL}$ & Alyk-balyk & 53.02 & 68.71 & 741 & 302 & $T$ & \\
\hline $\mathrm{ALB}$ & Ala-bota & 53.63 & 70.92 & 651 & 314 & $T$ & \\
\hline ART & Arti & 56.40 & 58.60 & 1488 & 307 & $\mathbf{P}$ & \\
\hline $\mathrm{BAY}$ & Bayan-Ayl & 50.82 & 75.55 & 211 & 303 & $T$ & \\
\hline BRV & Borovoye & 53.06 & 70.28 & 650 & 307 & $P$ & \\
\hline $\mathrm{CHK}$ & Chkalovo & 53.75 & 70.72 & 669 & 314 & $T$ & \\
\hline DZK & Dzhukek & 52.95 & 70.61 & 625 & 307 & $T$ & \\
\hline KKB & Kashkarbay & 53.09 & 69.07 & 723 & 304 & $T$ & \\
\hline KKR & Kar-Karalinsk & 49.33 & 75.38 & 200 & 256 & $T$ & \\
\hline KRD & Krasny Kordon & 52.96 & 69.03 & 719 & 303 & $T$ & \\
\hline KUS & Kustanay & 53.15 & 63.40 & 1082 & 296 & $T$ & \\
\hline MAK & Makinka & 52.57 & 70.62 & 604 & 304 & $T$ & \\
\hline SVE & Sverdlovsk & 56.80 & 60.60 & 1394 & 311 & $P$ & \\
\hline VED & Vedenevka & 52.63 & 69.50 & 675 & 301 & $T$ & \\
\hline VOS & Vostochnaya & 52.72 & 70.97 & 591 & 306 & $T$ & \\
\hline ZRN1 & Zerenda-1 & 52.93 & 69.05 & 716 & 303 & $T$ & Chiss \\
\hline ZRN2 & Zerenda-2 & 52.88 & 69.15 & 708 & 302 & $P$ & Chiss \\
\hline
\end{tabular}




\begin{tabular}{|c|c|c|c|c|c|c|c|c|c|c|c|}
\hline \multirow[b]{2}{*}{ Date } & \multirow[b]{2}{*}{ Time } & \multicolumn{9}{|c|}{ Number of stations use est sigma: } & \multirow{2}{*}{$\begin{array}{c}\text { waves } \\
\text { used }\end{array}$} \\
\hline & & $\#$ & $E$ & $S$ & $\mathrm{~W}$ & $\mathrm{~N}$ & (lat & long) & (lat & long) & \\
\hline & & & & & & & $\mathrm{km}$ & $\mathrm{km}$ & $\mathrm{km}$ & $\mathrm{km}$ & \\
\hline $61-0 c t-11$ & $07: 40: 00$ & 9 & 1 & 8 & & - & 2.6 & 32.4 & 8.9 & 0.8 & $P n$ \\
\hline $61-0 c t-11$ & $07: 40: 00$ & 11 & 2 & 8 & $\dddot{1}$ & 1 & 2.2 & 12.6 & 10.1 & -4.0 & avr \\
\hline $65-J u l-29$ & $03: 05: 00$ & 8 & 2 & 6 & 4 & - & 1.2 & 8.1 & 1.2 & -0.4 & $P_{n}$ \\
\hline $65-J u l-29$ & $03: 05: 00$ & 8 & 2 & 6 & & - & 2.2 & 19.1 & 5.0 & -4.4 & avr \\
\hline $65-$ oct- 14 & $04: 00: 00$ & 5 & 2 & 3 & & - & 3.4 & 14.8 & -2.9 & -3.0 & $P_{n}$ \\
\hline $65-0 \mathrm{ct}-14$ & $04: 00: 00$ & 5 & 2 & 3 & 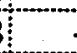 & - & 5.0 & 47.1 & 11.3 & -5.3 & $a v r$ \\
\hline $66-\mathrm{May}-07$ & $03: 58: 00$ & 2 & 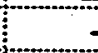 & 2 & & - & 10.0 & $(140)$ & -0.6 & $(-90)$ & avr \\
\hline 66 -Aug-19 & $03: 53: 00$ & 7 & 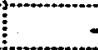 & 7 & & - & 4.1 & $(100)$ & 4.4 & $(100)$ & avr \\
\hline $67-J a n-30$ & $04: 02: 00$ & 8 & 1 & 7 & & - & 3.6 & 31.8 & -14.9 & 1.7 & $P_{n}$ \\
\hline $67-\operatorname{Jan}-30$ & $04: 02: 00$ & 8 & 1 & 7 & & -1 & 2.3 & 26.6 & -5.5 & 1.1 & $a v r$ \\
\hline $68-0 \mathrm{ct}-21$ & $03: 52: 00$ & 3 & 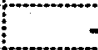 & 1 & 1 & 1 & 14.5 & 39.5 & 4.2 & -8.6 & $P n$ \\
\hline $68-0 c t-21$ & $03: 52: 00$ & 3 & 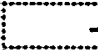 & 1 & 1 & 1 & 8.6 & 23.0 & -3.5 & -4.0 & avr \\
\hline $68-\mathrm{Nov}-12$ & $07: 30: 00$ & 6 & 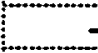 & 4 & 1 & 1 & 13.1 & 57.9 & 1.1 & 37.4 & $P_{n}$ \\
\hline $68-\mathrm{Nov}-12$ & $07: 30: 00$ & 6 & 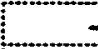 & 4 & 1 & 1 & 8.0 & 51.9 & -9.4 & -9.8 & avr \\
\hline $70-$ May -27 & $04: 03: 00$ & 3 & 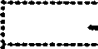 & 1 & 1 & 1 & 4.1 & 5.6 & 8.6 & 3.6 & $P_{n}$ \\
\hline $70-\mathrm{May}-27$ & $04: 03: 00$ & 3 & 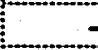 & 1 & 1 & 1 & 5.8 & 10.7 & 9.4 & -1.7 & avr \\
\hline $72-J u l-06$ & $01: 03: 00$ & 2 & 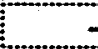 & 1 & 1 & . & 10.8 & 4.8 & 0.3 & -0.5 & $P n$ \\
\hline $72-J u 1-06$ & $01: 03: 00$ & 2 &. & 1 & 1 & 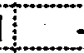 & 10.6 & 4.5 & 2.2 & 1.1 & $a v r$ \\
\hline $72-\mathrm{Dec}-28$ & $04: 27: 00$ & 9 & 2 & 1 & 5 & 3 & 2.3 & 3.5 & 8.2 & -2.1 & $P n$ \\
\hline 72-Dec-28 & $04: 27: 00$ & 10 & 3 & 1 & 6 & & 6.2 & 16.0 & 6.6 & 0.1 & avr \\
\hline $74-\mathrm{Dec}-07$ & $06: 00: 00$ & 6 & 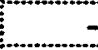 & 3 & 3 & 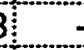 & 1.9 & 5.9 & -2.2 & -9.0 & $P n$ \\
\hline $74-\mathrm{Dec}-07$ & $06: 00: 00$ & 8 & 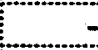 & 3 & 5 & 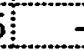 & 8.3 & 23.1 & 4.7 & 5.8 & $a v r$ \\
\hline $78-$ Sep-20 & $05: 03: 00$ & 3 & 1 & 1 & 1 & 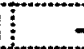 & 5.0 & 5.2 & -8.1 & -0.6 & $P_{n}$ \\
\hline 78 -Sep-20 & $05: 03: 00$ & 3 & 1 & 1 & 1 & T. & 0.3 & 1.7 & -0.8 & -2.6 & avr \\
\hline $79-$ Sep-27 & $04: 13: 00$ & 7 & 1 & 1 & 4 & 1 & 4.7 & 6.0 & 14.3 & -0.1 & $P_{n}$ \\
\hline $79-$ Sep-27 & $04: 13: 00$ & 7 & 1 & 1 & 4 & 1 & 2.8 & 3.8 & 8.8 & -0.7 & avr \\
\hline $79-N o v-30$ & $04: 53: 00$ & 4 & 1 & 1 & 2 & 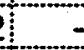 & 6.5 & 10.8 & -8.1 & 3.0 & $P_{n}$ \\
\hline $79-\mathrm{Nov}-30$ & $04: 53: 00$ & 4 & 1 & 1 & 2 & 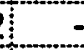 & 6.6 & 12.0 & -3.9 & 3.2 & avr \\
\hline 79-Dec-21 & $04: 42: 00$ & 5 & - & 1 & 3 & 1 & 5.7 & 10.2 & -10.9 & 1.3 & $P n$ \\
\hline $79-\mathrm{Dec}-21$ & $04: 42: 00$ & 5 & 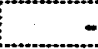 & 1 & 3 & 1 & 6.0 & 10.2 & -13.1 & 0.7 & avr \\
\hline 80-Sep-25 & $06: 21: 13$ & 6 & 2 & 1 & 3 & & 6.3 & 6.0 & 17.4 & -2.5 & $P n$ \\
\hline 80-Sep-25 & $06: 21: 13$ & 6 & 2 & 1 & 3 & - & 7.3 & 6.0 & 22.7 & -2.1 & $a v r$ \\
\hline $80-D e c-26$ & $04: 07: 09$ & 2 & 1 & 1 & 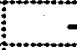 & 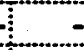 & 10.8 & 4.8 & -16.7 & 11.1 & $P n$ \\
\hline $80-\mathrm{Dec}-26$ & $04: 07: 09$ & 2 & 1 & 1 & 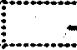 & 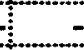 & 10.8 & 4.8 & -3.3 & 5.4 & avr \\
\hline 87-Sep-18 & $02: 32: 10$ & 3 & 2 & 1 & 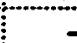 & - & 16.1 & 52.0 & -4.3 & 8.2 & avr \\
\hline
\end{tabular}




\begin{tabular}{|c|c|c|c|c|c|c|c|c|c|c|c|}
\hline \multirow[b]{2}{*}{ Date } & \multirow[b]{2}{*}{ Time } & \multicolumn{2}{|c|}{ est. location: } & \multicolumn{2}{|c|}{ est. sigma: } & \multicolumn{6}{|c|}{ Number of stations used } \\
\hline & & (lat, & long) & (lat, & long) & $\#$ & $E$ & $S$ & & $W$ & $\mathrm{~N}$ \\
\hline & & deg & deg & $\mathrm{km}$ & $\mathrm{km}$ & & & & & & \\
\hline $65-\mathrm{Mar}-27$ & $06: 30: 00$ & 49.85 & 77.94 & 4.2 & 12.2 & 3 & 1 & & 2 & & \\
\hline $66-0 \mathrm{ct}-29$ & $03: 58: 00$ & 49.64 & 78.05 & 7.0 & 4.9 & 4 & 1 & & 2 & 1 & \\
\hline $66-\mathrm{Nov}-19$ & $03: 58: 00$ & 49.84 & 78.09 & 4.8 & 16.6 & 5 & 2 & & 3 & - & \\
\hline 66-Dec-26 & $17: 39: 38$ & 49.40 & 78.75 & 8.0 & 15.0 & 10 & 2 & & 7 & 1 & \\
\hline $67-$ ep-02 & $04: 04: 00$ & 49.79 & 78.02 & 1.3 & 7.9 & 4 & - & & 4 & 1 & \\
\hline $68-0 c t-29$ & $03: 54: 00$ & 49.86 & 78.15 & 4.0 & 23.1 & 7 & - & & 5 & 1 & \\
\hline $69-\mathrm{Apr}-13$ & $04: 04: 00$ & 49.61 & 77.93 & 2.9 & 8.1 & 4 & 1 & & 3 & 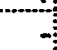 & \\
\hline $69-N o v-27$ & $05: 02: 00$ & 49.79 & 78.25 & 4.7 & 8.7 & 3 & - & & 1 & 2 & \\
\hline $71-\sqrt{a n}-29$ & $05: 03: 00$ & 49.77 & 78.11 & 3.6 & 15.2 & 5 & - & & 4 & 1 & \\
\hline $71-\mathrm{Apr}-09$ & $02: 33: 00$ & 49.88 & 78.02 & 5.3 & 9.5 & 5 & 1 & & 2 & 1 & 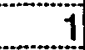 \\
\hline $73-\operatorname{Mar}-23$ & $06: 30: 00$ & 49.76 & 79.84 & 10.0 & 12.0 & 2 & 1 & & 1 & - & 7 \\
\hline $73-\mathrm{Dec}-31$ & $04: 03: 00$ & 49.75 & 78.04 & 4.8 & 7.7 & 8 & 1 & & 3 & 3 & 1 \\
\hline $75-0 \mathrm{ct}-05$ & $04: 27: 00$ & 49.81 & 78.10 & 2.0 & 5.3 & 7 & - & & 3 & 4 & 1 \\
\hline $76-\operatorname{Mar}-20$ & $04: 03: 39$ & 50.02 & 77.37 & 15.0 & 12.0 & 8 & - & & 4 & 3 & 1 \\
\hline $76-$ Aug-04 & $02: 57: 00$ & 50.04 & 77.91 & 6.9 & 7.4 & 4 & 1 & & 1 & 1 & 1 \\
\hline $77-$ Nov -27 & $03: 57: 00$ & 49.78 & 78.03 & 0.9 & 3.8 & 4 & 1 & & 3 & 7 & \\
\hline $78-J u l-31$ & $08: 00: 00$ & 49.68 & 78.33 & 17.3 & 25.0 & 3 & 1 & & 2 & - & \\
\hline 79-May-24 & $04: 07: 00$ & 49.96 & 78.81 & 4.8 & 11.0 & 4 & 1 & & 2 & - & 1 \\
\hline $79-5 e p-14$ & $07: 33: 00$ & 50.05 & 78.53 & 6.8 & 14.3 & 3 & - & & 2 & 1 & \\
\hline $79-$ sep-15 & $04: 07: 00$ & 49.75 & 78.41 & 11.5 & 21.6 & 4 & 1 & & 2 & 1 & \\
\hline $80-\mathrm{Jul}-13$ & $08: 10: 00$ & 50.00 & 78.39 & 8.5 & 15.6 & 4 & 1 & & 2 & 1 & \\
\hline $80-$ Sep- 20 & $10: 40: 01$ & 49.88 & 78.81 & 1.5 & 5.6 & 3 & 1 & & 2 & 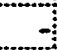 & \\
\hline $80-$ Sep-30 & $05: 57: 12$ & 49.97 & 78.05 & 8.6 & 20.2 & 5 & 1 & & 2 & 1 & 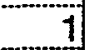 \\
\hline $80-$ Sep-30 & $05: 57: 17$ & 50.02 & 78.15 & 13.7 & 17.8 & 4 & 1 & & 2 & 1 & \\
\hline $80-N o v-06$ & $17: 42: 58.5$ & 50.15 & 78.80 & 2.0 & 4.0 & 3 & 1 & & 2 & 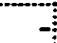 & \\
\hline $81-J u n-05$ & $03: 22: 20.5$ & 49.80 & 78.86 & 7.9 & 15.5 & 4 & 1 & & 2 & -1 & 1 \\
\hline $81-J u l-05$ & $03: 59: 18$ & 49.85 & 78.90 & 6.3 & 10.5 & 4 & 1 & & 2 & & 7 \\
\hline $81-$ Sep -30 & $12: 55: 10$ & 50.00 & 78.80 & 3.5 & 6.4 & 4 & 1 & & 2 & - & 1 \\
\hline $81-$ Nov-19 & $05: 57: 14$ & 50.20 & 78.71 & 10.0 & 10.0 & 4 & 1 & & 3 & & \\
\hline $82-$ Jun-11 & $10: 59: 07$ & 50.00 & 78.62 & 4.1 & 12.9 & 4 & 1 & & 2 & & 1 \\
\hline $82-J u l-12$ & $10: 29: 18$ & 49.82 & 78.24 & 10.2 & 39.5 & 3 & - & & 2 & & 1 \\
\hline 82-Sep-04 & $05: 47: 17$ & 50.10 & 78.56 & 18.4 & 26.1 & 3 & 1 & & 2 & & \\
\hline 82-Sep-15 & $04: 33: 19$ & 49.84 & 79.02 & 2.5 & 5.0 & 4 & 1 & & 2 & & \\
\hline $83-J u l-28$ & 034128 & 50.01 & 78.15 & 5.7 & 13.7 & 4 & 1 & & 2 & & 1 \\
\hline 84-Jun-23 & $02: 57: 16$ & 49.93 & 79.01 & 2.2 & 4.5 & 3 & 1 & & 2 & & \\
\hline $85-\mathrm{Jul}-11$ & $02: 57: 02$ & 49.82 & 78.02 & 10.0 & 20.5 & 2 & 1 & & 1 & & .... \\
\hline $87-$ Sep-16 & $07: 30: 01$ & 49.85 & 78.79 & 6.7 & 12.7 & 8 & 1 & & 5 & 1 & 1 \\
\hline $88-S e p-26$ & $07: 45: 02$ & 49.93 & 78.90 & 18.0 & 16.0 & 8 & 2 & & 4 & 1 & 1 \\
\hline $88-$ Dec-28 & $05: 28: 08$ & 50.22 & 77.89 & 51.8 & 13.1 & 8 & 3 & & 3 & 2 & \\
\hline
\end{tabular}




\begin{tabular}{|c|c|c|c|c|c|c|c|c|c|c|}
\hline \multirow[b]{2}{*}{ Date } & \multirow[b]{2}{*}{ Time } & \multicolumn{2}{|c|}{ est. location: } & \multicolumn{2}{|c|}{ est. sigma: } & \multicolumn{5}{|c|}{ Number of stations used: } \\
\hline & & (lat, & longl & (lat. & long) & $\#$ & $E$ & $S$ & $W$ & $N$ \\
\hline & & deg & deg & $\mathrm{km}$ & $\mathrm{km}$ & & & & & \\
\hline $64-J$ & 0 & 49.80 & $(77.40)$ & 7.8 & 100.0 & 6 & & 6 & & \\
\hline 64 -Aug- 18 & $06: 00: 00$ & 49.81 & $(79.10)$ & 8.5 & 100.0 & 2 & - & 2 & & \\
\hline $65-\mathrm{Feb}-04$ & $06: 00: 00$ & 49.80 & $(78.90)$ & 6.4 & 40.0 & 4 & - & 4 & & \\
\hline $87-$ Jun-29 & $04: 55: 08$ & 50.10 & 78.96 & 18.0 & 16.0 & 2 & 2 & & & \\
\hline
\end{tabular}

\begin{tabular}{|l|c|c|c|c|c|}
\hline Date & Time & Station & phases & $\Delta D$ & direction \\
\hline $61-J u n-05$ & $03: 50: 00$ & MX & avr-4 & 3 & North \\
\hline $69-A p r-04$ & $03: 57: 00$ & $T L$ & $a v r-3$ & 6 & North \\
\hline $74-$ Sep-27 & $07: 34: 00$ & $\mathrm{TG}$ & $\mathrm{avr}-3$ & 30 & North \\
\hline $81-\mathrm{May}-28$ & $04: 08:$ & $\mathrm{UKN}$ & $\mathrm{avr}-2$ & 13 & West \\
\hline $85-\mathrm{Jun}-27$ & $11: 57: 00$ & $\mathrm{UKN}$ & $\mathrm{avr}-2$ & 10 & West \\
\hline $89-$ Oct-20 & $13: 22: 45$ & $\mathrm{BRV}$ & avr-2 & 21 & West \\
\hline
\end{tabular}

Table 7

\begin{tabular}{|c|c|c|c|c|c|c|c|c|c|c|}
\hline \multirow[b]{2}{*}{ Date } & \multirow[b]{2}{*}{ Time } & \multicolumn{2}{|c|}{ est. location: } & \multicolumn{2}{|c|}{ est. sigma: } & \multicolumn{5}{|c|}{ Number of stations used: } \\
\hline & & (lat, & (ong) & (lat, & long) & $\#$ & $E$ & $S$ & $W$ & $N$ \\
\hline & & deg & deg & $\mathrm{km}$ & $\mathrm{km}$ & & & & & \\
\hline 66-Jun-03 & $09: 21: 10$ & 51.68 & 75.10 & 6.5 & 13.0 & 3 & 1 & 2 & & \\
\hline $67-\mathrm{Jul}-16$ & $4: 07$ & 51.80 & 78.90 & 25.0 & 3.0 & & & 1 & & \\
\hline $81-\operatorname{Mar}-31$ & $07: 51: 30$ & 47.97 & $(80.00)$ & 10.0 & 50.0 & 5 & - & 5 & & \\
\hline $84-A u g-26$ & $03: 32: 57$ & 50.38 & 71.64 & - & - & 2 & 2 & - & & \\
\hline same event & alt. location: & 55.60 & 95.70 & - & 4 & 2 & 2 & - & & \\
\hline $80-0 c t-26$ & $11: 49: 44$ & far from & STS & $(\Delta D=8$ & $13 \mathrm{~km})$ & 1 & - & 1 & & \\
\hline $83-F e b-13$ & $03: 02: 09$ & also far: & $(\Delta D=2$ & 277 or 34 & $40 \mathrm{~km})$ & 1 & 1 & - & & 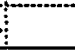 \\
\hline
\end{tabular}




\begin{tabular}{|c|c|c|c|c|c|c|c|}
\hline & & & \multicolumn{4}{|c|}{ FVE DIFFERENT MAGNITUDES } & \\
\hline Date & Time & $\mathrm{K}$ & $M(K)$ & $\mathrm{M}(\mathrm{CHISS})$ & NORSAR & HFS & ISC \\
\hline & & & & & & & \\
\hline $61-J u n-05$ & $03: 50: 00$ & 10.5 & 4.09 & & & & \\
\hline $61-0 \mathrm{ct}-11$ & $07: 40: 00$ & & 4.81 & & & & \\
\hline $62-\mathrm{Feb}-02$ & $08: 00: 00$ & 14.0 & 5.63 & & & & 5.5 \\
\hline $64-J u n-06$ & $00: 00: 00$ & 11.0 & 4.31 & & & & \\
\hline $64-$ Aug- 18 & $06: 00: 00$ & 8.5 & 3.21 & & & & \\
\hline $65-\mathrm{Feb}-04$ & $06: 00: 00$ & 12.5 & 4.97 & & & & \\
\hline $65-\mathrm{Mar}-27$ & $06: 30: 00$ & 8.4 & 3.17 & & & & \\
\hline $65-J u l-29$ & $03: 05: 00$ & 10.7 & 4.19 & & & & 4.5 \\
\hline $65-0 \mathrm{ct}-14$ & $04: 00: 00$ & 10.7 & 4.16 & & & & \\
\hline $66-0 c t-29$ & $03: 58: 00$ & 9.0 & 3.43 & & & & \\
\hline $66-N o v-19$ & $03: 58: 00$ & 8.7 & 3.30 & & & & \\
\hline $66-\mathrm{Dec}-26$ & $17: 39: 38$ & 10.7 & 4.18 & & & & \\
\hline $67-\mathrm{Jun}-03$ & $09: 21: 10$ & 11.7 & 4.62 & & & & \\
\hline $67-\mathrm{Sep}-02$ & $04: 04: 00$ & 10.3 & 4.00 & & & & \\
\hline $68-0 \mathrm{ct}-21$ & $03: 52: 00$ & 10.2 & 3.96 & & & & \\
\hline $68-0 c t-29$ & $03: 54: 00$ & 10.8 & 4.22 & & & & \\
\hline $68-\mathrm{Nov}-12$ & $07: 30: 00$ & 10.6 & 4.13 & & & & \\
\hline $69-\mathrm{Apr}-04$ & $03: 57: 00$ & 9.2 & 3.52 & & & & \\
\hline $69-\mathrm{Apr}-13$ & $04: 04: 00$ & 11.3 & 4.44 & & & & \\
\hline $69-\mathrm{Nov}-27$ & $05: 02: 00$ & 10.3 & 4.00 & & & & \\
\hline $70-M a y-27$ & $04: 03: 00$ & 10.3 & 4.02 & 3.80 & & & \\
\hline $71-J a n-29$ & $05: 03: 00$ & 11.1 & 4.35 & & & & \\
\hline $71-\mathrm{Apr}-09$ & $02: 33: 00$ & 9.6 & 369 & & & & \\
\hline $72-D e c-28$ & $04: 27: 00$ & 11.4 & 4.46 & & & & \\
\hline $73-\mathrm{Mar}-23$ & $06: 30: 00$ & 9.5 & 3.65 & & 3.7 & & \\
\hline $73-D e c-31$ & $04: 03: 00$ & 10.6 & 4.13 & & 4.0 & & \\
\hline $74-S e p-27$ & $07: 34: 00$ & 10.5 & 4.09 & & 3.9 & & \\
\hline $75-0 \mathrm{ct}-05$ & $04: 27: 00$ & 10.7 & 4.18 & & 4.0 & & \\
\hline $76-A u g-04$ & $02: 57: 00$ & 10.5 & 4.09 & & 3.8 & & 4.1 \\
\hline $77-$ Nov- 27 & $03: 57: 00$ & 9.9 & 3.83 & & 3.4 & & \\
\hline $78-\mathrm{Jul}-31$ & $08: 00: 00$ & 10.2 & 3.96 & & 3.9 & & \\
\hline $79-$ Мау-24 & $04: 07: 00$ & 10.3 & 4.00 & & 3.9 & & 3.9 \\
\hline $79-S e p-14$ & $07: 33: 00$ & 10.8 & 4.22 & & 4.4 & & \\
\hline $79-S e p-15$ & $04: 07: 00$ & 8.8 & 3.34 & 3.90 & 3.8 & & 4.6 \\
\hline $80-J u \mid-13$ & $08: 10: 00$ & 10.2 & 3.96 & 4.30 & & 5.0 & \\
\hline $80-$ Sep-20 & $10: 40: 01$ & 9.6 & 3.69 & 4.06 & 3.8 & & \\
\hline $80-S e p-30$ & $05: 57: 12$ & - & & & 3.8 & & 3.8 \\
\hline $80-S e p-30$ & $05: 57: 17$ & 10.7 & 4.18 & & 4.4 & & 4.4 \\
\hline $80-\mathrm{NoV}-06$ & $17: 42: 58$ & 9.6 & 3.69 & & 3.9 & & \\
\hline $81-\mathrm{Mar}-31$ & $07: 51: 30$ & 12.2 & 4.84 & & & & \\
\hline $81-\mathrm{May}-28$ & $04: 08: 28$ & 7.7 & 2.86 & & & & \\
\hline $81-J u n-05$ & $03: 22: 18$ & 10.4 & 4.05 & 4.34 & 4.0 & & \\
\hline $81-J u l-05$ & $03: 59: 14$ & 10.1 & 3.91 & 4.27 & & 4.6 & \\
\hline $81-\mathrm{sep}-30$ & $12: 55: 10$ & 10.2 & 3.96 & & 4.3 & & \\
\hline $81-N o v-19$ & $05: 57: 14$ & 9.6 & 3.69 & & 4.0 & & \\
\hline $82-$ Jun-11 & $10: 59: 07$ & 10.3 & 4.00 & 4.21 & 4.1 & & \\
\hline $82-J u \mid-12$ & $10: 29: 18$ & 10.6 & 4.13 & 4.26 & 3.9 & & \\
\hline $82-S e p-04$ & $05: 47: 17$ & 9.5 & 3.65 & & 3.6 & & \\
\hline $82-S e p-15$ & $04: 33: 19$ & 10.7 & 4.18 & 4.40 & 4.2 & & \\
\hline $83-F e b-13$ & $03: 02: 09$ & 9.9 & 3.83 & & & & \\
\hline $83-J u i-28$ & $03: 41: 28$ & 10.7 & 4.18 & 4.25 & 4.3 & & \\
\hline $84-J u n-23$ & $02: 57: 16$ & 11.1 & 4.35 & & 4.4 & & \\
\hline $84-$ Aug-26 & $03: 32: 57$ & 8.3 & 3.12 & & & & \\
\hline 85-Jun-27 & $11: 57: 00$ & 8.5 & 3.21 & & & & \\
\hline $85-\mathrm{Jul}-11$ & $02: 57: 02$ & 10.2 & 3.96 & & 3.5 & & \\
\hline 87-Jun-29 & $04: 55: 08$ & 8.5 & 3.21 & & & & \\
\hline $87-$ Sep-16 & $07: 30: 01$ & 10.4 & 4.05 & 4.28 & & & 4.3 \\
\hline $88-S e p-26$ & $07: 45: 04$ & 10.7 & 4.18 & & & & 4.3 \\
\hline 88-Dec-28 & $05: 28: 09$ & 9.5 & 3.65 & & & & \\
\hline
\end{tabular}




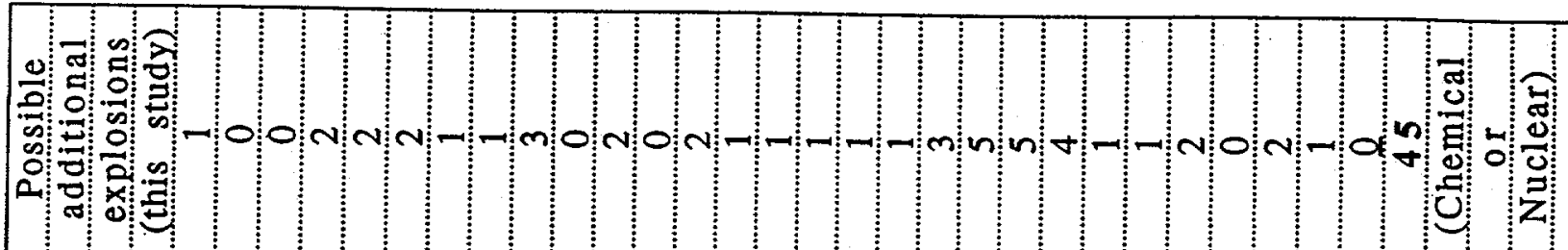

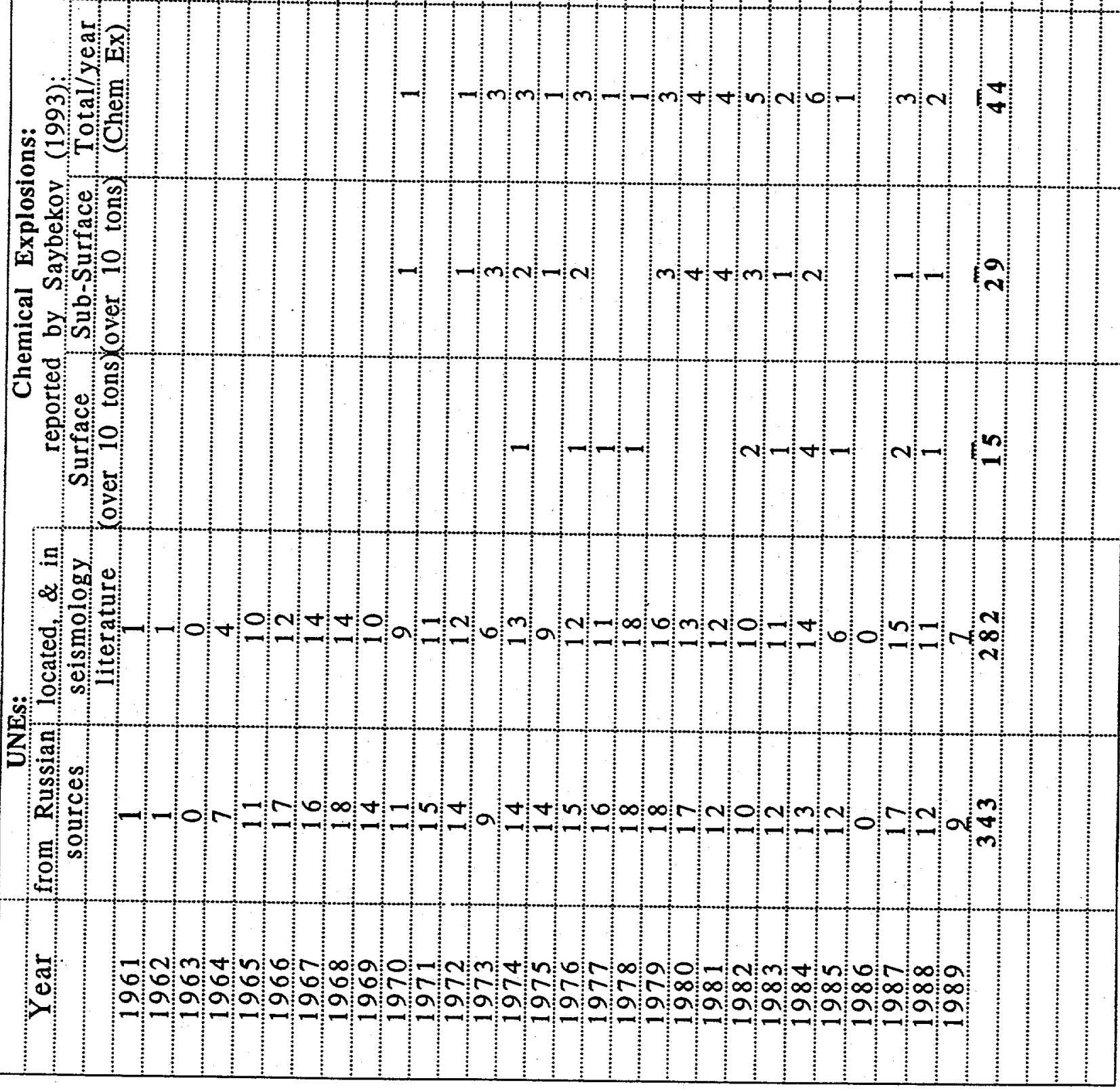

Table 10 


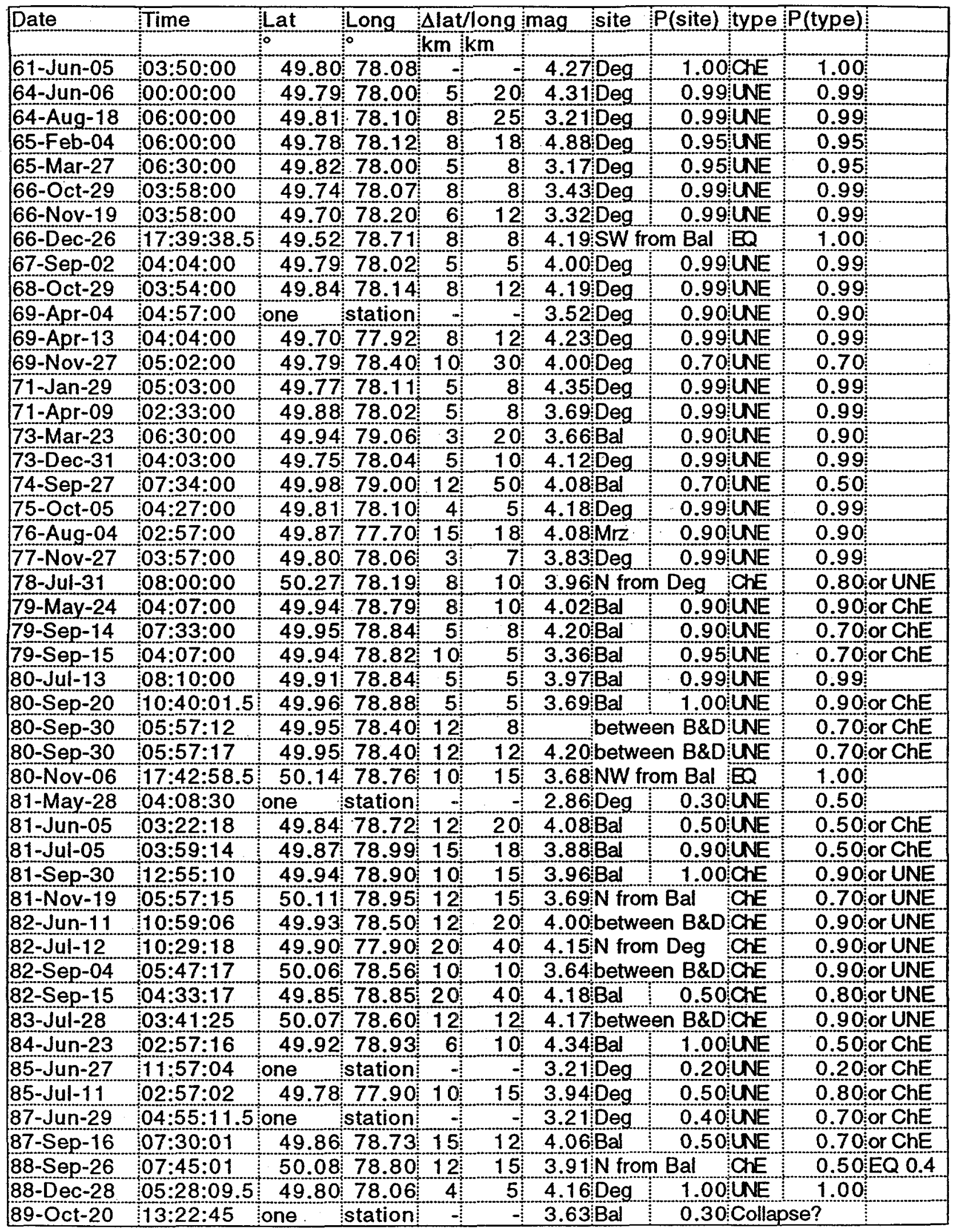

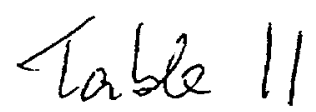




\begin{tabular}{|c|c|c|c|c|c|c|c|c|c|c|c|c|c|}
\hline \multirow[t]{2}{*}{ Date } & \multirow[t]{2}{*}{ Time } & \multirow[t]{2}{*}{ Lat } & \multirow[t]{2}{*}{ Long. } & \multirow{2}{*}{\multicolumn{2}{|c|}{$\begin{array}{l}\text { Alat/long } \\
\mathrm{km} \mathrm{km}\end{array}$}} & \multirow{2}{*}{$\begin{array}{l}\text { records } \\
\text { used }\end{array}$} & \multirow{2}{*}{$\begin{array}{l}\text { Hsta } \\
\text { to }\end{array}$} & \multirow{2}{*}{$\begin{array}{l}\text { \# sta } \\
\text { tow\&E }\end{array}$} & \multirow{2}{*}{$\begin{array}{l}\text { Total \# of } \\
\text { arrivals }\end{array}$} & $K$ & if sta & mag & Comment \\
\hline & & & & & & & & & & & for $K$ & & \\
\hline $61-\mathrm{Jun}-05$ & $03: 50: 00$ & 49.80 & 78.08 & & & 1 & 1 & - & & 10.5 & 1 & 4.09 & ODeg ChE before first UNE \\
\hline $61-0 c t-11$ & $07: 40: 00$ & 49.77 & 78.00 & & & & & & & & & 4.81 & 1 Degifirst Soviet UNE; Boch \\
\hline $62-F e b-02$ & $08: 00: 00$ & 49.78 & 78.00 & & & & & & & 14.0 & 4 & 5.63 & 3 Dog UNE Boch. \\
\hline $64-$ Jun-06 & $00: 00: 00$ & 49.79 & 78.00 & 5 & 20 & 2 & 5 & 1 & 11 & 11.0 & 3 & & $1 \mathrm{Deg}_{2} \mathrm{UNE}$ \\
\hline $64-A 49-18$ & $06: 00: 00$ & 49.81 & 78.10 & 8 & 25 & 1 & 2 & - & 5 & 8.5 & 1 & 3.21 & IDeg UNE \\
\hline $65-\mathrm{Feb}-04$ & $06: 00: 00$ & 49.78 & 78.12 & 28 & 18 & 1 & 4 & $=$ & 6 & .125 & 1 & 4.97 & ZDeg.UNE obscur \\
\hline $65-M a r-27$ & :06:30:00 & 49.82 & 78.00 & 5 & 8 & 1 & 2 & 1 & 6 & 8.4 & & 3.17 & TDQ UNE \\
\hline $65-J u 1-29$ & 03:05:00 & 49.78 & 78.00 & & & & & & & 10.7 & 3 & & $9 \mathrm{Deg}$ UNE; Boch \\
\hline $65-0 c t-14$ & $04: 00: 00$ & 49.99 & 77.64 & & & & & & & 10.7 & 2 & 4.16 & GMrz UNE; 1100 tons, Boch \\
\hline $66-0 \mathrm{ct}-29$ & $03: 58: 00$ & 49.74 & 78.07 & 78 & 8 & 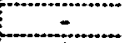 & 2 & 2 & 10 & 9.0 & 3 & 343 & BDog: UNE \\
\hline $66-\mathrm{Nov}-19$ & $03: 58: 00$ & 49.70 & 78.20 & 6 & 12 & 1 & 4 & 2 & 9 & 87 & 2 & 3.32 & ZDeg UNE \\
\hline $66-D e c-26$ & $17: 39: 38$. & 49.52 & 78.71 & 8 & 8 & 3 & 8 & 3 & 27 & 10.7 & $3:$ & 4.19 & $9 \mathrm{~S}$ of $\mathrm{Bal} ; \mathrm{Eq}$ \\
\hline $67-\mathrm{Jun}-03$ & $09: 21: 10$ & 51.70 & 75.40 & & & & & & & 11.7 & 3 & 4.62 & 2Off Test Site to NW, ChE 4 sta. \\
\hline $67-\mathrm{Jul}-16$ & $04: 07: 09$ & 50.70 & 76.50 & & & & & & & 10.5 & 1 & 4.08 & Boff Test Site to NI \\
\hline $67-\operatorname{sep} 02$ & $04: 04: 00$ & 49.79 & 78.02 & 5 & 5 & 3 & 3 & 1 & 9 & 10.3 & 2 & 4.00 & Deg UNE \\
\hline $68-$ oct-21 & $.03: 52: 00$ & 49.73 & 78.49 & & & & & & & 10.2 & 2 & 3.96 & UNE crater shot 200 tons; Boch. \\
\hline $68-0 c t-29$ & $03: 54: 00$ & 49.84 & 78.14 & 8 & 12 & 1 & 5 & 2 & 14 & 10.8 & 3 & 4.19 & Deg: UNE \\
\hline $68-\mathrm{Nov}-12$ & $07: 30: 00$ & 49.71 & 78.46 & & & & & & & 10.6 & 3 & 4.13 & Three UNE crater shots; Boch: \\
\hline $68-\mathrm{Nov}-12$ & $07: 30: 00$ & 49.71 & 78.46 & & & & & & 2nd of thre & ee con & current & ti shots & all three shots are $E$ of Deg \& \\
\hline $6 \mathrm{~B}-\mathrm{Nov}-12$ & $07: 30: 00$ & 49.71 & 78.46 & & & & & & 3 rd of thre & ie cone & current & t shots & SW of Bali 200 tons each \\
\hline $69-$ Apr-04 & $04: 57: 00$ & one & station & 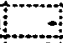 & & 1 & 1 & $=$ & 3 & 9.2 & $0 \mathrm{~s}$ & 3.52 & Degi UNE \\
\hline $69-A p r-13$ & $04: 04: 00$ & 49.70 & 77.92 & 8 & 12 & & 3 & 1 & 13 & 11.3 & 3 & 4.43 & Dog:UNE \\
\hline 69-Nov-27 & $05: 02: 00$ & 49.79 & 78.40 & 10 & 30 & 1 & 1 & 2 & 8 & 10.3 & 11 & 4.00 & Dog:UNE \\
\hline $70-M a y-27$ & $04: 03: 00$ & 49.73 & 78.10 & & & & & & & 10.3 & 3 & 4.01 & Dog; UNE; Boch. \\
\hline $71-j a n-29$ & $05: 03: 00$ & 49.77 & 78.11 & 5 & 8 & 2 & 5 & 1 & 14 & 11.1 & 2 & 4.35 & $\mathrm{DEg} ; \mathrm{UNE}$ \\
\hline $71-$ Apr-09 & $02: 33: 00$ & 49.88 & 78.02 & 5 & 8 & 1 & 3 & 4 & 16 & 9.6 & 1 & 3.69 & Deg:UNE \\
\hline $72-$ Dec- 28 & $04: 27: 00$ & 49.74 & 78.11 & & & & & & & 11.4 & 2 & 4.62 & Deg UNE BOCh \\
\hline $73-M a r-23$ & $06: 30: 00$ & 49.94 & 79.06 & 3 & 20 & - & 2 & & 5 & 9.5 & 3 & 3.66 & $\mathrm{Bal}$ :ChE \\
\hline $73-\mathrm{Dec}-31$ & $04: 03: 00$ & 49.75 & 78.04 & 5 & 10 & 1 & 3 & 5 & 13 & 10.6 & 3 & 4.12 & Dog UNE \\
\hline $74-\mathrm{Sep}-27$ & $07: 34: 00$ & 4998 & 79.00 & 12 & 50 & & 3 & $=$ & 6 & 10.5 & 3 & 4.08 & $\mathrm{Ba}: \mathrm{CHE}$ \\
\hline $75-0 \mathrm{ct}-05$ & $04: 27: 00$ & 49.81 & 78.10 & 4 & 5 & 2 & 4 & 3 & 15 & 10.7 & 5 & 4.18 & Dog, UNE \\
\hline $76-\mathrm{Mar}-20$ & $04: 03: 36$ & 50.00 & 77.25 & 8 & 15 & 8 & 4 & 4 & 17 & 13.0 & & 5.19 & Wof Deg; \\
\hline $76-$ Aug-04 & $02: 57: 00$ & 49.87 & 77.70 & 15 & 18 & 1 & 1 & 4 & 10 & 10.5 & 3 & 4.08 & $\mathrm{M}=\mathrm{UNE}$ \\
\hline $77-\mathrm{NoV}-27$ & $03: 57: 00$ & 49.80 & 78.06 & 3 & 7 & & 4 & 1 & 11 & 9.9 & 3 & 3.83 & DOg:UNE \\
\hline $78-J u \mid-31$ & $08: 00: 00$ & 50.27 & 78.19 & 8 & 10 & & 5 & 1 & 14 & 10.2 & 5 & & N of Deg: ChE or UNE \\
\hline $79-M a y-24$ & $04: 07: 00$ & 49.94 & 78.79 & 8 & 10 & 1 & 2 & 2 & 14 & 10.3 & 3 & 4.02 & $\mathrm{Bad} \mathrm{CHE}$ \\
\hline $79-$ Sep-14 & $07.33: 00$ & 49.95 & 78.84 & 5 & 8 & & 2 & 1 & 8 & 10.8 & 2 & 4.20 & $\mathrm{Bal} ; \mathrm{ChE}$ \\
\hline- Sep-15 & $04: 07: 00$ & 49.94 & 78.82 & 10 & 5 & 1 & 1 & 2 & 6 & 8.8 & 2 & 3.36 & Bal $\mathrm{ChE}$ \\
\hline $0-j u l-13$ & $08: 10=0$ & 49.91 & 78.84 & 5 & 5 & $\because$ & 2 & 2 & 11 & 10.2 & 3 & 3.97 & $\mathrm{Bal} ; \mathrm{ChE}$ \\
\hline -Sep-20 & $10: 4001.5$ & 4996 & 78.88 & 5 & 5 & $=$ & 2 & 2 & 9 & 9.6 & 3 & 3.69 & $\mathrm{Ba} ; \mathrm{CTE}$ \\
\hline -Sep-30 & $05: 57: 12$ & 49.95 & 78.40 & 12 & 8 & 1 & 2 & 3 & 10 & & 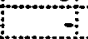 & & between $\mathrm{Bal} \& \mathrm{De}$ \\
\hline $80-$ Sep-30 & $05: 57: 17$ & 49.95 & 78.40 & 12 & 12 & 1 & 2 & 4 & 12 & 10.7 & 2 & $4.20:$ & between Bal \& Deg;ChE \\
\hline $80-0 \mathrm{ct}-26$ & 11149944 & 43.00 & 96.00 & & & & & & & & & & Far from Test Site; 3 sta. \\
\hline$-N o v-06$ & $17: 42: 58.5$ & 50.14 & 78.76 & 10 & 15 & $=$ & 4 & 1 & 12 & 9.6 & 3 & 3.68 & $\mathrm{NW}$ of $\mathrm{Bal}$ ChE \\
\hline$-M a r-31$ & $07: 51: 30$ & 4780 & 8100 & & & & & & & 12.2 & 3 & 4.84 & Off Test Site to \\
\hline $81-M a y=28$ & $04: 08: 30$ & one & station & & & & $\because$ & & 2 & 7.7 & 4 & 2.86 & DOg UNE \\
\hline un-05 & $03: 22: 18$ & 49.84 & 78.72 & 12 & 20 & 1 & 2 & 2 & 10 & 10.4 & 3 & $4.08:$ & Bal:ChE \\
\hline $41-05$ & $03: 59: 14$ & 49.87 & 78.99 & 15 & 18 & 1 & 2 & 2 & 12 & 10.1 & 3 & $3.88 \mathrm{:}$ & $\mathrm{Bal}: \mathrm{CHE}$ \\
\hline$e p=30$ & $12: 55: 10$ & 4994 & 78.90 & 10 & 15 & $\because$ & 2 & 2 & 12 & 10.2 & 3 & 3.96 & $\mathrm{Bal}: \mathrm{CHE}$ \\
\hline $81-\mathrm{Nov}-19$ & $05: 57: 15$ & 50.11 & 78.95 & 12 & 15 & & 3 & 1. & 11 & 9.6 & $4:$ & 3.69 & Nof Bal; ChE \\
\hline$-j u n-11$ & $10.59: 06$ & 49.93 & 78.50 & 12 & 20 & 1 & 2 & $\because$ & 13 & 10.3 & 4 & $4.00 \mathrm{i}$ & botween Bal \& Deg; ChE \\
\hline Jul-12 & $10: 29: 18$ & $49.90:$ & 77.90 & 20 & 40 & 1 & 2 & 1 & 12 & 10.6 & 3 & $4.15 i$ & N O Deg; ChE or UNE \\
\hline Sep-04 & $05: 47: 17$ & 50.06 & 78.56 & 10 & 10 & 1 & 2 & 1 & 10 & 9.5 & 3 & 3.64 & between Bal \& Deg; ChE \\
\hline $82-$ Sep-15 & $04: 33: 17$ & 49.85 & 78.85 & 20 & 40 & 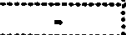 & 2 & 2 & 14 & 10.7 & 3 & $4.18: \mathrm{E}$ & $\mathrm{Bad}: \mathrm{ChE}$ \\
\hline $83-F e b-13$ & $03: 02: 09$ & 39.50 & 74.00 & & & & & & & 9.9 & 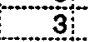 & 3.83 & $\mathrm{mTe}$ \\
\hline $83-J 1-28$ & $03.41: 25$ & 50.07 & 78.60 & 12 & 12 & 1 & 2 & & 4 & 10.7 & 3 & $4.17:$ & between $\mathrm{Bal}$ \\
\hline $4-j u n-23$ & $02: 57: 16$ & 49.92 & 78.93 & 6 & 10 & 1 & 6 & 1 & 24 & 11.1 & 7 & 4.34: & Bal:ChE \\
\hline 84 -Aug-26 & $03.32: 57$ & 5040 & 7160 & & & & & & & 8.3 & 2 & & Far from Tes \\
\hline $85-J u n-27$ & $11: 57: 04$ & one & station: & + & $-:$ & & $\because$ & 1 & 2 & 8.5 & 1 & 32110 & Ded ChE or \\
\hline $85-\mathrm{Jul}-11$ & $02: 57: 02$ & 49.78 & 77.90 & 10 & 15 & & 1 & 1 & 6 & 10.2 & 2 & & DOg:UNE \\
\hline$-\mathrm{Jun}-29$ & $04: 55: 11.5$ & one & station: & 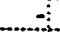 & - & - & - & 2 & $F$ & 8.5 & 1 & $3.21: \mathrm{L}$ & Deg:UNE \\
\hline Sep-16 & $07: 30: 01$ & 49.86 & 78.73 & 15 & 12 & & 5 & 3 & 21 & 10.4 & 5 & $4.06: 5$ & $\mathrm{Baj} ; \mathrm{ChE}$ \\
\hline $88-\mathrm{sep}-26$ & $07: 45: 01$ & 50.08 & 7880 & 12 & 15 & 2 & 5 & 8 & 32 & 107 & :- & 4.160 & $\mathrm{Nof} \mathrm{B}$ \\
\hline $88-0 e c-28$ & $05: 28: 09.5$ & $49.80:$ & 78.06 & $4 !$ & 5 & 2 & 3 & 6 & 24 & 9.5 & & 0 & \\
\hline $89-0 \mathrm{ct}-20$ & $13: 22: 45$ & one & station: & & & & & & & & & & Deg:ChE or UNE cavily collapse? \\
\hline
\end{tabular}

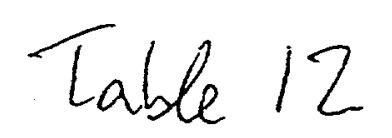




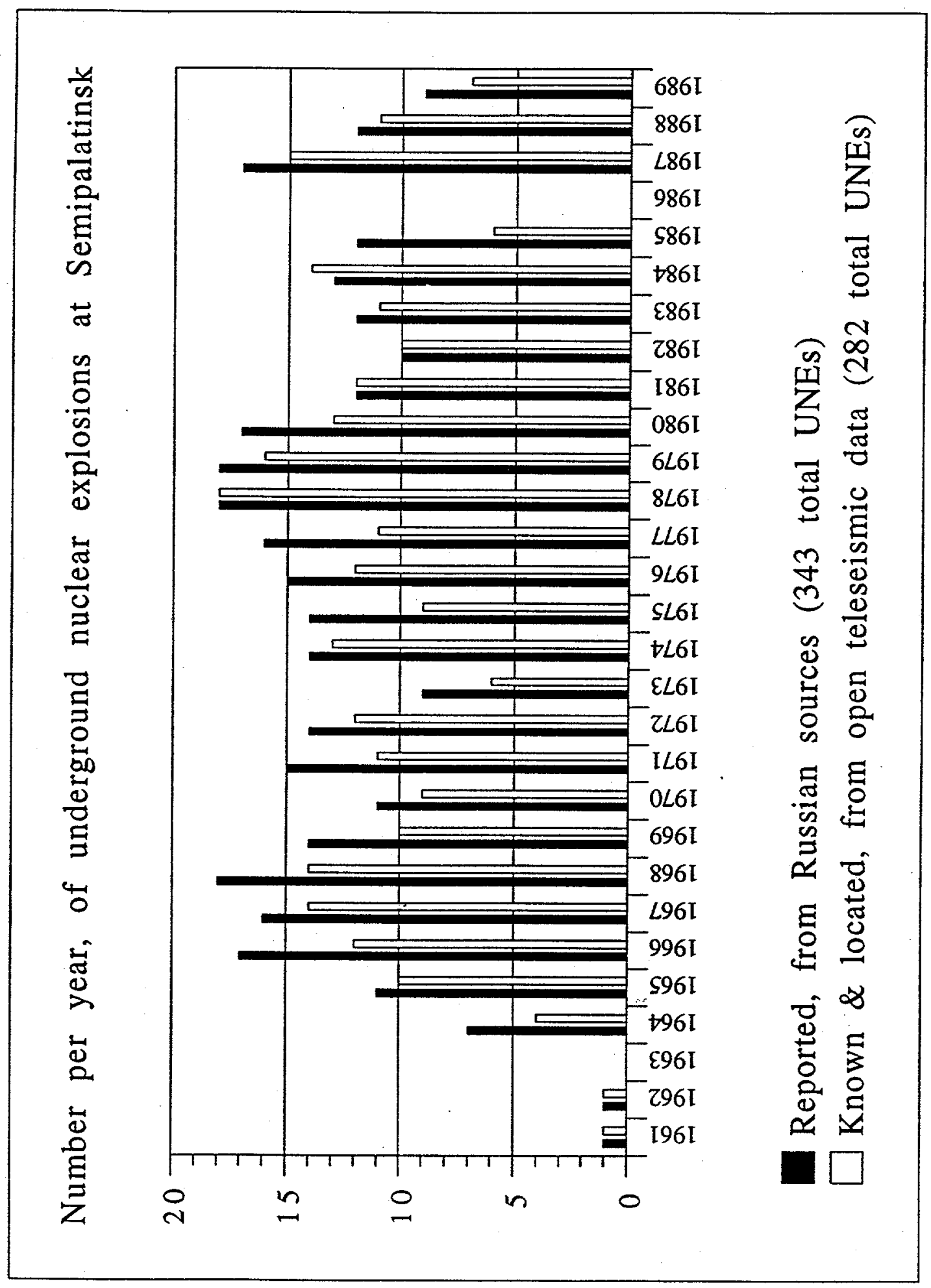

Figurel 


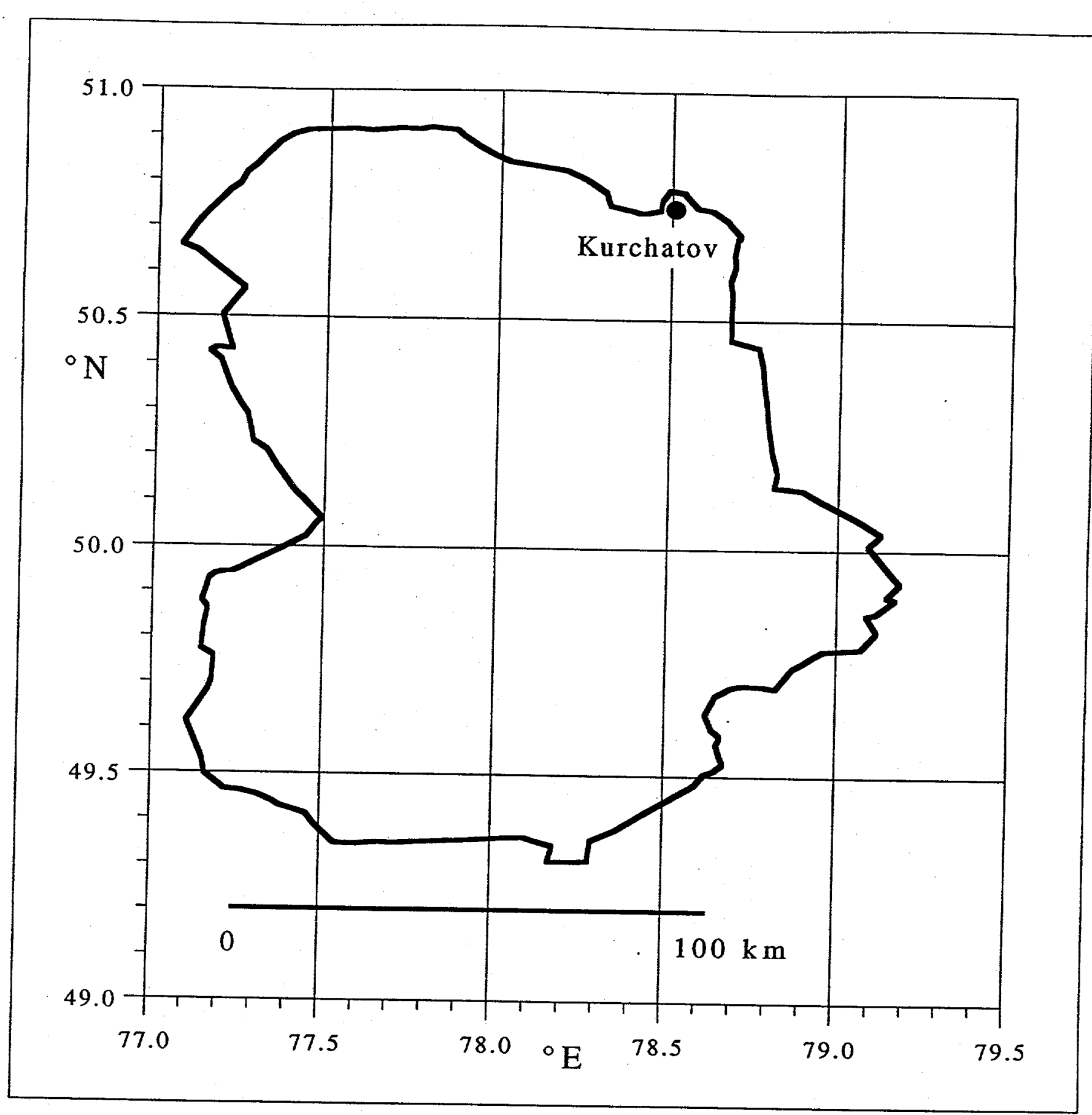

The boundaries of the Semipalatinsk Test Site, East Kazakhstan

Fighe 2 
52 stations at regional distances from the Semipalatinsk Test Site

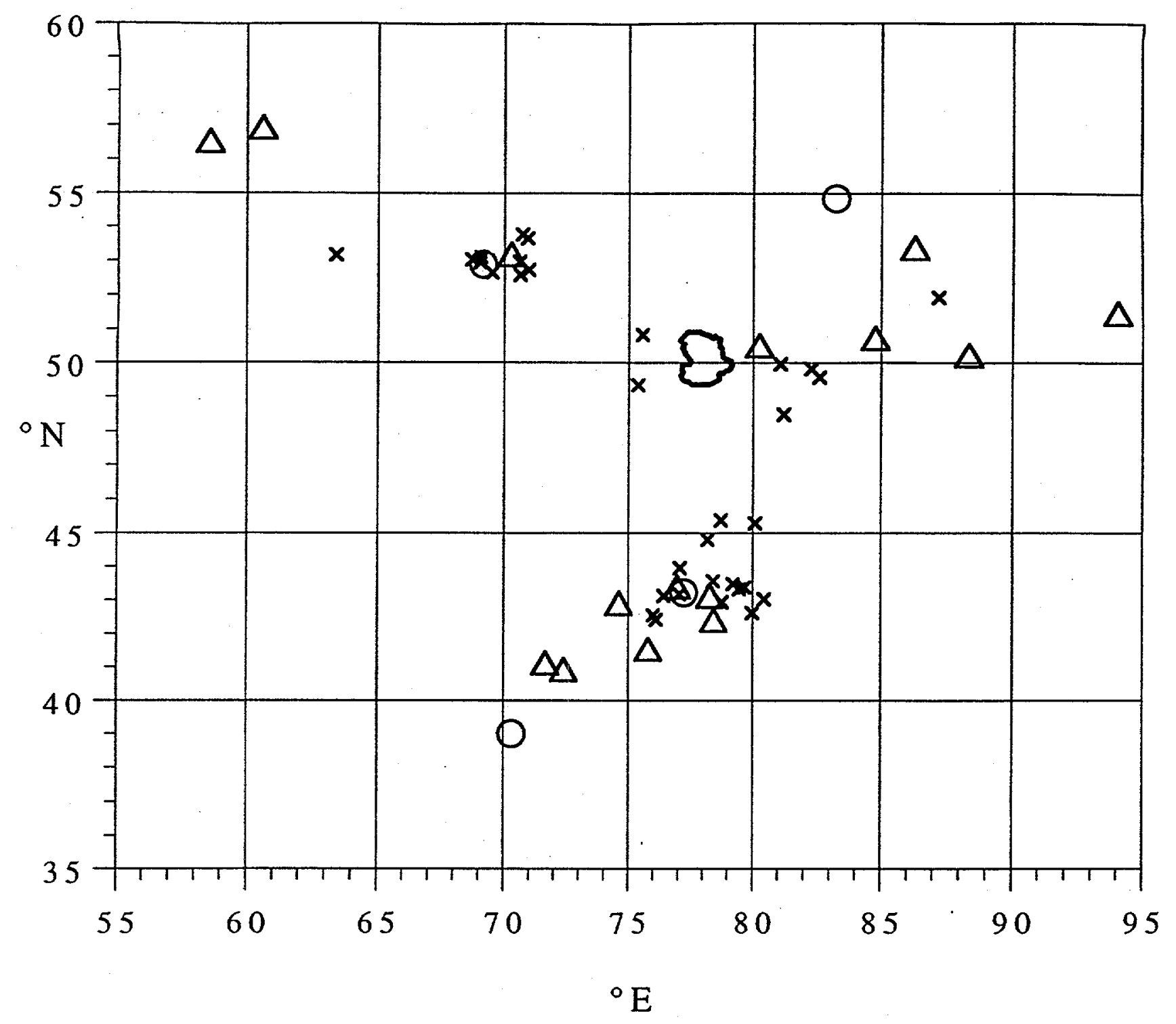

छ

Semipalatinsk Test Site Boundary

33 temporary stations
$\Delta 15$ permanent stations

O 4 permanent ChISS stations

$$
\text { Figure } 3
$$




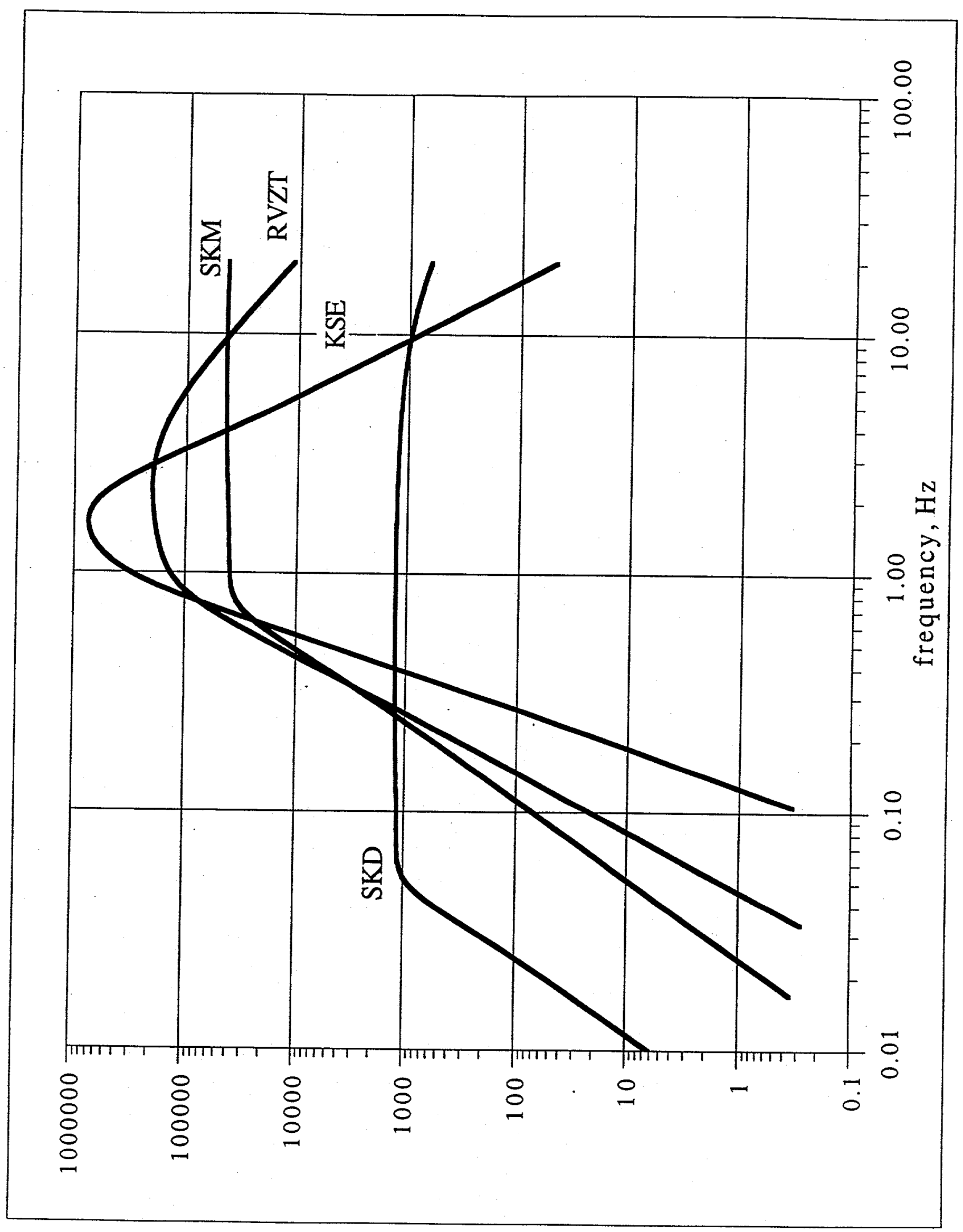

Figure $4 a$ 
ChISS amplitude response

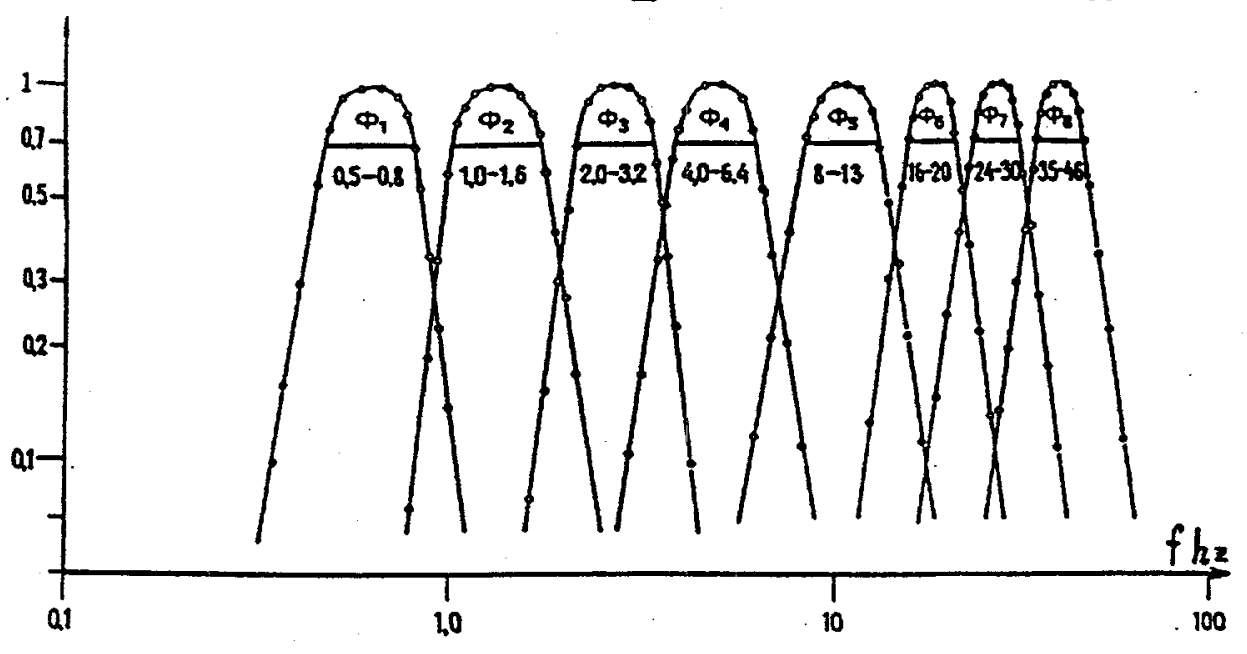

\section{ChISS impulse response}

$$
4.0-6.4 \mathrm{~Hz}
$$
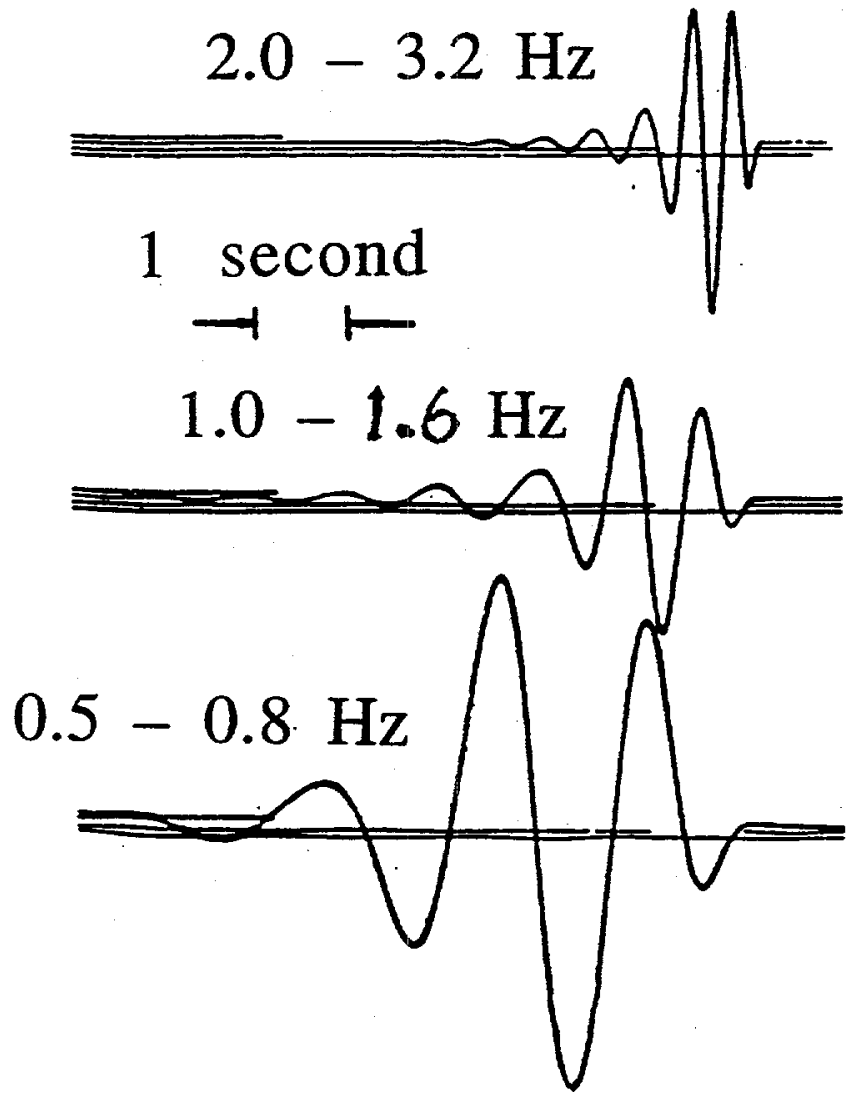

Figure 46 


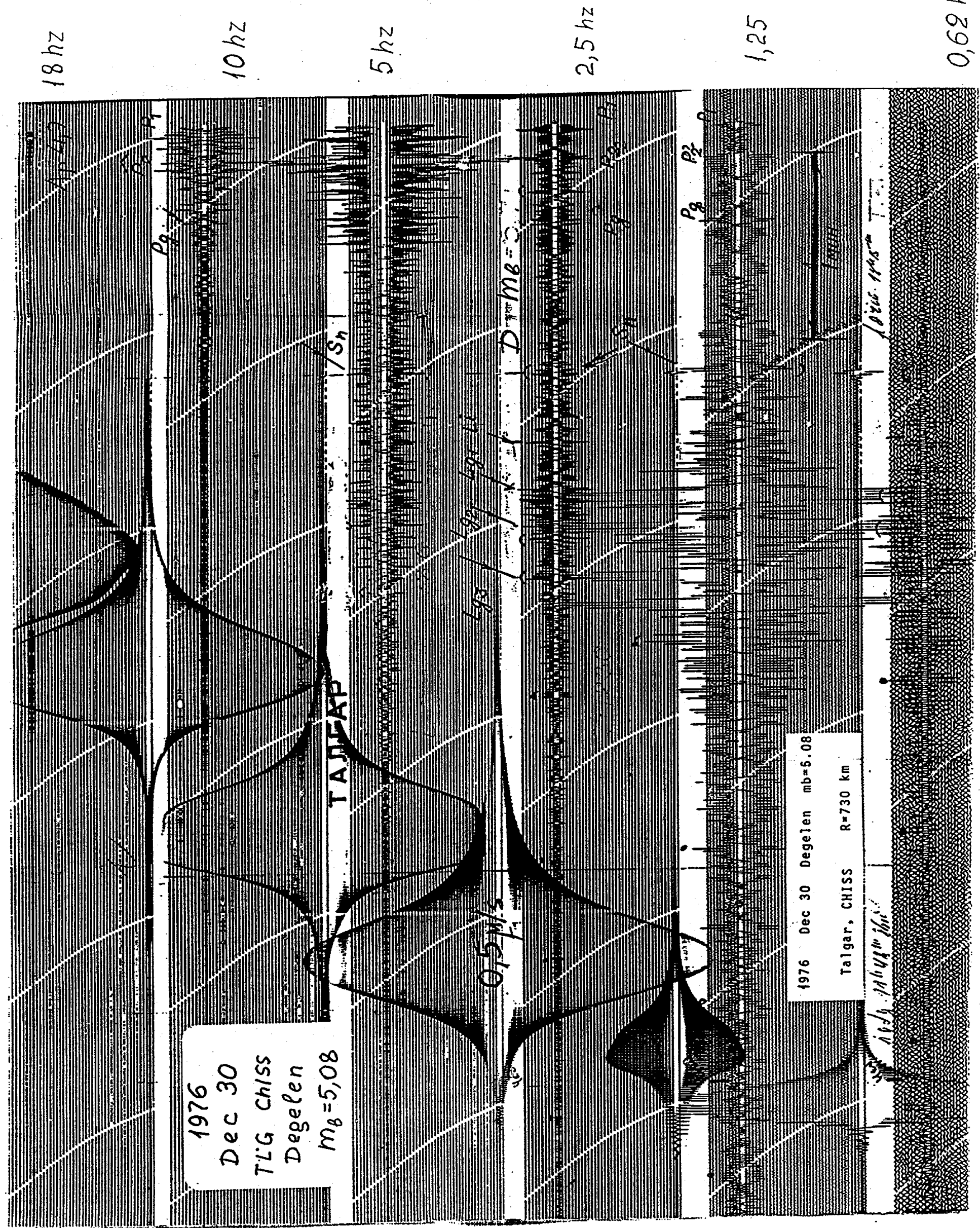

Figure 5 a 


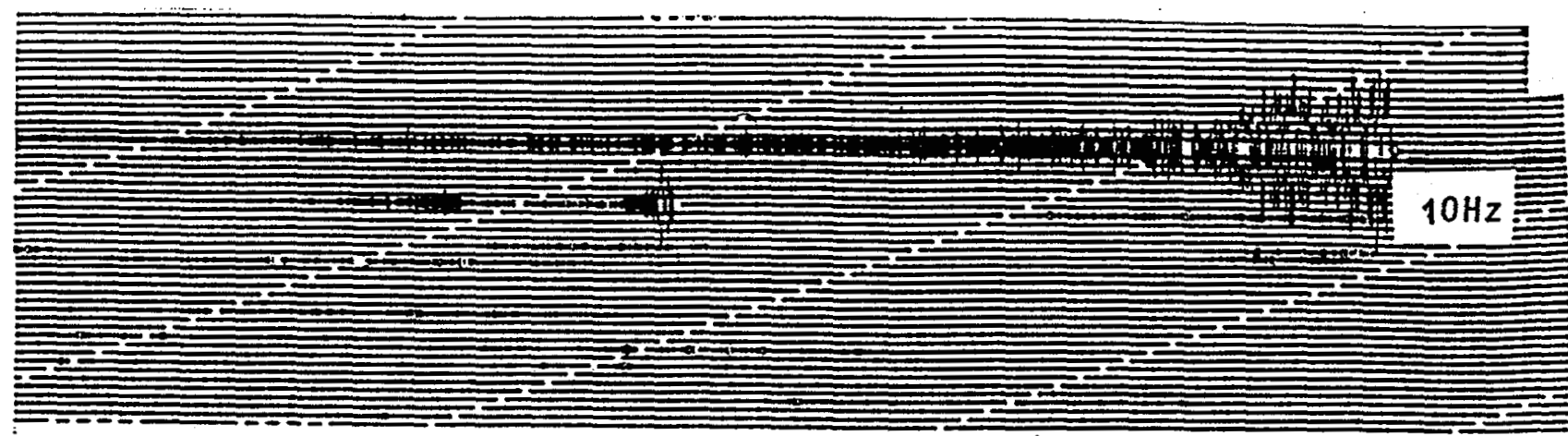

$T L G \quad N 137 \quad t_{p} 04-59-32,0$

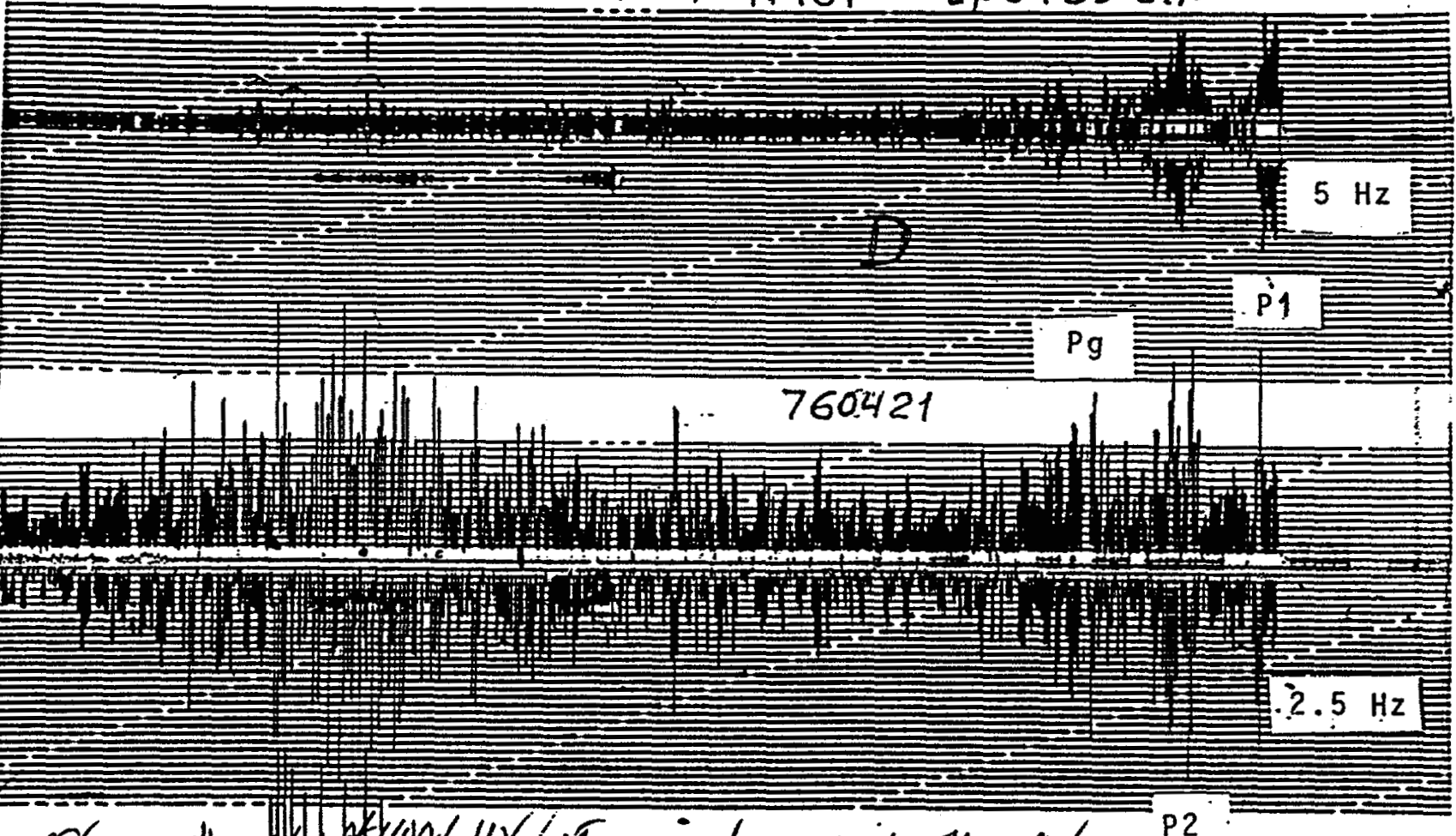

$11,8^{2}$ isulph 1210
(1)
W
L
$\operatorname{Lg} 1$
L
W
$1.25 \mathrm{~Hz}$
$\begin{array}{lll}\mathrm{Li} & \mathrm{Apr} 21 & \text { DEGELEN } \\ \mathrm{mb}=5.1 & \text { Talgar CHISS }\end{array}$
㳕
D. $\quad m_{B}=5,1$

${ }_{\mathrm{Lg} 2}$ 


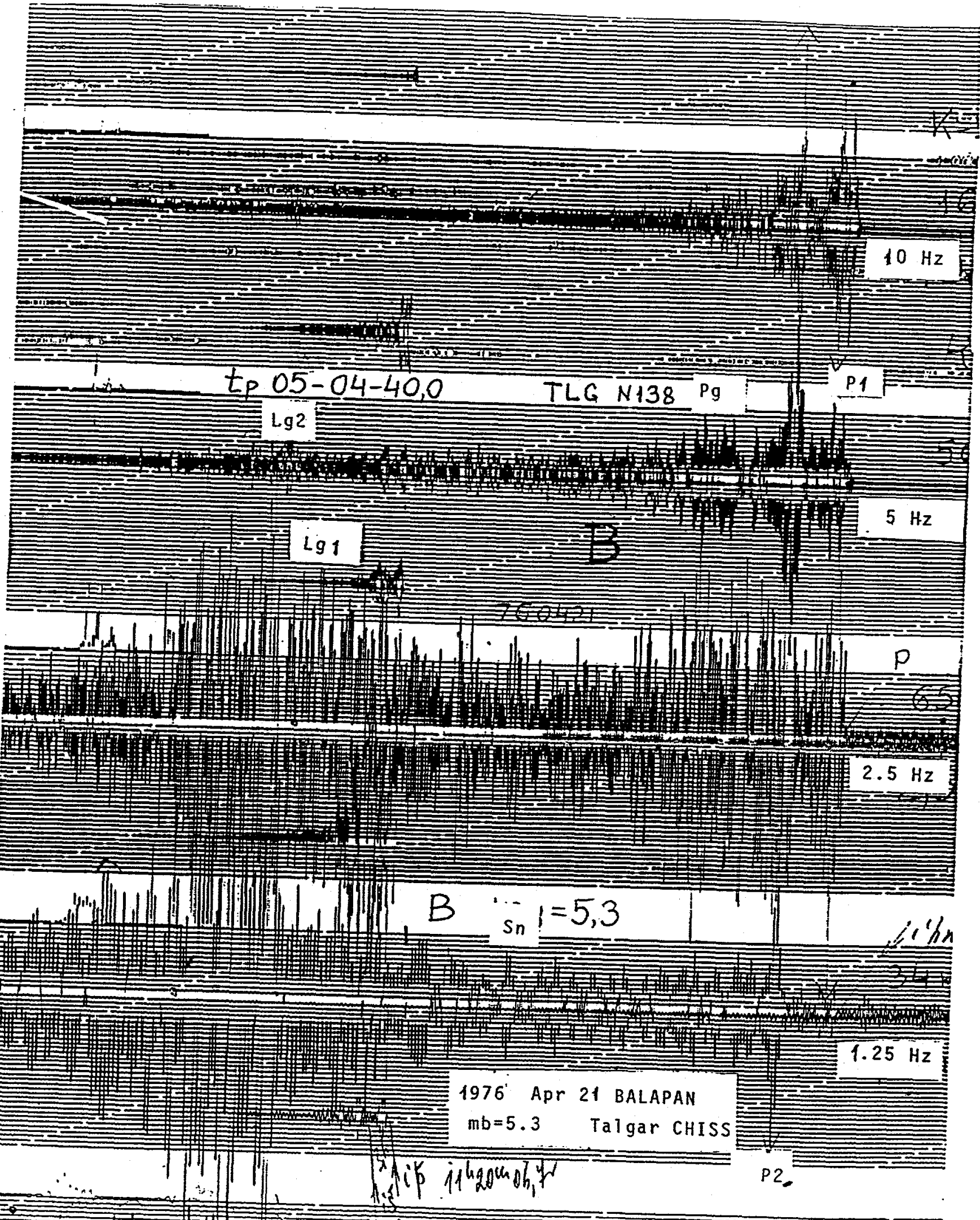

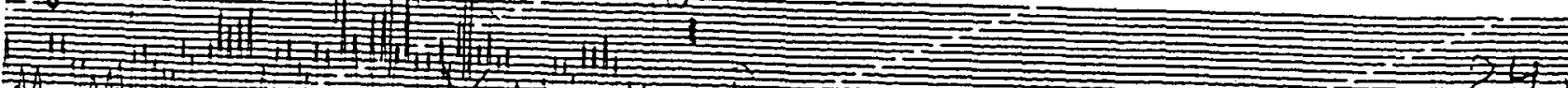

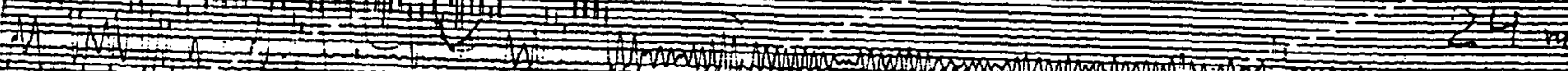

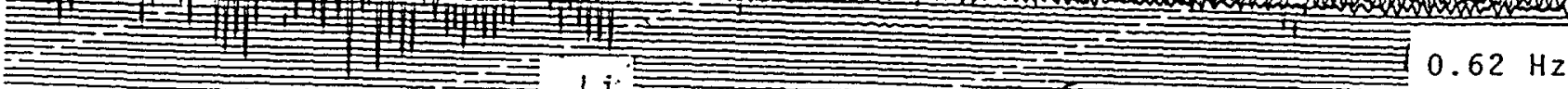




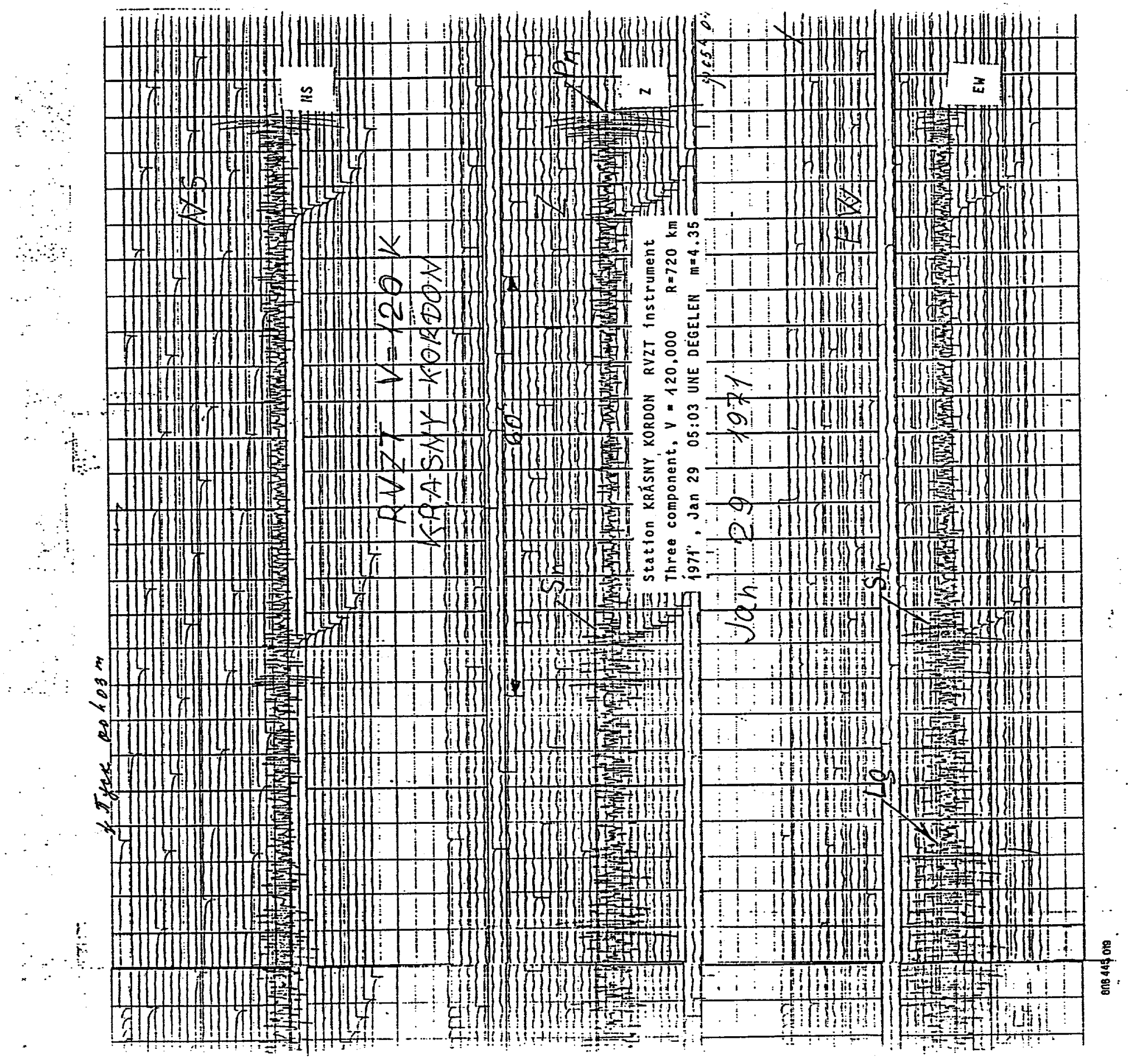

$$
\text { Figure ba }
$$




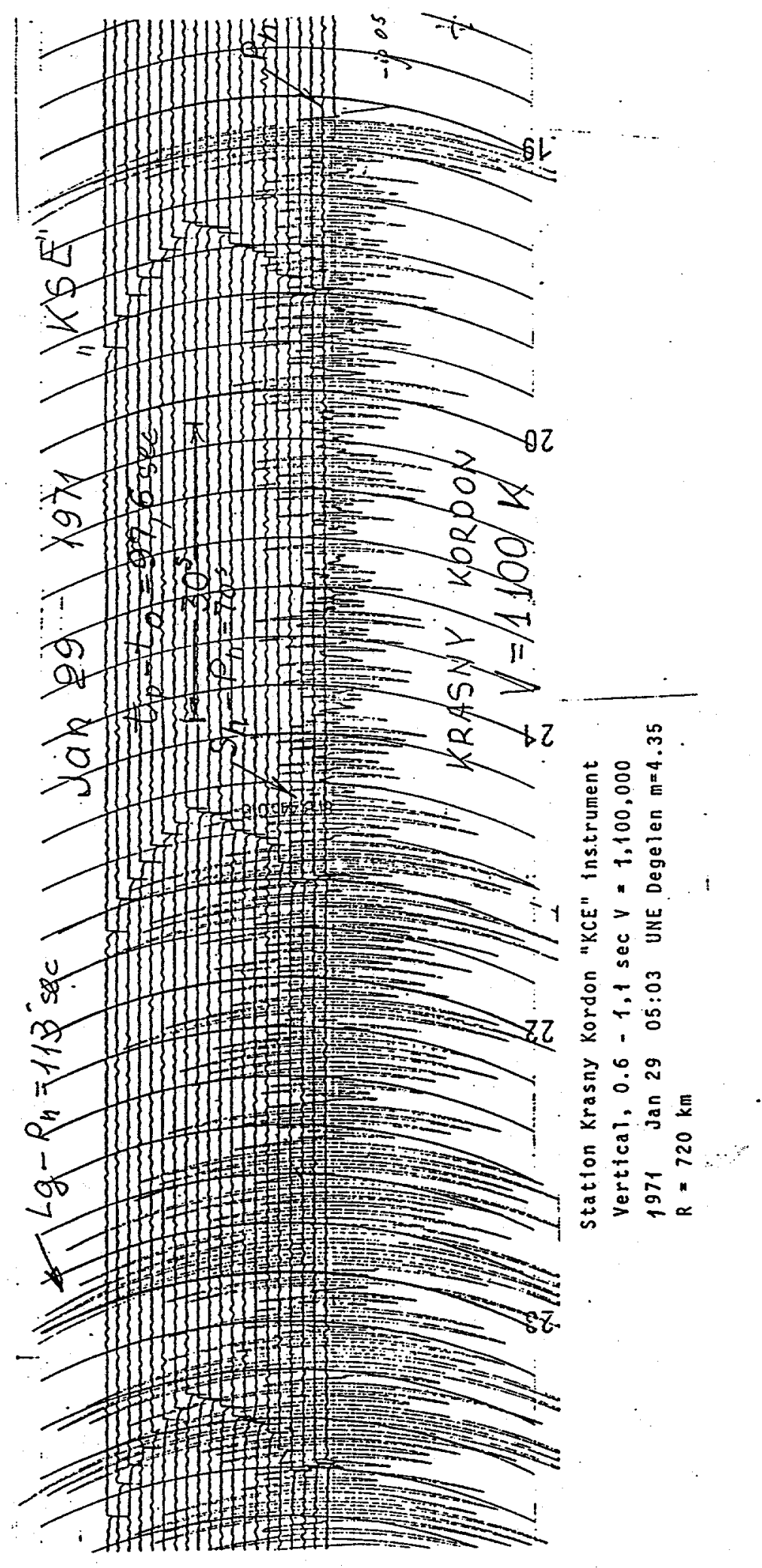

Figure 66 


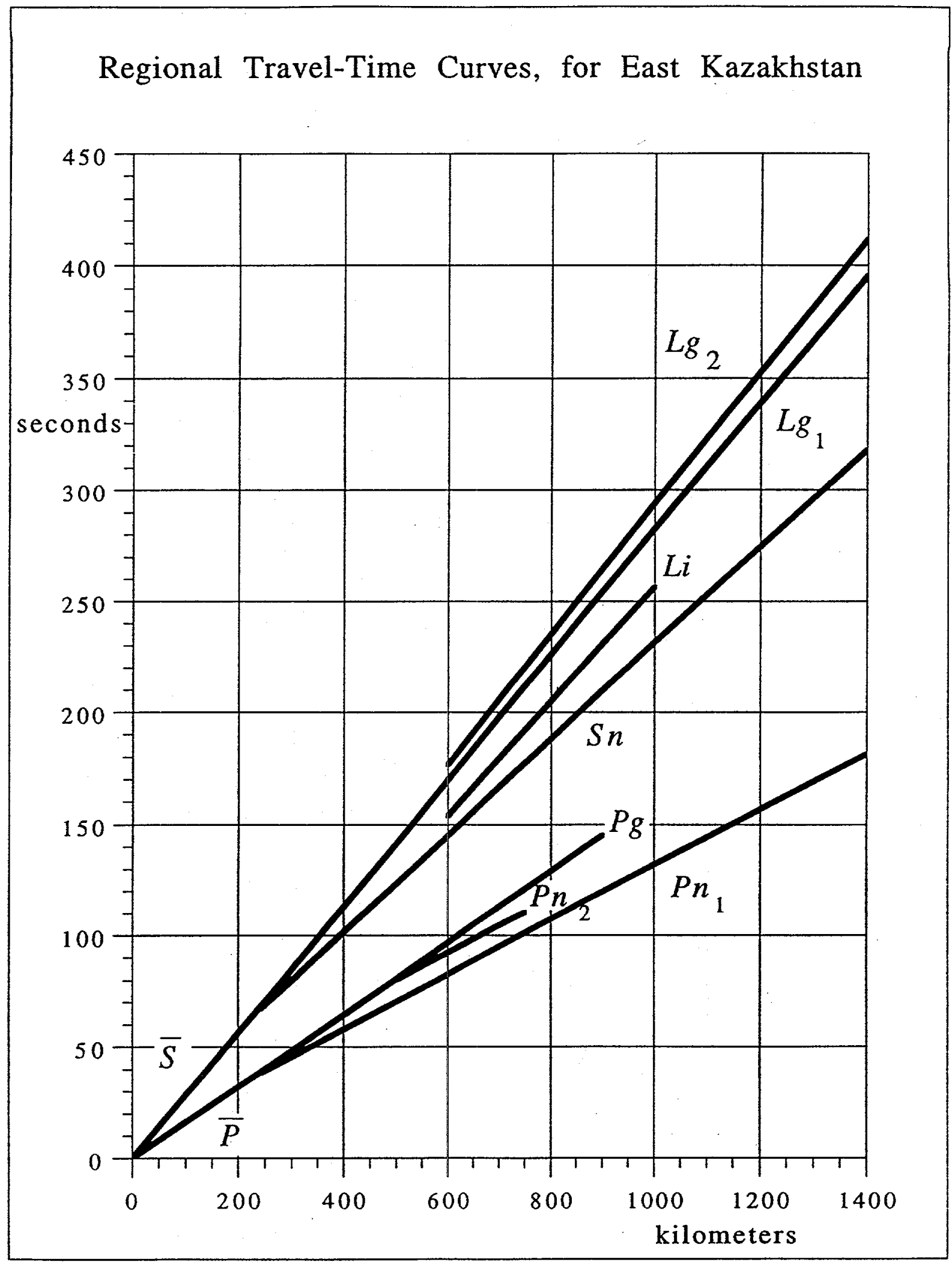

Figme 7 


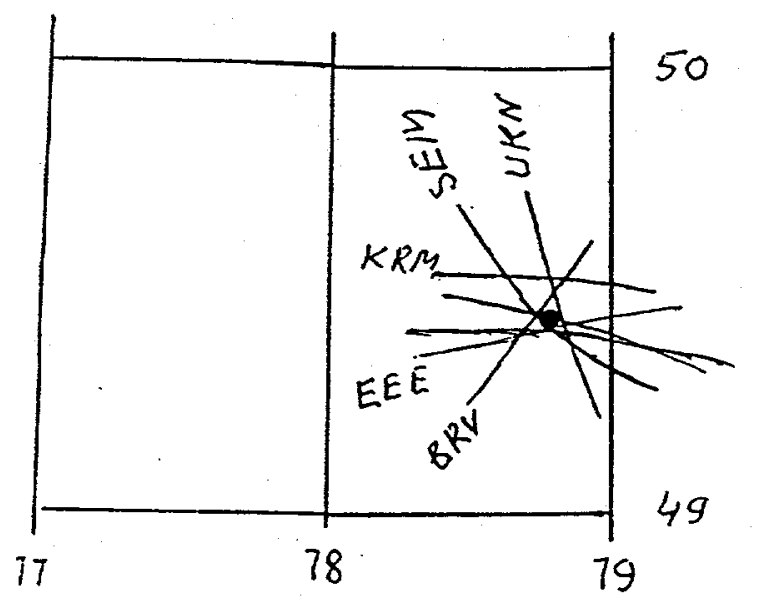

1966-Dec-26 $\quad\left(49.40^{\circ}, 78.75^{\circ}\right)$

$(8 \mathrm{~km}, 15 \mathrm{~km})$

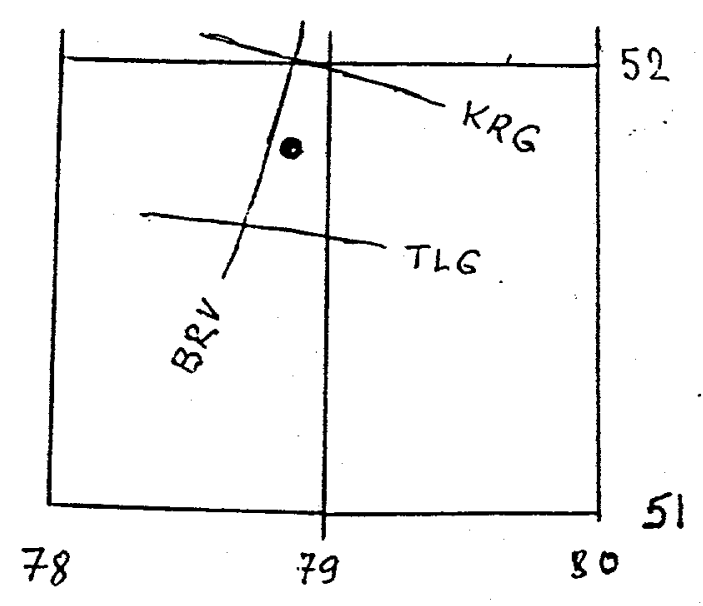

$1967-\mathrm{Jul}-16 \quad\left(51.80^{\circ}, 78.90^{\circ}\right)$
$(10 \mathrm{~km}, 25 \mathrm{~km})$

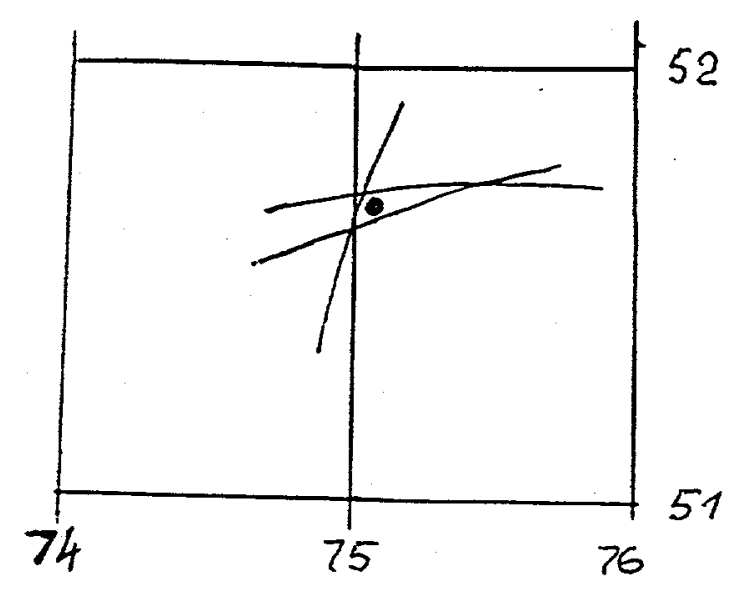

$1967-$ Jun-03 $\quad\left(51.68^{\circ}, 75.10^{\circ}\right)$ $(6.5 \mathrm{~km}, 13 \mathrm{~km})$

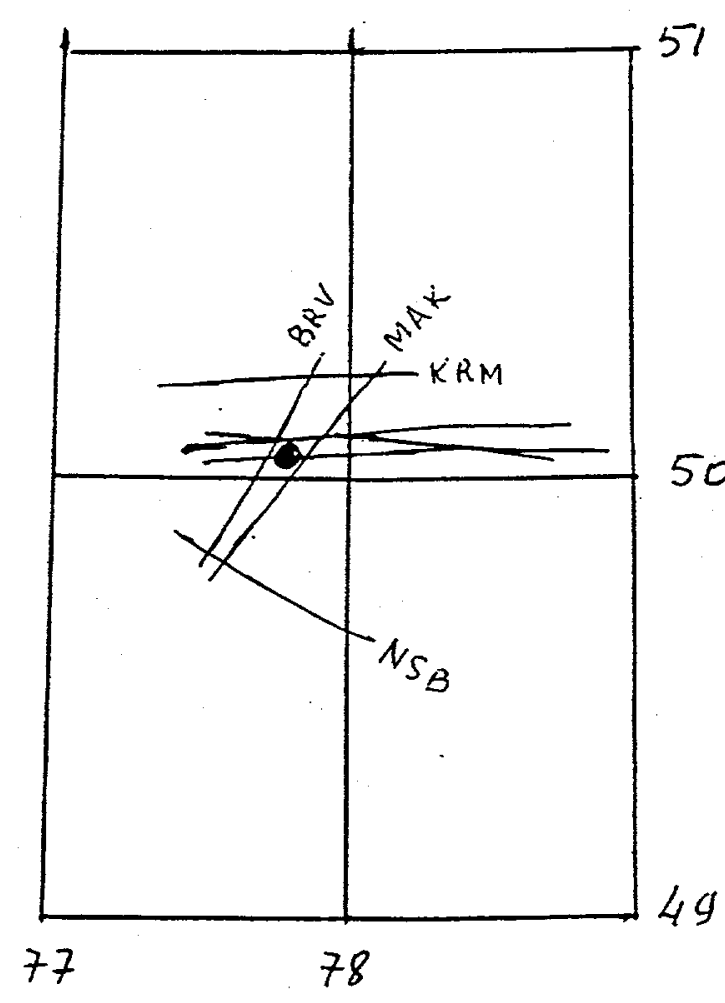

$1976-\mathrm{Mar}-20 \quad\left(50.02^{\circ}, 77.37^{\circ}\right)$
$(15 \mathrm{~km}, 12 \mathrm{~km})$

Figure $8(16+3)$ 

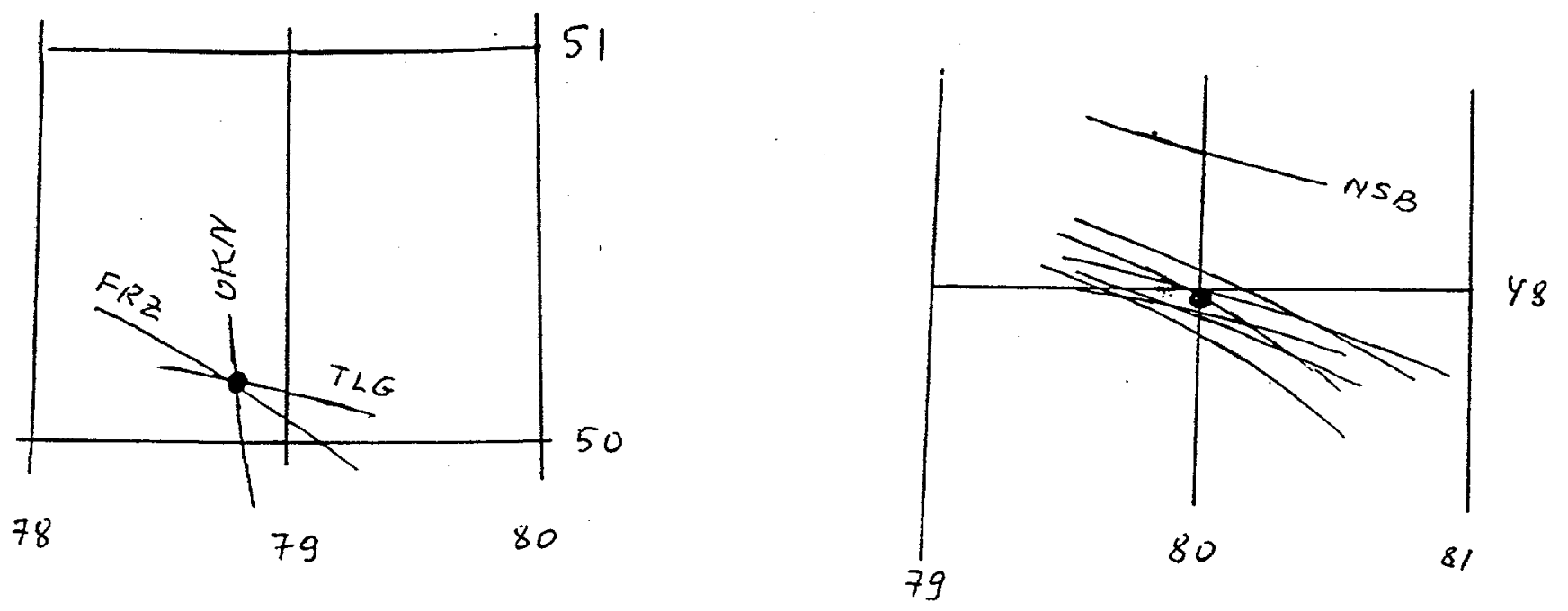

$\begin{aligned} & 1980-\text { Nov-06 }\left(50.15^{\circ}, 78.80^{\circ}\right) \\ &(2 \mathrm{~km}, 4 \mathrm{~km})\end{aligned}$

$1981-\mathrm{Mar}-31 \quad\left(47.97^{\circ}, 80.00^{\circ}\right)$ $(10 \mathrm{~km}, 50 \mathrm{~km})$
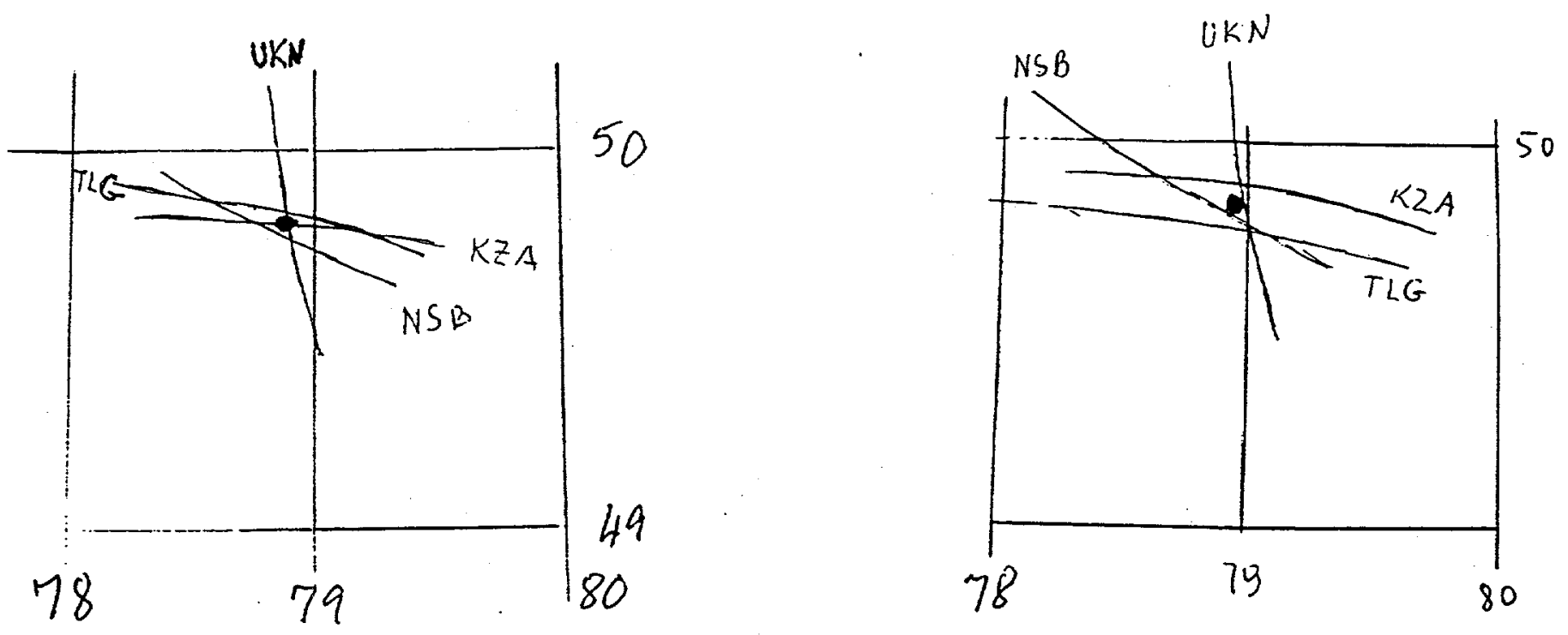

1 981 -Jun-05 $\left(49.80^{\circ}, 78.86^{\circ}\right)$ $(7.9 \mathrm{~km}, 15.5 \mathrm{~km})$

$1981-\mathrm{Jul}-05 \quad\left(49.85^{\circ}, 78.90^{\circ}\right)$ $(6.3 \mathrm{~km}, 10.5 \mathrm{~km})$

Figure 8 (28,3) 
$\leftarrow \rightarrow$ trace of possitle enicenter if change to (origin time)

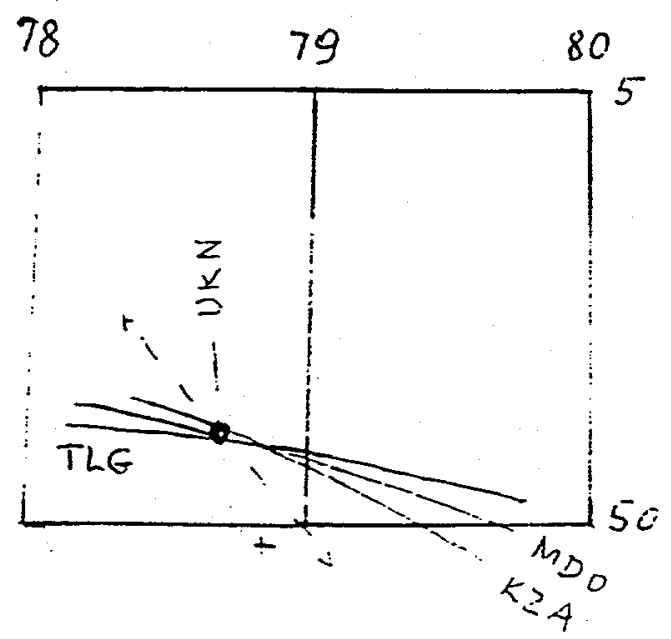

$1981-$ Nov-19 $\left(50.20^{\circ}, 78.71^{\circ}\right)$

$(10 \mathrm{~km}, 10 \mathrm{~km}$ )

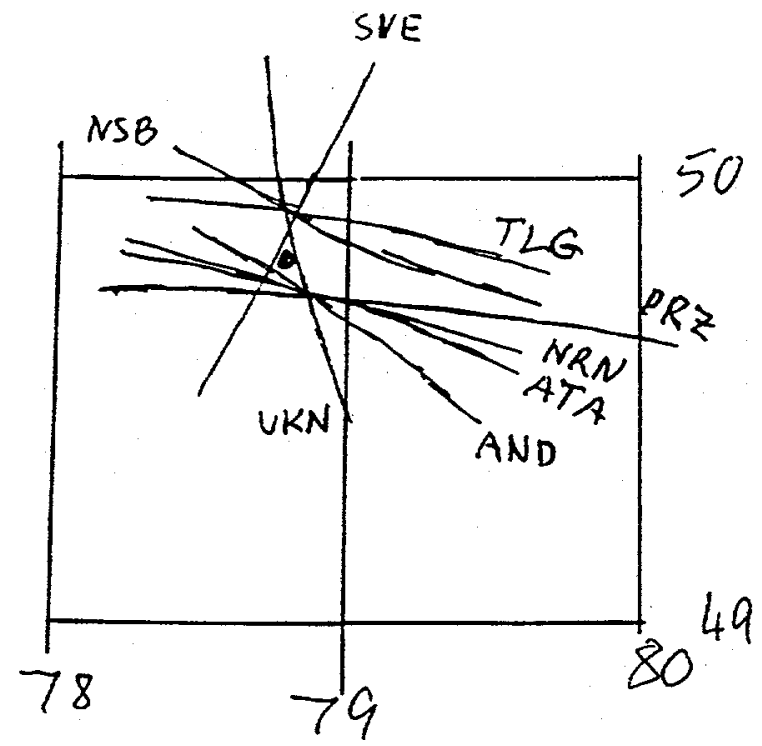

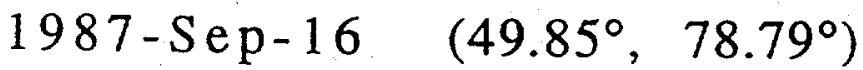
$(6.7 \mathrm{~km}, 12.7 \mathrm{~km})$

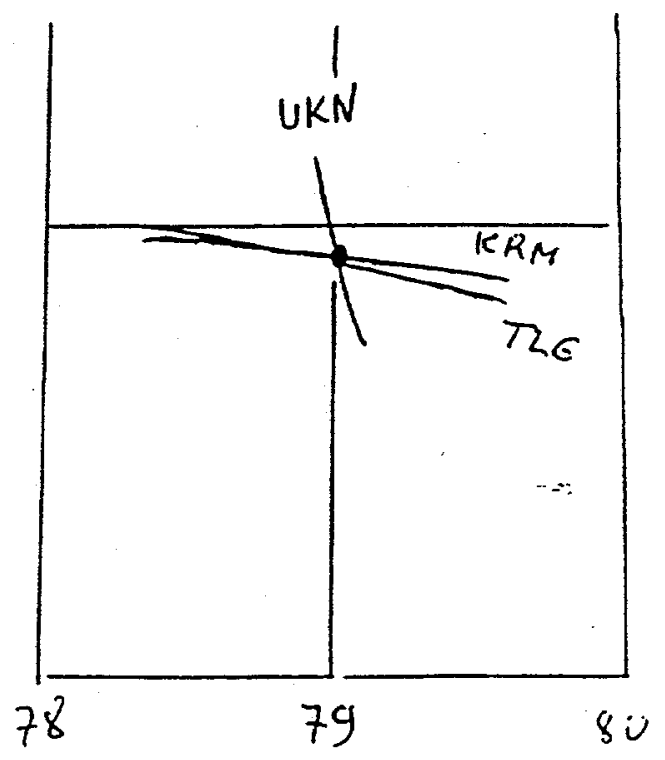

$1984-\mathrm{Jun}^{2} 3 \quad\left(49.93^{\circ}, 79.01^{\circ}\right)$ (2.2 km, $4.5 \mathrm{~km})$

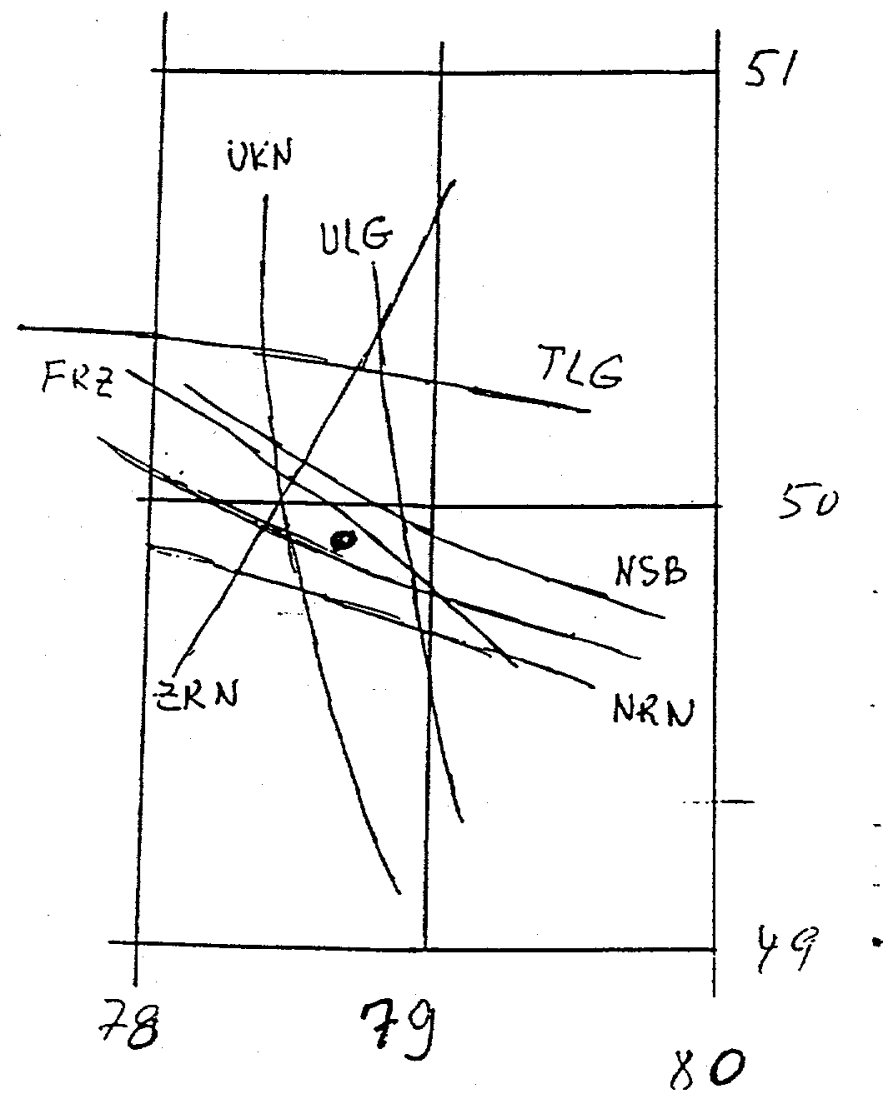

$1988-$ Se p-26 $^{2}\left(50.10^{\circ}, 78.96^{\circ}\right)$

$(18 \mathrm{~km}, 16 \mathrm{~km})$ Figure 8 (3og) 
Comparison of $\mathrm{mb}(\mathrm{AWE})$ with $\mathrm{mb}(\mathrm{ISC})$ for 100 Balapan UNEs

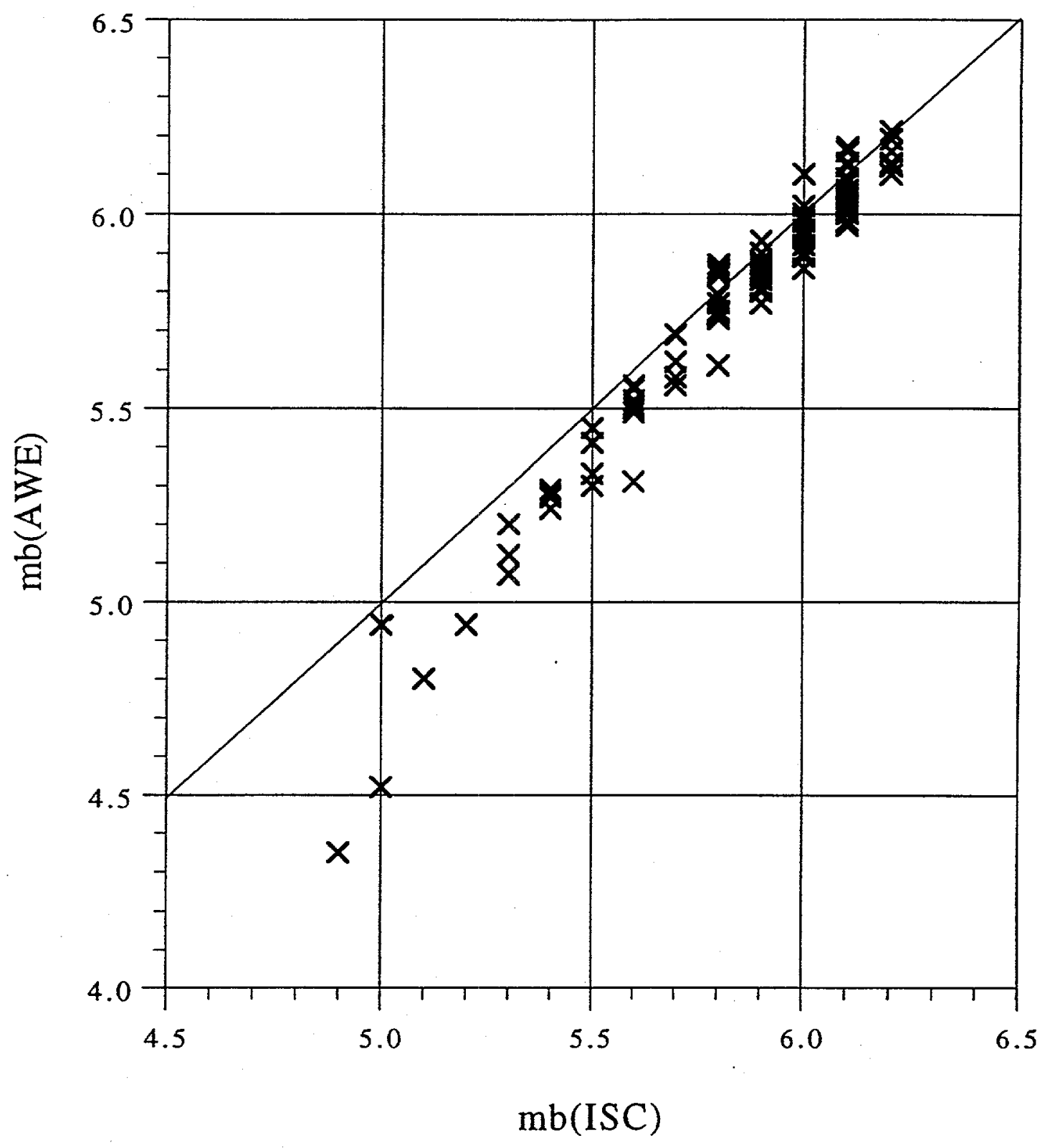

Figure $9 a$ 
Comparison of $\mathrm{mb}(\mathrm{Lg})$ at NORSAR with $\mathrm{mb}(\mathrm{P})$ from AWE

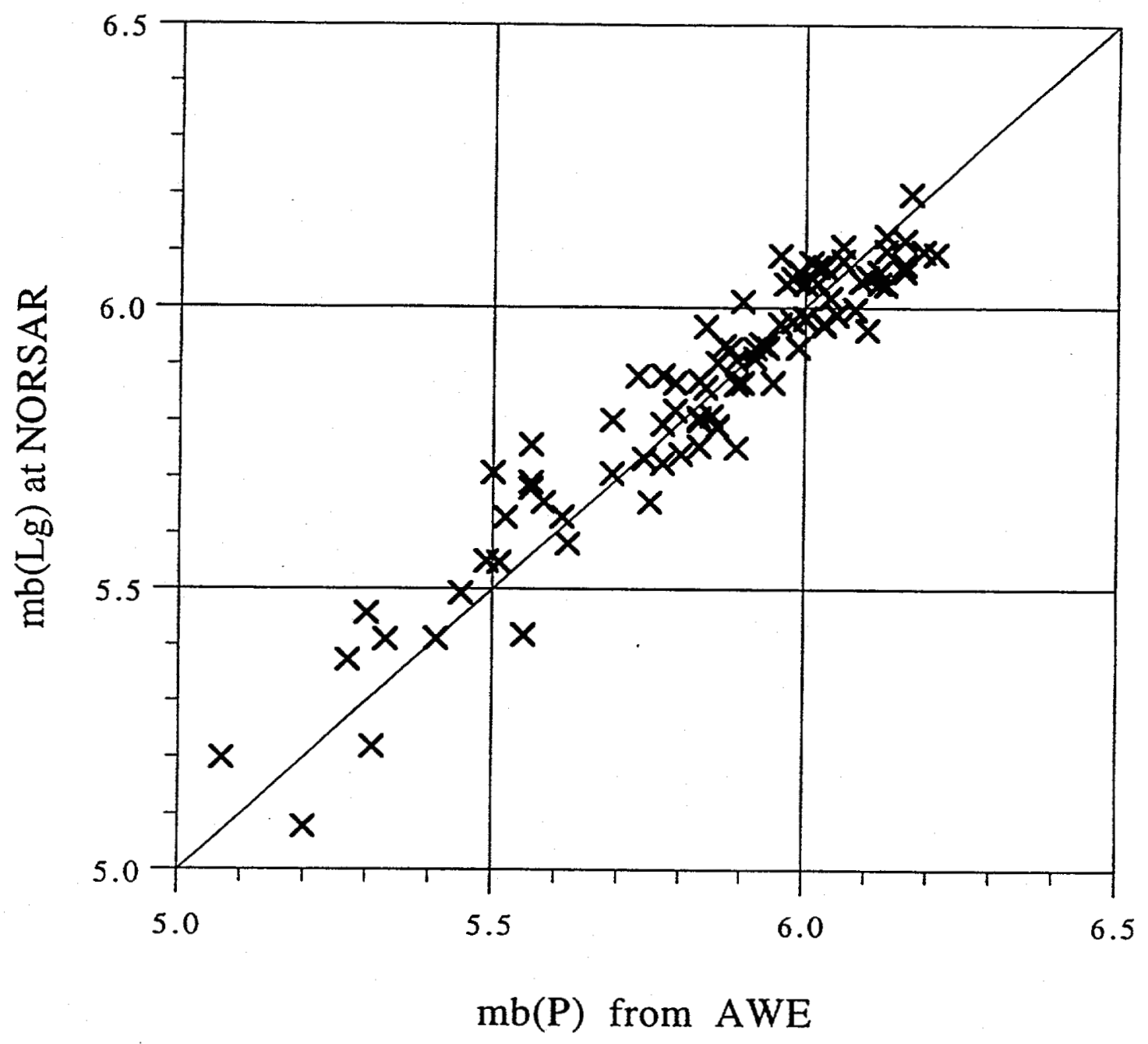

Figure 96 


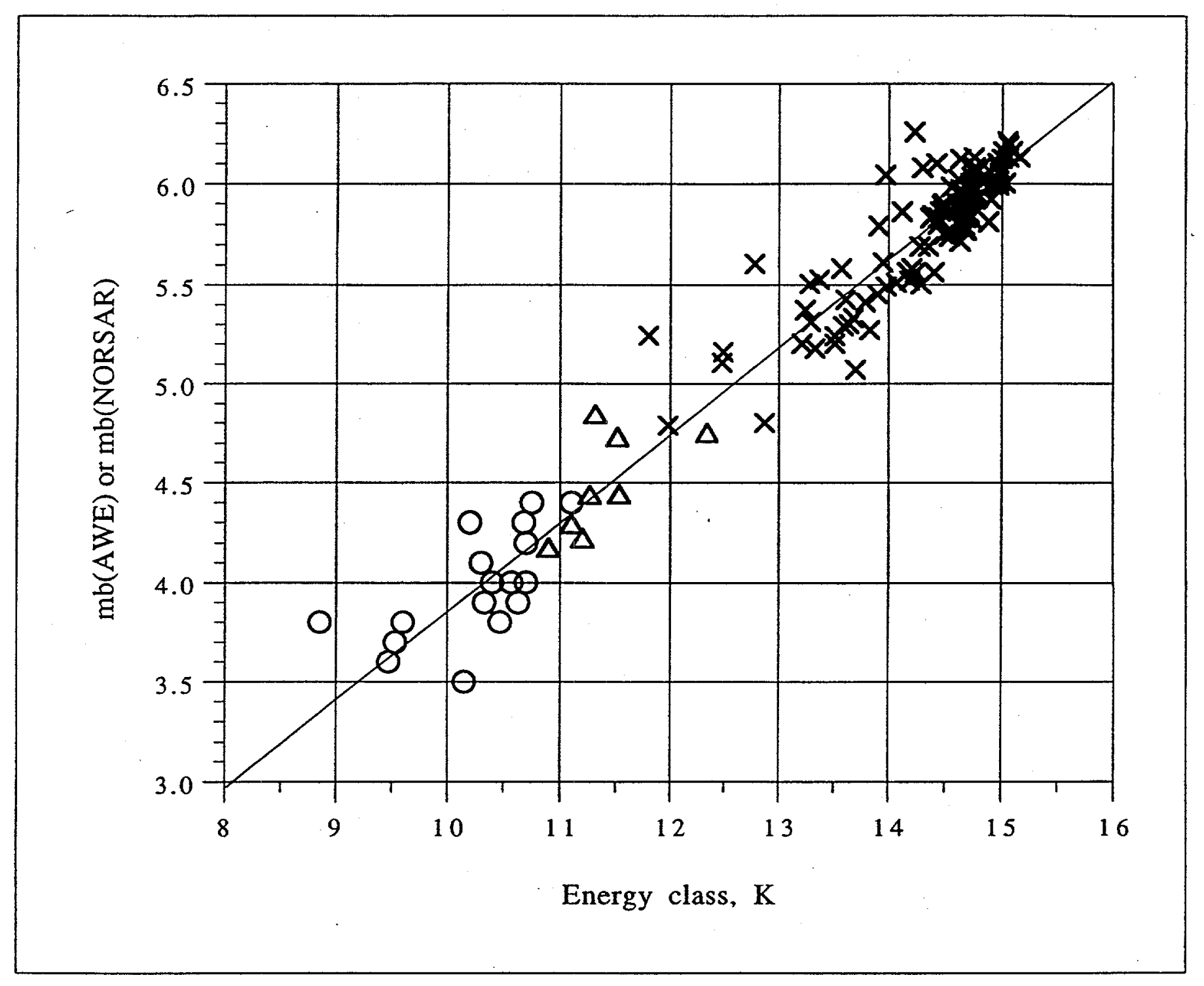

Figure $9 \mathrm{c}$ 


$$
m(\text { AWRE })=1.17 m(\text { CHISS })-1.02
$$

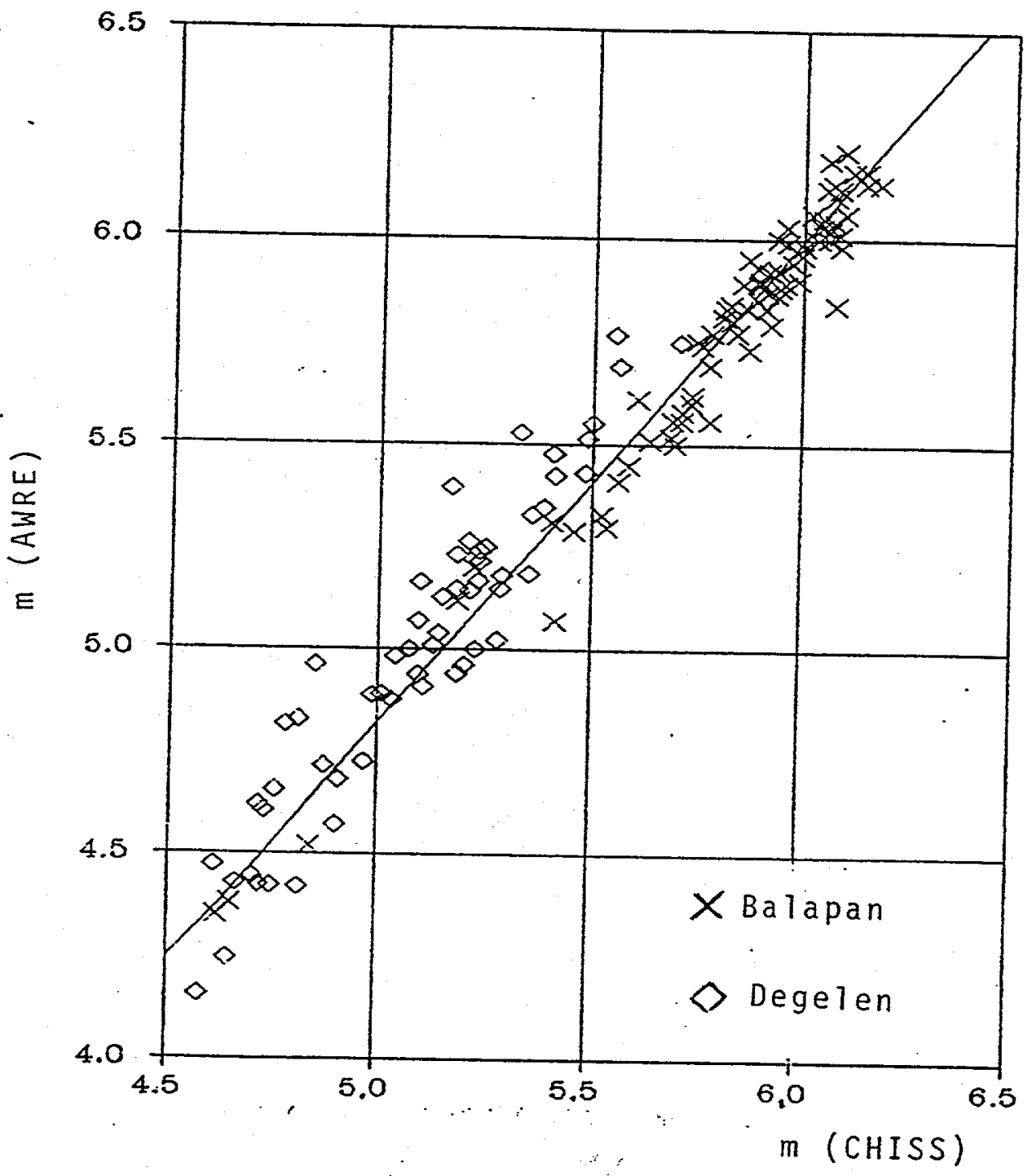

Fignre $9 d$ 


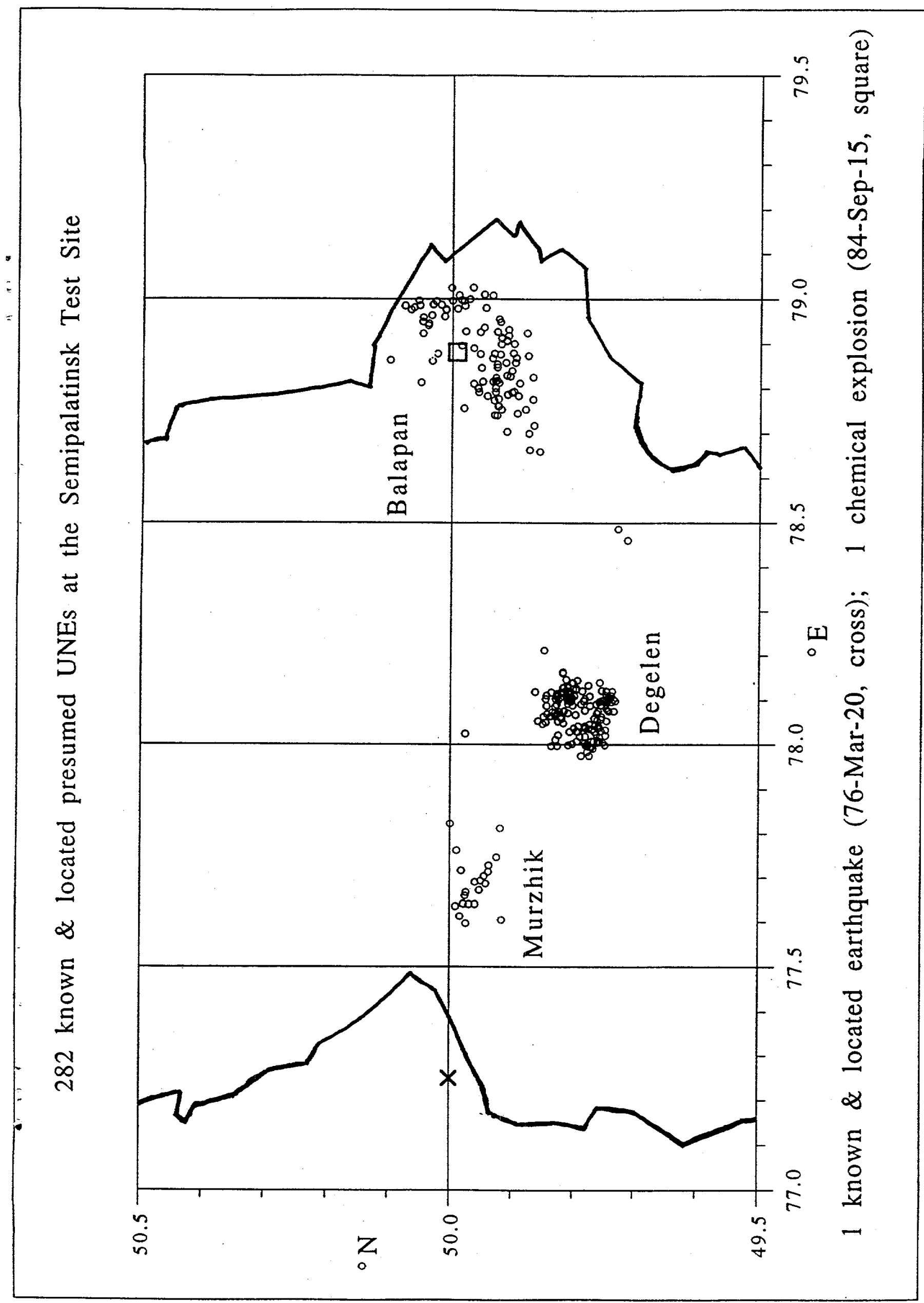

Figure 10 


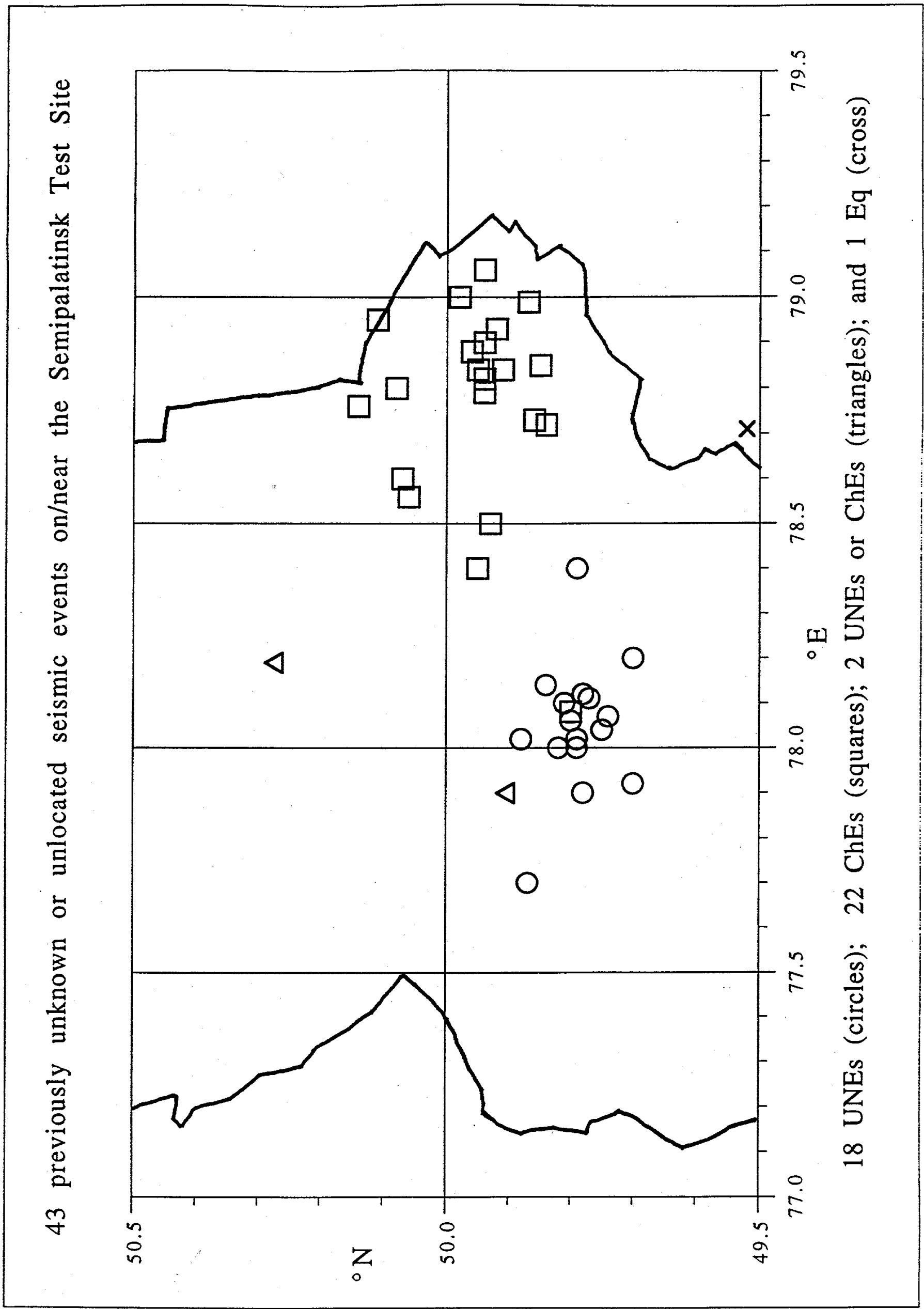

Figure 11 


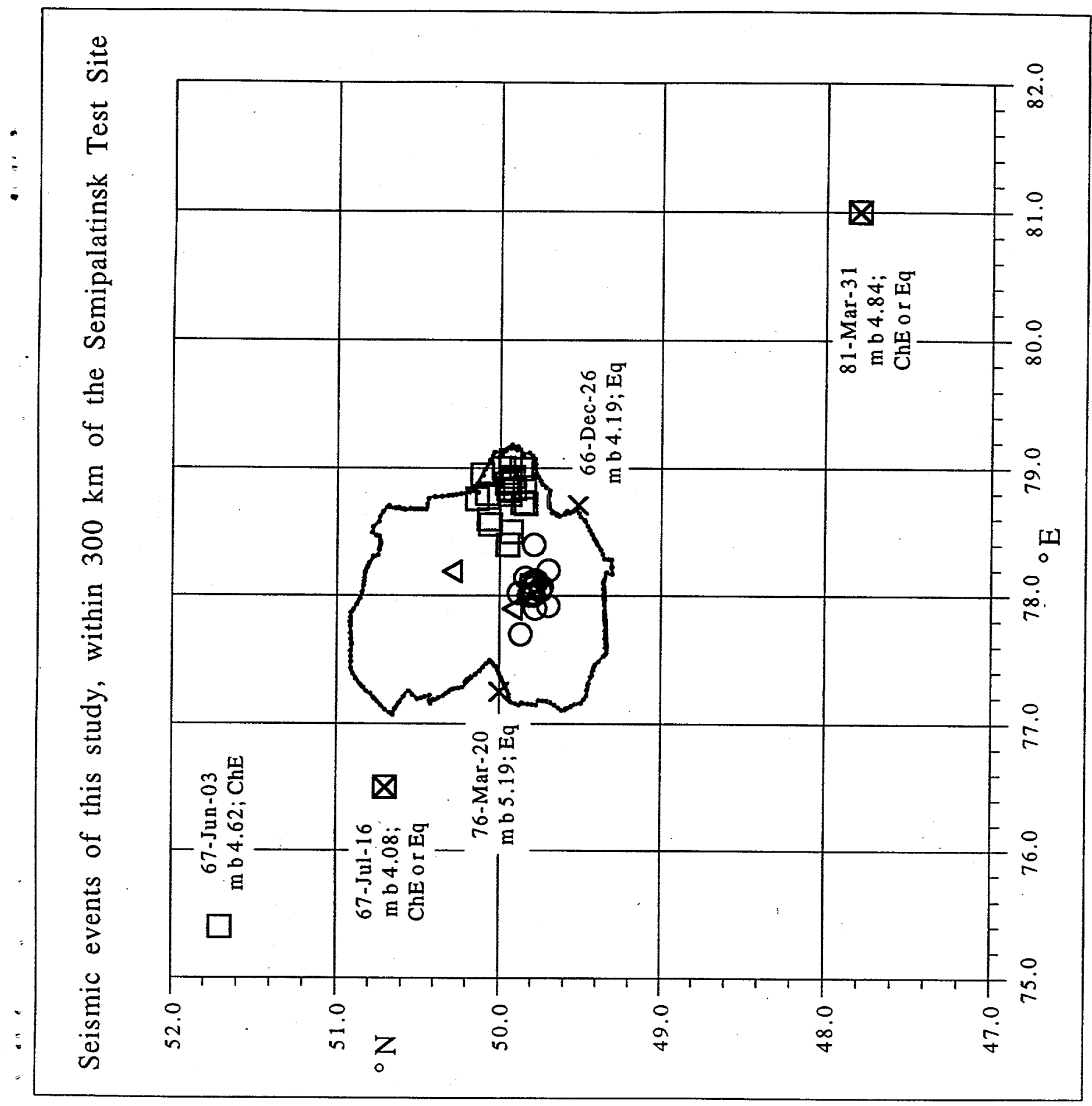

Figure 12 


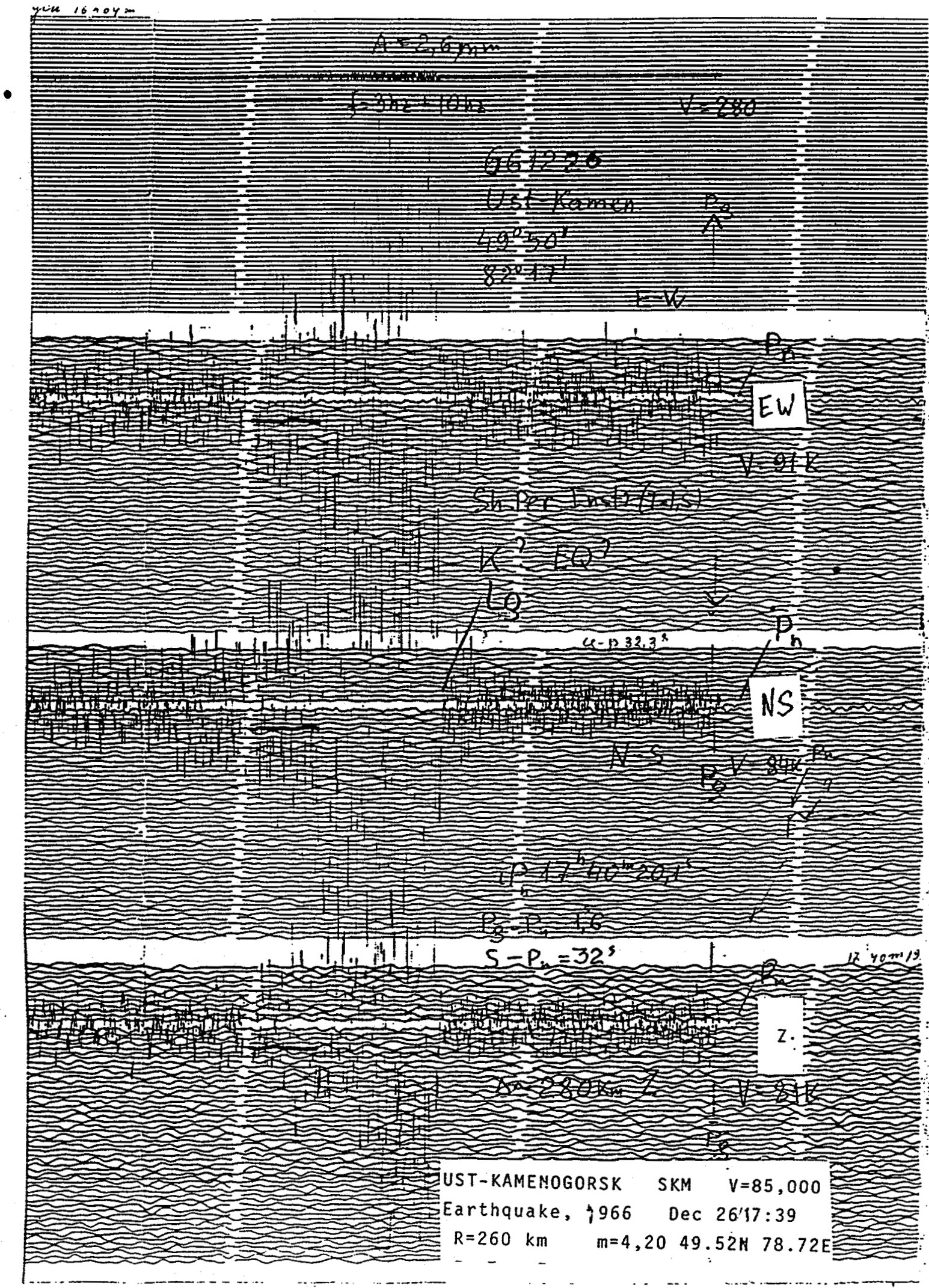

$$
\text { Figure } 13 a
$$




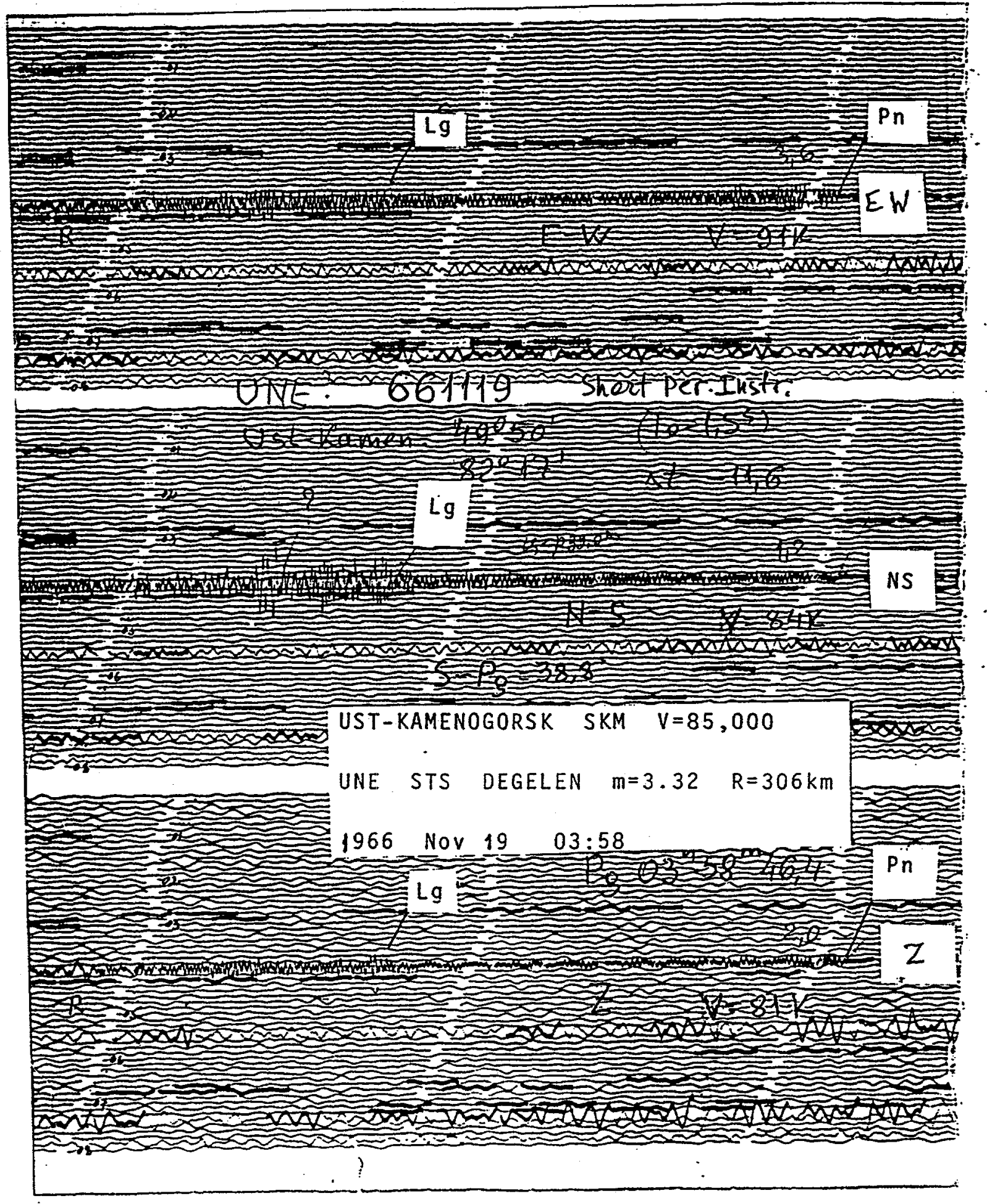

$$
\text { Figure } 136
$$

